\title{
Consuming Figures:
}

\section{A Comparative Study of Visual Conventions in Fashion, Advertising, and} Pornography

\author{
by \\ Jennifer L. Johnson \\ Bachelor of Fine Arts, Media Arts and Digital Technology \\ Alberta College of Art and Design, 2004 \\ Calgary, Alberta, Canada \\ A thesis/project \\ Presented to Ryerson and York University \\ In partial fulfillment of the requirements for the degree of \\ Master of Arts \\ In the Programme of \\ Communication and Culture
}

Toronto, Ontario, Canada, 2009

(C) Jennifer Johnson 2009 
I hereby declare that I am the sole author of this thesis.

I authorize Ryerson University and York University to lend this thesis to other institutions or individuals for the purpose of scholarly research.

Jennifer Johnson

I further authorize Ryerson University and York University to reproduce this thesis or dissertation by photocopying or by other means, in total or in part, at the request of other institutions or individuals for the purpose of scholarly research.

Jennifer Johnson 
Consuming Figures:

A Comparative Study of Visual Conventions in Fashion, Advertising, and Pornography Jennifer Johnson

Master of Arts, Program in Communication and Culture

Ryerson University and York University

2009

\begin{abstract}
This thesis is concerned with the complex relations between consumerism, visual representations, and sex evident in the comparison of pornography and mainstream fashion advertising. Vogue, Cosmopolitan, and Playboy are the primary materials used to identify representational tactics unique to, and common between, pornography and fashion magazines. Multiple methods are used to analyze and engage with the visual conventions found in examples of each genre's source materials. Claims of diffusion between the genres are assessed through quantitative content analysis, which is in turn examined through semiotics, and ultimately interpreted through artistic practice. This is in order to gain general insight into how desire and meaning are transmitted through the photographic imagery popularized by each genre. The purpose of this study is to illuminate how sexualized images are reproduced and manipulated to stimulate, satiate, and direct desire for divergent commercial purposes.
\end{abstract}




\section{Acknowledgements and Dedications}

This thesis and project is dedicated in loving memory to my father Arthur Johnson, whose pride transcends physical presence. Your name is a constant reminder for me to honour my talents and hold true to my practice. Your and Mom's (Sylvia/Margy) endless love and support have made me who I am, and you are both responsible for all of my accomplishments. Margy, thanks for always making the time to talk, knowing what to say, and giving me the courage to work through my doubts. I know you would love and accept me regardless of circumstance, but your confidence always pushes me to strive to be the best. Mike, thanks for being the perfect big brother, always ready with words of advice, commiseration, and the occasionally needed jibe. Thanks for looking out for Margy and keeping an eye out for me as well. Kelly, thanks for calling and understanding when I am too work focused to do the same. Your and Ron's lifestyle is an inspiration and a reminder that we are all living the life we choose. To my love, Ian Dahlman, thank you for your endless patience and faith. You keep me sane, grounded and dreaming. You have challenged me like no other and inspired me more than I think you know - my world is a better place for having you in it. Thank you to all of the friends I have made in ComCult and Toronto. It would not have been nearly as enjoyable without all of you. Thank you for always being there for both procrastination and brainstorming. Finally, thank you to Jennifer Brayton, Caitlin Fisher, Don Snyder, Murray Pomerance, Abby Goodrum, and all of the other professors I worked with at Ryerson and York Universities. 


\section{TABLE OF CONTENTS}

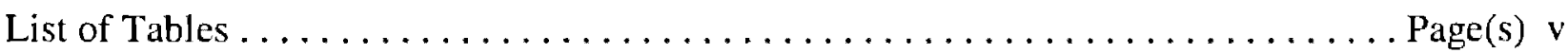

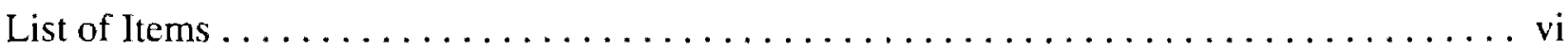

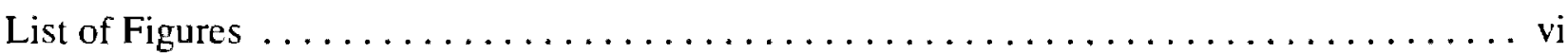

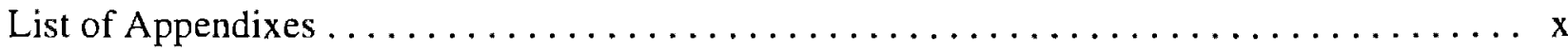

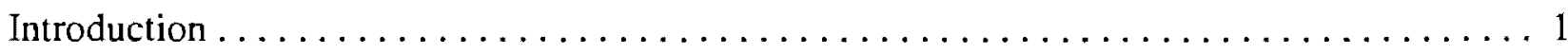

Chapter One: What is Pornography and Pornification? .................... 8

Chapter Two: Quantitative Methodology . .......................... 31

Chapter Three: Qualitative Interpretation and the Affect Economy . . . . . . . . . . 42

Chapter Four: Speaking Through Images - Art as Research . . . . . . . . . . . . . 65

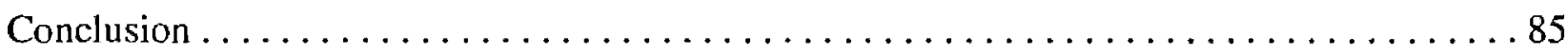

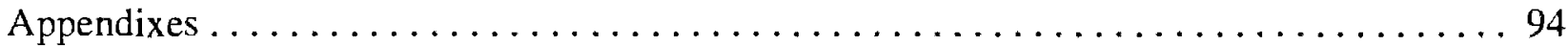

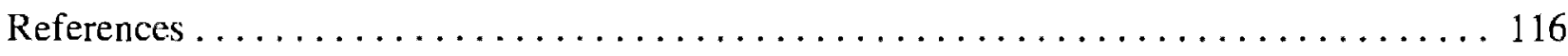




\section{$\underline{\text { List of Tables }}$}

Table 1.1: Overview - magazine sample content $\ldots \ldots \ldots \ldots \ldots \ldots \ldots \ldots$ Page(s) 34

Table 2.1: Sample table - Instances of full vs. partial display of figures . . . . . . . . 97

Table 2.2: Sample table - Camera position $\ldots \ldots \ldots \ldots \ldots \ldots \ldots \ldots \ldots \ldots \ldots \ldots \ldots \ldots \ldots \ldots$

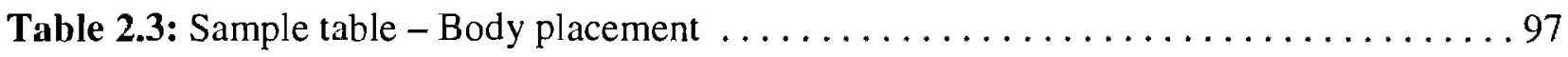

Table 2.4: Sample table - Body parts - visible exposure: full and partial ........... 98

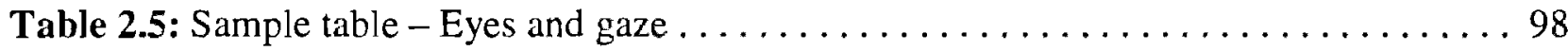

Table 3.1: Cosmopolitan - Instances of full vs. partial figures ................ 98

Table 3.2: Cosmopolitan - Camera position ........................ 99

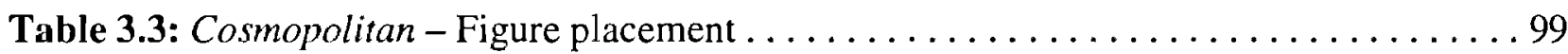

Table 3.4: Cosmopolitan - Visible exposure of body parts . . . . . . . . . . . . . . 99

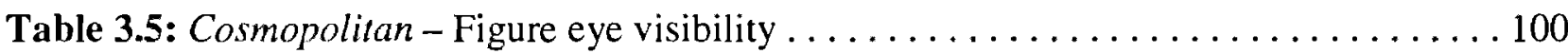

Table 3.6: Cosmopolitan - Figure gaze direction and focus .................. 101

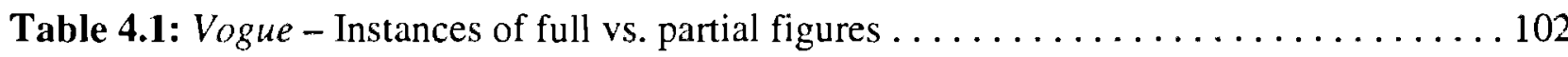

Table 4.2: Vogue - Camera position ........................... 102

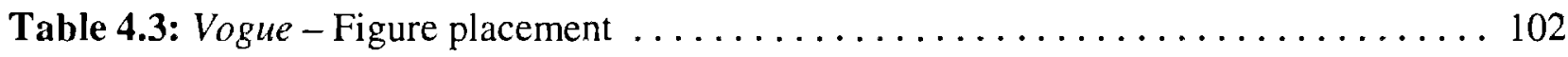

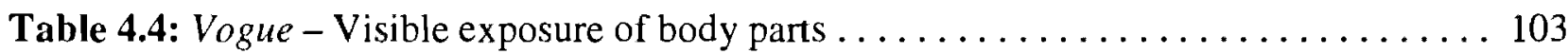

Table 4.5: Vogue - Figure eye visibility . . . . . . . . . . . . . . . . . . . 104

Table 4.6: Vogue - Figure gaze direction and focus . . . . . . . . . . . . . . 105

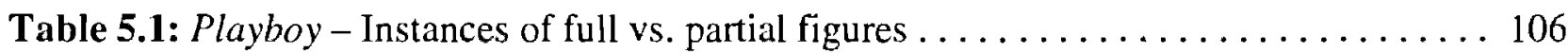

Table 5.2: Playboy - Camera position . . . . . . . . . . . . . . . . . . . 106

Table 5.3: Playboy - Figure placement $\ldots \ldots \ldots \ldots \ldots \ldots \ldots \ldots \ldots \ldots \ldots \ldots \ldots \ldots \ldots \ldots \ldots \ldots$

Table 5.4: Playboy - Visible exposure of body parts . . . . . . . . . . . . . . 107

Table 5.5: Playboy - Figure eye visibility . . . . . . . . . . . . . . . . 108

Table 5.6: Playboy - Figure gaze direction and focus ................... 109

Table 6.1: Comparative overview: Instances of full vs. partial figures $\ldots \ldots \ldots \ldots \ldots \ldots 110$

Table 6.2: Comparative overview: Camera position ................... 110

Table 6.3: Comparative overview: Figure placement $\ldots \ldots \ldots \ldots \ldots \ldots \ldots \ldots \ldots \ldots \ldots 11$

Table 6.4: Comparative overview: Visible exposure of body parts . . . . . . . . . . 111

Table 6.5: Comparative overview: Figure eye/gaze overview ................. 114 
Table 6.6: Comparative overview: Figure eye visibility $\ldots \ldots \ldots \ldots \ldots \ldots \ldots \ldots \ldots \ldots \ldots$

Table 6.7: Comparative overview: Figure gaze direction and focus . . . . . . . . . 115

\section{$\underline{\text { List of Items }}$}

Item 1.1: Template data collection form -method one $\ldots \ldots \ldots \ldots \ldots \ldots \ldots$, Page(s) 94

Item 1.2: Example of method one - Cosmopolitan ..................... 94

Item 1.3: Example of method one - Vogue ........................ 96

Item 1.4: Example of method one - Playboy ....................... 96

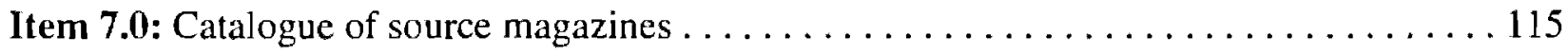

\section{$\underline{\text { List of Figures }}$}

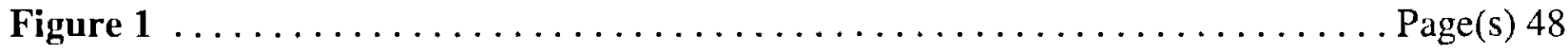

"Coco Mademoiselle" by Chanel in Vogue: Dec. 2008, p. 45

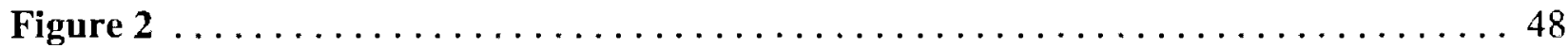

"Flowerbomb" by Viktor \& Rolf in Vogue: Dec. 2008, p. 37

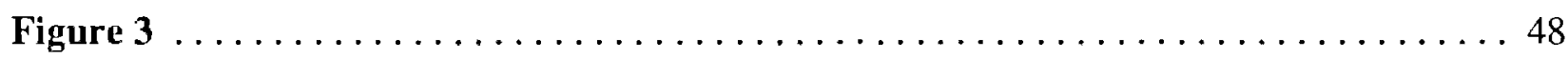

"Secret Obsession" by Calvin Klein in Cosmopolitan: Dec. 2008, p. 37

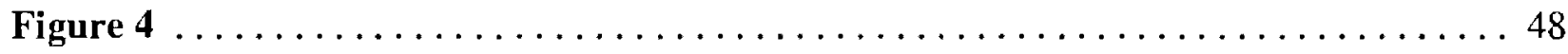

"White Patchouli" by Tom Ford in Vogue: Dec. 2008, p. 23

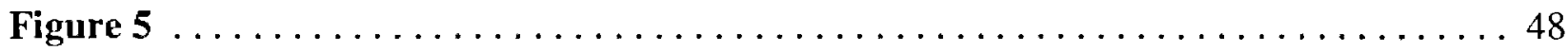

Gucci jewelry in Vogue: Dec. 2008, p. 154

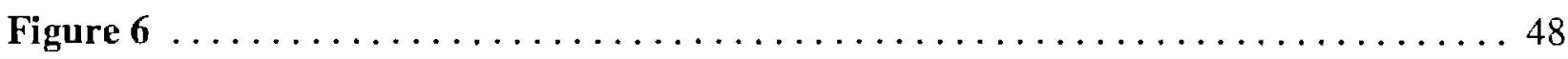

Bulova watches in Vogue: Dec. 2008, p. 102

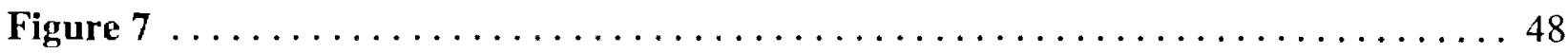

David Yurman in Vogue: Dec. 2008, p. 25

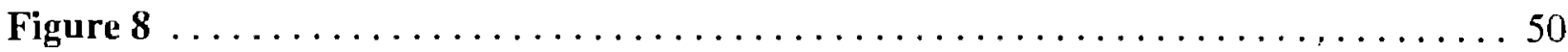

Michael Kors in Vanity Fair: March 2009, p. 35

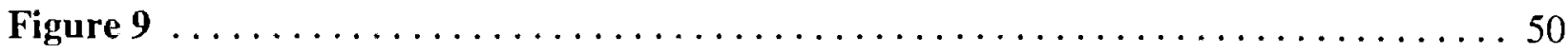

Louis Vuitton in Vogue: Dec. 2008, p. 10 


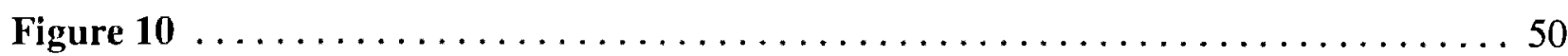

Dolce \& Gabbana in Vogue: Dec. 2008, p. 16

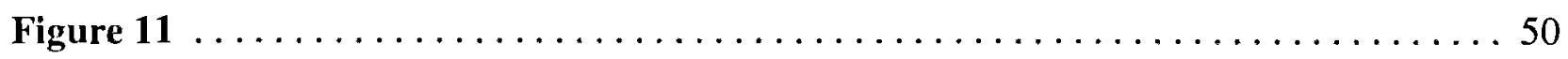

Tommy Hilfiger in Vogue: Dec. 2008, p. 35

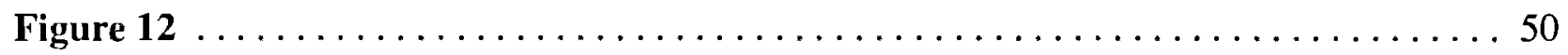

Jimmy Choo in Vanity Fair: March 2009, p. 163

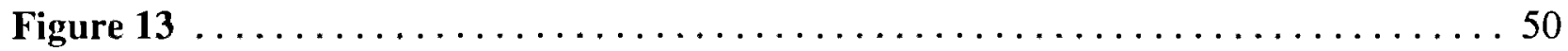

Gucci in Vanity Fair: March 2009, p. 7

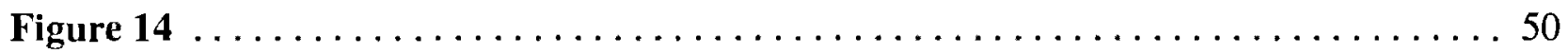

Dior in Vogue: Dec. 2008, p. 15

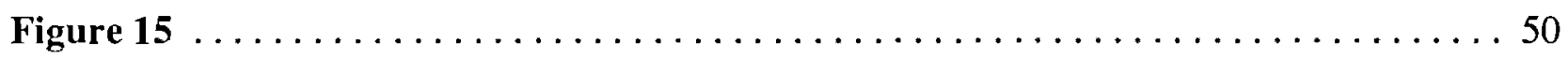

"Tattoo Heart Collection" by Gucci in Vogue: Dec. 2008, p. 7

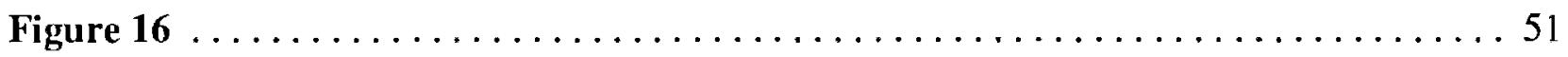

"Riders" by Lee in Cosmopolitan: Dec. 2008, p. 38

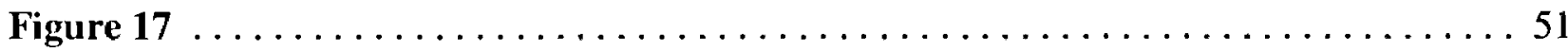

OPI in Cosmopolitan: Dec. 2008, p. 31

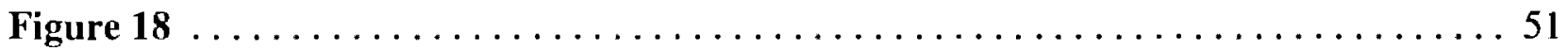

Pantene Pro-V in Cosmopolitan: Jan. 2009, p. 62

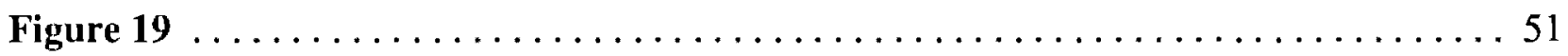

"American Living" by JC Penney in Cosmopolitan: Dec. 2008, p. 6

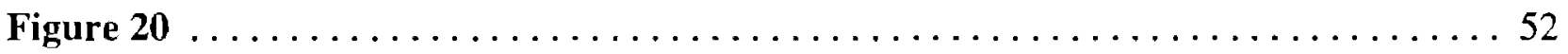

"Microminerals" by Cover Girl in Vogue: Jan. 2009, p.51

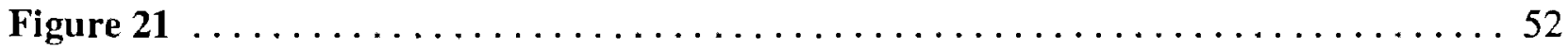

"Lift Lumiere" by Chanel in Vanity Fair: March 2009, p. 29

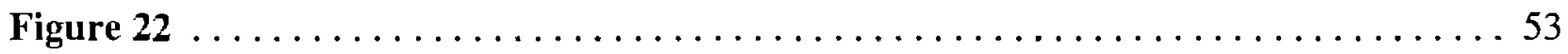

"Best of Beauty" in Allure: Oct. 2008, p. 291

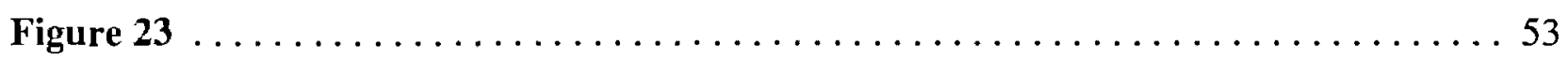

"Coastal Blend" in Vogue: Dec. 2008, p. 294

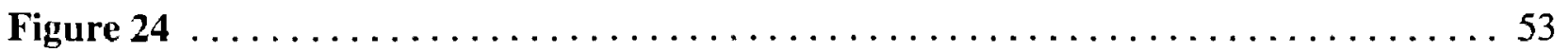

“The Match Game” in Vogue: Jan. 2009, p. 153 
Figure 25

In Cosmopolitan: Dec. 2008, p. 192

Figure 26 54

"Carol Alt in the Raw" in Playboy: Dec. 2008, p. 145

Figure 27 54

"Icon" in Playboy: Jan. 2009, p. 56

Figure 28 - Composite 54

Upper: Dahm triplets in excerpt from "The 1990s" in Playboy: Jan. 2009, p. 107

Lower: "Double Trouble" in Playboy: Dec. 2008, p. 102

Figure 29 - Composite 55

Left: excerpt from " $55^{\text {th }}$ Anniversary Playmate" in Playboy: Jan. 2009, p. 84

Center: excerpt from "Hunt for $55^{\text {th }}$ Anniversary Playmate" in Playboy: Dec. 2008, p. 122

Right: Joanna Krupa in excerpt from "The 2000s" in Playboy: Jan. 2009, p.117

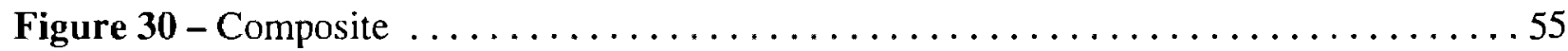

Upper-left: Carmen Electra in excerpt from "The 1990s" in Playboy: Jan. 2009, p. 107

Upper-right: excerpt from "Icon" in Playboy: Jan. 2009, p. 56

Lower-right: excerpt from "Double Trouble" in Playboy: Dec. 2008, p. 102

Lower-left: excerpt from "Hunt for $55^{\text {th }}$ Anniversary Playmate" in Playboy: Dec.

2008, p. 121

Figure 31 - Composite 55

Left: excerpt from "Hunt for $55^{\text {th }}$ Anniversary Playmate" in Playboy: Dec.

2008 , p. 122

Center: excerpt from "Hunt for $55^{\text {th }}$ Anniversary Playmate" in Playboy: Dec.

2008, p. 121

Right: "Playboy's Playmate Review" in Playboy: Jan. 2009, p.127

Figure 32 56

"Hunt for 55 $5^{\text {th }}$ Anniversary Playmate" in Playboy: Dec. 2008, p. 121

Figure 33 56

"Hunt for 55 $5^{\text {th }}$ Anniversary Playmate" in Playboy: Dec. 2008, p. 122

Figure 34 66 
“The Human Race Machine," by Nancy Burson, image from website. 1999

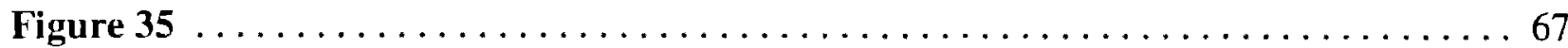

“Barbie Dolls," by Chris Jordan. 2008, 60x80"

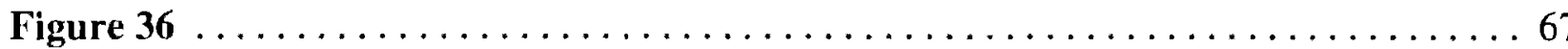

"Barbie Dolls," by Chris Jordan, partial zoom. 2008

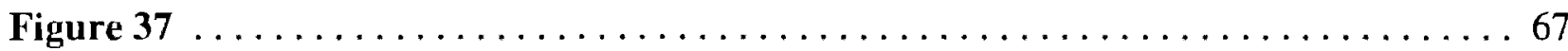

“Barbie Dolls," by Chris Jordan, full zoom. 2008

Figure 38

Detail from "Carol Alt in the Raw" in Playboy: Dec. 2008, p. 145

Figure 39

Process: isolated detail extracted from Figure 38 in Photoshop

Figure 40 75

Process: isolated detail from Figure 39 mirrored in Photoshop

Figure 41 75

Process: Figure 40 repeated and rotated in Photoshop

Figure 42 75

Process: Figure 41 repeated and shifted to right six times in Photoshop

Figure 43 75

Process: Figure 41 repeated and shifted to right continuously in Photoshop

Figure 44 75

Pattern developed from layering Figure 43 and 41 continuously

Figure 45 75

“Stiletto from JLJ Collection '09," by Jennifer Johnson, Photoshop composite, 2009

Figure 46 75

“Fringe-purse from JLJ Collection '09," by Jennifer Johnson, Photoshop composite, 2009 Figure 47 76

“Flower-purse from JLJ Collection '09," by Jennifer Johnson, Photoshop composite, 2009 
Detail of "Flower-purse from JLJ Collection '09," by Jennifer Johnson, Photoshop composite, 2009

Figure 49 79

Detail of Figure 40 to be used as first frame in an animation

Figure 50 79

Detail of Figure 40 altered to be used as a mid-frame in an animation

Figure 51

Detail of Figure 40 altered to be used as the end-frame in an animation

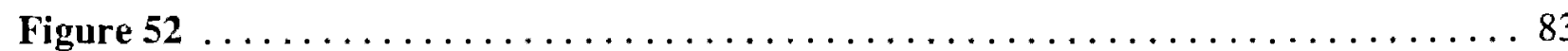

"J'adore JLJ, no. 19," by Jennifer Johnson, Photoshop composite, 2009

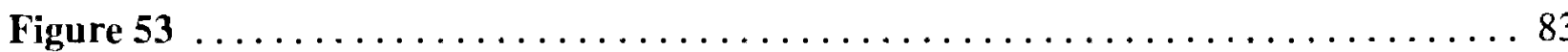

Detail zoom of "J'adore JLJ, no. 19," by Jennifer Johnson, Photoshop composite, 2009

Figure 54 83

Composite of "J'adore JLJ, no. 1-30," by Jennifer Johnson, Photoshop composite, 2009

\section{List of Appendixes}

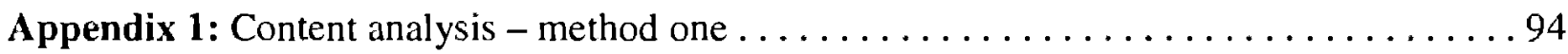

Appendix 2: Content analysis - method two - sample tables . . . . . . . . . . . . 97

Appendix 3: Overview of advertising and editorial content analysis: Cosmopolitan . . . . . 98

Appendix 4: Overview of advertising and editorial figure analysis - Vogue $\ldots \ldots \ldots \ldots 102$

Appendix 5: Overview of advertising and editorial figure analysis - Playboy $\ldots \ldots \ldots 106$

Appendix 6: Comparative overview of advertising and editorial figures between

Cosmopolitan, Vogue, and Playboy ..................... 110

Appendix 7: Source materials ............................... 115 


\section{INTRODUCTION}

There is pervasive sexualization of mainstream media, evident in the proliferation of sexually explicit, graphic material in magazines, music videos, billboards, television, and the Internet. This trend has been observed by many academics and social critics who have labeled the phenomenon "pornographication" (McNair, 1996; Driver, 2004; Merskin, 2006), the pornography of everyday life (Caputti, 1999), "porno chic" (McNair, 2002), the rise and acceptance of raunch culture (Levy, 2005), and "pornification" (Paul, 2005; Paasonen, Nikunen, and Saarenmaa, 2007). All but one of these labels include a variant of the term pornography, suggesting a difference between the expansion of sexualized material and the mainstreaming of pornographic conventions. My particular interest is how so-called pornographic practices have been incorporated into women's fashion and beauty advertisements. Both advertisements and pornography use representations of sex to encourage consumption. In pornography, sex, at least in representational form, is the commodity for sale. Sex sells itself. In fashion and lifestyle magazines, sex is used to increase desire for and sales of consumer items such as apparel, accessories, cosmetics, entertainment and leisure services. Sex sells other commodities.

Considering its prevalence in contemporary consumer culture, "sex sells" is a platitude in desperate need of dissection to determine how sex is operating uniquely within these specific genres. David Andrews rightly criticizes the many studies mapping the proliferation of sex as a promotional device for failing "to include a fundamental qualifier, namely, that sex sells in particular ways, at particular moments, in particular channels" (Paasonen, Nikunen, and Saarenmaa 2007, p. 53). I will examine the particular visual signifiers that denote the operations of sex in current mainstream women's fashion and lifestyle magazines, compare them to 
mainstream print pornography, and probe what these signifiers reveal about the relationships between desire, consumerism, and visual representations. These relationships will be explored through artistic experimentation, reappropriating and manipulating the identified conventions to reveal how they construct visual signification.

As both an artist and an academic, I am analyzing and playing with the generation and assignation of meaning between genres (advertisements and pornography) and disciplines (social sciences and fine arts). What began as an exploration of the relationships between consumerism and visual representations of sex has become a long, self-reflexive examination of how consumerism affects our perceptions, how we derive meaning and feeling from images, and how artistic practice can be combined with social science methodology to create new forms of knowledge - all well beyond the scope of my original study. It came as somewhat of a surprise that at the heart of this inquiry was the mysterious and intangible power of photographic images and the creative potential of harnessing that power intuitively. I gained significant insight into my topic by combining research methods, simultaneously investigating what mainstream magazine content and pornographic images say about the relationship between consumerism and visual representations of desire and how different modes of study and creative play change how we are able to understand this material.

In order to identify the relevant factors and variables, I reviewed literature pertaining to the portrayal of sex in popular media, sex in advertising, the history and critical analysis of advertising, pornography, visual research methods and forms of analysis, as well as how artists have engaged with the topic. I referenced previous studies to select an appropriate subject and to define my terminology, sample, and method of research. The first section of Chapter One begins by providing a brief overview of the controversial history of pornography and the debate 
surrounding its contentious definition. While many agree on a correlation between the representational forms of pornography and mainstream media, few are able to agree on a definition of pornography. The lack of a commonly-accepted definition leads to fractured debate and little consensus about how to read pornography, how to classify its material, and what the implications of such a classification would be. It is critical to have a consistent working definition of pornography that, at least temporarily, eschews moral and political judgments in favor of a strong material grounding with pornography's structural content. This section outlines the evaluative process I use to weigh the implications of implementing a particular definition of pornography over another, culminating in the definition of pornography I will adopt for the remainder of this study.

In the second section, I review articles and studies that deal with the increased sexualization of mass media. The texts are evaluated on the following criteria: the definition of pornography and how/if it is distinguished from sex; the measure by which instances of sex/pornography are evidenced; speculation of causal factors contributing to the sexualization of media; and the projected social consequences of sexualized media. These studies together present a synopsis of the social landscape and political economy of popular media's engagement with sex. The final part of the chapter focuses on the advertising and fashion industries and how their developments correlate with the evolution and dissemination of photographic images and the rise of consumer culture. Through these reports, I will be better able to position my inquiry and develop valid parameters for study.

Chapter One addresses huge and complex topics for discussion. Due to the limited scope of this study, I am unable to dive fully into a deep, nuanced reading of these issues and instead restrict my review to primarily descriptive summaries of the discourse surrounding these fields, 
and note where I situate my own opinion. It is recommended that the reader visit any of the authors listed in these sections for further elaboration on the subject. This analysis of pornographic media is limited to mainstream, static, print examples, excluding verbal and cinematic representations, as well as the multiplicity of sub-cultural representations. This is not due to the excluded material's lack of importance, but to the limited resources available for this inquiry.

Chapter Two describes my methodology of obtaining data and its execution. Visual content analysis is used to isolate compositional features in advertising and pornography, and chart their frequency. My goal is to catalogue and categorize the formal compositional conventions that these industries use to represent the female body in a manner that incites desire and encourages consumption. The first section of this chapter details this goal and justifies the appropriateness of this method according to past studies and practitioners of social science and cultural studies research. It also explains my selection of source materials, units of analysis, coding parameters, and the scope of study. I was forced by the complexity of the factors involved to limit the selection of variables; although racial, socio-economic, and sexual orientations are pertinent features of visual representations of desire, they cannot be properly addressed within the confines of this study. This study is not meant to be comprehensive and externally generalizable, but instead aims to offer insight into the claims made in Chapter One, and to provide the material for additional methods of inquiry and interpretation (elaborated upon in Chapters Three and Four). Future studies can use these methods to address the factors excluded from this study.

"Content analysis alone is seldom able to support the statements about the significance, effects, or interpreted meaning of a domain of representation" (Van Leeuwen and Jewitt, 2001, p. 
13). As such, content analysis must be used in conjunction with other methods to derive meaning, and to either substantiate or challenge the trends outlined in Chapter One. Further complicating engagement with these trends is the difficulty of analyzing visual content. There is no universally accepted method to read meaning into and from images, thus the purpose of Chapters Three and Four is to explore how visual information can be interpreted to best describe the functioning of sexual representations in pornography and advertising.

Chapter Three is primarily concerned with the semiotic analysis of the data collected in Chapter Two. Semiotics is employed by the foundational studies I use to draft my own exploration and so is the first method used to analyze my findings. My technique is based heavily on the approach of Roland Barthes, Erving Goffman, Annette Kuhn, and Jensen and Dines, as adopted by Deborah Merskin in a study that initially resembles my own since it addresses my central research question: how do visual representations of sex comparatively operate in fashion advertising and pornography? However, Merskin accepts biased definitions of pornography and viewer reception without question and without reapplying them to the source material of each category in a comparative study.

Pornography and advertising engage the viewer on an affective level as well as one of meaning. As such, it is necessary to assess the viewer's relationships to photographs and to question how pictures, specifically photographs, are able to evoke and direct desire in addition to meaning. Drawing heavily on Roland Barthes and W.J.T. Michell, this and the proceeding chapter concurrently focus on how to interpret meaning from photographs while exploring photography's affective capacity. Photography's ability to evoke feeling is examined in the context of how the industries of advertising, women's publications, and pornography use images to exchange commodities and circulate attention in an affective economy. 
In Chapter Four I review and reflect upon my artistic process as a response to the similarities between pornography and women's fashion and lifestyle magazines. I also delve deeper into Mitchell's exploration of what pictures, as autonomous entities, want themselves distinct from the desires of the artist or beholder. While it is logical to present my findings through written texts, charts and graphs, I find these methods lacking in their ability to convey an emotional response from their source material to the viewer. In an attempt to reconnect the viewer to an affective response from quantitative information, photographer Chris Jordan constructs photographic representations of statistical data that challenge statistics' tendency to "feel abstract and anesthetizing, making it difficult to connect with and make meaning..." (Jordan, n.d.). Pornography and advertising are meant to affect bodily desire, while empirical data tends to engage only through meaning. Jordan utilizes images to give data resonance - I do the same. I find it necessary to speak about images through images, to evoke and comment upon their ability to transmit feeling as well as meaning.

A typology of visual conventions derived from my content analysis informs the palette $\mathbf{I}$ use for a series of animations and digital prints that conflate and parody the relationship between desire, pornography, and consumerism. Similarly to Chris Jordan, I employ the obsessive compiling of smaller images in Photoshop to express larger patterns. Photographic images of commodities and poses from fashion and pornography magazines are scanned into Photoshop, where I then repeat the fragmented and repositioned forms into geometric sequences. The repetition and subsequent distortion of fetishized objects distorts their iconic meaning and signification, leaving them open to reappropriative organization.

Although not developed in depth until Chapter Four, my artistic practice is instrumental in formulating meaning from the data collected in previous chapters. While my understanding of 
the underlying issues is informed by social science research, my artistic practice is largely intuitive. I reflect upon my intuitive process and how it relates to my content analysis and other research methods in my conclusion. "When we have collected all the bits and pieces in our scientific explorations we need aesthetic intuition to conclude our research - to see it as a whole" (Guillet de Monthoux, 1999, p. 42). I have come to view my own artistic practice as a mini, auto-ethnographic case study, exploring how I analyze and synthesize meaning from images in an attempt to better understand the aesthetic relationship between pornography and mass media. My process, as an exercise in play and translation, explores the meaning and poignancy inherent to varying modes of expression and celebrates the creative potential of merging methods to investigate a given subject matter. I conclude this exploration by reflecting simultaneously on my findings and the process deriving those results. 


\section{CHAPTER ONE: What is Pornography and Pornification?}

"We see the difficulty - rampant in studies of pornography - of talking about a genre without first defining its form."

(Williams, Hardcore, 1999, p. 13)

Pornography's etymology has Greek roots in pornographos: pornē means prostitute, and graphos - graphein means to write. Pornography is thus the writings of prostitutes, a term that invokes sex, representational accounts, and commerce. "Of prostitutes" implies that pornography is from the perspective of the prostitute, the subject-producer, and thus highlights an important shift in contemporary pornography's focus from production to consumption. How a text is read and received may supercede, or at least parallel, its authorial intent as evidenced in the popular definition of pornography as "sexually explicit pictures, writing, or other material whose primary purpose is to cause sexual arousal," (Pornography (2)). Other definitions include negative social and moral judgment: "books, photographs, magazines, art, or music designed to excite sexual impulses and considered by public authorities or public opinion as in violation of accepted standards of sexual morality. American courts have not yet settled on a satisfactory definition of what constitutes pornographic material," (Pornography (1)). The second definition illustrates two points: the contention regarding pornography's definition and its relation to standards of obscenity.

It is important to note that the term "pornography" has legal implications under Canadian law that are not meant to be evoked for the purpose of this study. Under the Canadian Criminal Code, "pornography" is used in conjunction with children. Legal adult content can also be restricted under Canadian law if it is deemed obscene, as per chapter C-46 of the Canadian Criminal Code which states "for the purposes of this Act, any publication a dominant characteristic of which is the undue exploitation of sex, or of sex and any one or more of the 
following subjects, namely, crime, horror, cruelty and violence, shall be deemed to be obscene" (Department of Justice Canada). However, the material I am reviewing is legal and does not fit into the legally defined category of obscene. For the remainder of this study "pornography" should be understood as legal adult content. I am using the term "pornography" to be consistent with the relevant literature, which is primarily American. It is notable that in Canada the terminology is associated with material deemed not only immoral, but also illegal, and is not applied to the legal material I am studying.

This primarily semantic debate is further complicated by the subjective nature of pornography and resulting difficulties in classifying material. Although the actual definitions of pornography are relatively straightforward, there is little consensus as to what material is sexually exciting, what is with or without artistic merit, and what crosses socially defined standards of decency. Supreme Court Justice Potter Stewart infamously stated, when asked at the 1986 Meese Commission to define what constitutes pornographic material, "I shall not today attempt further to define [hard-core pornography]...; and perhaps I could never succeed in intelligibly doing so. But I know it when I see it" (McElroy, 1995, p. 41).

The debate over what merits materials' classification as pornography is primarily split between what representations of sexual acts are deemed as offensive, and which representations, if any, are deemed acceptable. Current definitions are largely theoretical or political, either inclusive to the point of vagueness, or polarized around moral judgments promoting pornography as a right of expression or condemning pornography as socially corrupting. Deborah Merskin whose comparative study between fashion advertising and pornography is the starting point for my own exploration, begins by focusing on a spectrum of feminist positions on pornography. She divides the continuum into three camps: the Liberals, who favor uncensored expressions of 
female sexuality in all permutations; the Socialists, who focus on power relationships and the subordination of women in pornography; and the Radicals, who blame the subordination on patriarchy (2006, p. 201). Merskin's explanation is problematic as she tends to be absolutist in her divisions and applies the terms Radical and Liberal to perspectives that are contradictory to their traditional connotations in feminist rhetoric and history. While Merskin's perspective is limited, it provides a point of departure against which I frame my own study, and so for the remainder of this chapter "Radical" and "Liberal" feminist perspectives will be understood according to Merskin's definition.

Often, the feminist debate regarding pornography from the 1970's to the 1990's is oversimplified into a division between anti-pornography and pro-pornography/anti-censorship feminists polarized between the Liberals and Radicals, and typically only addresses pornography portraying women. Stephanie Samuels argues against the essentialism pervasive in the "pro-“ and "anti-" positions, and argues in favor of a third-wave feminist stance that encompasses all of the factors that contribute to a given perspective stating:

.... in a third-wave framework, the category of "women" cannot be reduced to assumptions that make all women the same. The third wave demands a perspective that takes account of issues of race, class, sexuality, nation, age, and ability, among other factors of social identity in relationship to gender (2006, p. 20).

A third-wave position cautions against reductive, over-generalizing statements about pornography based on gender alone. However, because of the limited nature of this study, I do little more than reference these factors that are none-the-less pivotal to how the body is visually transcribed and subsequently read. The following outlines the oversimplified view as outlined by Merskin.

Anti-pornography and Radical feminists such as Robin Morgan, Andrea Dworkin, Susanne Kappeler, and Catherine MacKinnon are some of loudest voices championing the 
censorship of pornography. They define pornography as "the sexually explicit subordination of women, graphically depicted, whether in pictures or in words" (Itzin, 1992, p. 435), and cite examples of objectification, degradation, and violence as defining features of pornography. They believe that through pornography, "women are presented as dehumanized sexual objects, things or commodities" (McElroy, 1995, p. 46), culminating in claims, such as those made by Dworkin, that the penetration-invasion of the male subject into the passive female is a root of sexual violence, and that representations of this sort of violence (i.e., pornography) support acts of physical violence against women (Williams, Hardcore, 1999, p. 17-21). The supposed intercausal relationship between physical domination and representation is exemplified in Morgan's famous slogan "pornography is the theory, and rape the practice" (1980, p. 139). Radical feminists argue, to varying degrees, that pornography either reinforces or establishes patriarchal gender relations. Some Radicals argue that there is a causal relationship between pornography and patriarchal violence, while other Radicals argue for a more complex interrelated understanding of pornography as reinforcing and propagating patriarchal power dynamics that are cyclically re-inscribed in pornography. In this view, all pornography contains examples of hierarchal power dynamics and depictions of violence against women that contribute to and perpetuate patriarchal domination and as such, should be eradicated.

Power dynamics are at the heart of many definitions regarding pornography (Williams, Hardcore, 1999, p. 15: Wicke, 1993, p. 62). Merskin frames the Radicals as a homogenous group contesting pornography as an example of patriarchal power abuse. Others place less control in the hands of the producers and believe it is the audience that establishes the standards of decency that classify pornography by the transgression of those standards. They argue that there is nothing inherently obscene in the nature of the genre - it is a matter of public opinion. 
Public tastes are relative and the community standards of obscenity they institute are as culturally contingent and contentious as the pornography debate itself. Walter Kendrick, for example, believes that "pornography is created by those with the power to censor" (Williams, Hardcore, 1999, p. 15). Kendrick's view corroborates Brian McNair's argument that pornography is culturally reliant. McNair contends that the representations found in pornography are market driven and the result of blending consumer desires with the producers' values and goals (2002, p. 47). Pornography is thus situated as a reflection of preexisting consumer values formulated as sexual desires revalidating the values upon which they are founded. McNair concedes that pornography, like other modes of representation, has historically been white male dominated because the market is traditionally patriarchal, Caucasian, and heterosexual. McNair argues that pornography reflects social values and already present sexual power dynamics; it does not establish them, as purported by many Radical feminists.

Pornography's cultural contingency, as expressed by McNair and Kendrick, is copasetic to the Socialist feminist position. While the Socialist feminists are often anti-pornography, typically finding its content offensive, they disagree with the Radical belief that such representations are akin to acts of violence and that pornography's existence promotes and condones physical violence and discrimination against women. They tend to adopt a viewpoint similar to that of McNair, citing social politics as responsible for establishing pornography's conventions. As such, they tend to view pornography as symptomatic of sexual attitudes - the result of and not the impetus for contemporary conventions.

Liberal viewpoints argue against denying the sexual expression and pleasure available through pornography. They argue that all humans, male and female, have the right to express themselves, sexually or otherwise, including through visual and verbal representations. These 
Liberals do not necessarily argue in favor of pornography, but rather in opposition to censorship. They agree with Kendrick and McNair that pornography is not inherently iniquitous, but subjective and justifiable from an individualist feminist stance. Wendy McElroy contends that this tradition supports women's rights "on the basis of self-ownership: that is, it is a woman's body, it is a woman's right" to use her body as she pleases (1995, p. ix). McElroy goes as far as promoting pornography as potentially sexually freeing to individual women and marginalized perspectives and, as such, beneficial to feminism as a whole. Ellen Willis also justifies a woman's right to pornography, either as practitioner or viewer, taking aim at the alleged liberation aims of the anti-pornography feminists. Willis states that Radical feminists are adhering to antiquarian neo-Victorian notions as to what constitutes feminine sexuality and are obscuring the goal of unrepressed feminine agency:

Rape and pornography, redefined as a form of rape, are regarded not as aspects of a larger sexist system but as the foundation and essence of sexism, while victimization is seen as the central fact of women's oppression. Just as male violence against women is equated with male supremacy, freedom from violence is equated with women's liberation. From this standpoint the positive aspect of freedom - freedom for women to act - is at best a secondary concern, and freedom for women to assert an active genital sexuality is, by the logic of neo-Victorianism, a contradiction in terms" (1982, p. 9).

Liberal feminists seek the right for every woman to pursue her own sexuality without shame or censure. They adhere to the definition of pornography as "the explicit artistic depiction of men and/or women as sexual beings" (McElroy, 1995, p. 51).

Anti-censorship advocates often glorify pornography's diversifying and democratizing potential as giving a voice to individual tastes along lines of varying sexual preferences. Counter-cultural, niche market practices and amateur porn are touted by anti-censorship activists as an empowering avenue for self-identification, expression, and personal agency. But these venues for fringe expressions do not constitute all, or even a significant majority, of the 
pornography market. The Liberal classification of pornography "illuminates the heterogeneity of pornography and questions any generalizations concerning the field - yet, in doing so, they risk downplaying the continuing popularity, visibility, tenacity and economic dominance of mainstream heteroporn" (Paasonen, Nikunen, and Saarenmaa 2007, p. 18). The presence of diversity alone does not indicate much of a shift in the overall economic and social power relations. Paasonen, Nikunen, and Saarenmaa's comment illustrates the nuanced complexities of the pornography market that is often oversimplified by the binary positions of Radical and Liberal feminism.

Lynn Chancer sees the polar split on the feminist pornography debate and argues for a more balanced position acknowledging a network of "relative emphases" where all are concerned with the goals of challenging the sexism evident in traditional pornography and liberating female sexuality in its various expressions. The feminists only differ in their prioritization between freedom of expression and protection from social exploitation, and the means to achieve those aims (Johnson, 2006, p. 246). Chancer's perspective unifying the feminist front may be somewhat optimistic, but is beneficial in opening dialogue between camps by highlighting shared goals as opposed to semantic differences.

There are also those who prefer to forgo the feminist debate by defining pornography solely on socio-economic terms. Paasonen, Nikunen, and Saarenmaa take a neutral position from varying international perspectives on pornography, recognizing that it is culturally contingent with varying meanings in different contexts based on local standards of decency. However, they generally define pornography as "sexually explicit material produced specifically for sexual arousal," that "concerns material practices, economic and embodied ones alike" (2007, p. 16; p. 18). They differentiate pornography from sex as the commodification of sexuality used 
to sell both material and immaterial products $(2007$, p. 12). Joel Kovel and Jennifer Wicke define pornography as the commodification of sex; classifying it either as a process (Wicke, 1993, p. 68) or product (Kovel, 1990) of late-capitalist consumer societies politicized by divisions between high and low culture, private and public consumption. Kovel is critical of pornography's proliferation. For Kovel, pornography is a genre defined on debased tastes resulting from its mass distribution. He views pornography as the mass-market contamination of erotica; in an analysis reminiscent of the Frankfurt School, he claims individuals are imprisoned by the co-option and commercialization of their desires. Pornography is defined by its lack of artistic merit and normalizing function due to its pandering to mass (plebian) sensibilities. "Pornography cannot be divorced from the means of its representation... [it] is the marketing of sex, it needs an advanced commercial society, with highly developed technology and marketing, if it is to flourish" (Kovel, 1990, p. 154). For Kovel, capitalism is the culprit, and pornography is defined as such by its mass reproduction and dissemination in the commercial, not private, sector.

In this case the material does not define pornography; the concept of pornography determines its material through authorial intention and viewer interpretation and reception. Jennifer Wicke employs this concept in her classification of pornography as a "genre of consumption" defined by its production, distribution, and consumption (1993, p.68). It is not the material itself that defines pornography but its reception. To Wicke, consumption is the work done by the user to interpret material, and it is the user's reception, sexual arousal, that defines the product as pornographic or not (1993, p. 70). It is not uncommon to generalize a variety of stimuli into a genus by the similarity of the response it evokes. This occurs often with genres that affect the body like horrors, tearjerkers, and comedies. 
Arguably then, content is not the only determining factor as to whether or not material can or should be deemed pornographic. It is generally disputed whether pornography should be classified by its content, how its content is represented, how it is consumed, or the context through which it is consumed. McNair defines pornography as "(a) a particular content with (b) an intention to produce (c) a particular kind of effect" (Merskin, 2006, p. 201). While this definition is somewhat vague, it does provide a platform that addresses the content, intentions, and reception of pornography and is the ideal starting point for addressing the concerns in defining pornography for the purpose of this study.

\section{What's in a name? The stakes in defining pornography}

"Whoever controls the definition will determine the content."

(McElroy, 1995, p. 44)

As the definition I select will determine what material I study, how I study it, and the conclusions I will draw from it, it is necessary that I select parameters that are neither too broad nor too reductive, and that pre-evaluative judgments are avoided. The danger of including politicized moral judgments as criteria for definitions is that this restricts the reading of pornography's visual data. According to Bruno Latour, scientific practices of categorization validate and naturalize the conditions that predicate their existence (Hayles, 1999, p. 9). Readings of pornography defined by instances of violence ensure that subsequent interpretations provide further evidence of its occurrence, and reinforce the need for a moralized reading in the first place. Such practices are reductive; assuring that visual conventions associated with pornography will be interpreted as linked to objectification and violence. It is imperative to find a definition of pornography that would not predispose the resulting data into specific readings. I 
agree with Susan Driver's argument that there is need for a layered process of interpretation when engaging in public discourse over the cultural representation of private pleasure. Driver states:

What is needed is a process of reading experience as a social semiotic process capable of attending to textual representations and institutional power formations that organize popular pleasures, without foreclosing the nuances of the erotic subjective and collective engagements with culture that exceed and disturb hegemonic meanings (2004).

A single definition cannot achieve this aim in its entirety, but it must allow for this process without unduly limiting or biasing its functioning.

An aim of this study is to contribute to our understanding of pornography based on its structural forms rather than its politicized interpretations. My criticism of the Radical position is its assumptive nature and political bias. However, its perspective cannot be out rightly dismissed since so many definitions of pornography include aspects of subjugation, and that the market supports this practice. Gendered power dynamics must be a point of inquiry for this study, but will remain hypothetical until examined through my research, and before being included as an integral part of pornography's definition. Consequently, I believe the Liberal perspective, exemplified in Wendy McElroy's definition, is lacking acknowledgement of authorial intention and viewer reception. McElroy consciously excludes these considerations, deeming them too subjective in nature. This omission disregards pornography's socio-economic characteristics. Pornography is a multi-billion dollar industry, generally estimated to total between $\$ 10$ and $\$ 14$ billion annually in the United States, profiting on its ability to produce an expected effect from its viewer (Rich, 2003, p. 49). I argue that as the intent to create a particular viewer response is necessary to the definition of pornography, only material that defines itself as pornographic by its intent to elicit such a response will be included in this study. 
The resulting definition is most aligned with the middle ground of the Socialist feminists; it is more specific than the Liberal position, yet not as restrictive and biased as that of the Radicals. Based on content, intention, and effect, I decided to refine McNair's broad definition to material that depicts women and/or men as sexual beings with the intent of arousing desire.

\section{Pornification: The boundaries between porngraphy and the mainstream}

The visual representation of sex is manifest in the cultural products of fine art, commercial advertising, adult entertainment, television programming, music videos, and video games, among others. Increasingly, the boundaries between these cultural industries are becoming more fluid and the designation of a particular representation is more difficult to classify within a specific genre. This fluidity has been branded by many scholars and authors as the mainstreaming of pornographic conventions - or pornification, named by Brian McNair as a "term pointing to the increased visibility of hardcore and soft-core pornographies, and the blurring of boundaries between the pornographic and the mainstream" (Paasonen, Nikunen, and Saarenmaa, 2007, p. 8). More specifically, McNair states pornification is "the representation of porn in non-pornographic art and culture; the pastiche and parody of, the homage to and investigation of porn; the postmodern transformation of porn into mainstream cultur[e]... advertising art, comedy, and education" (2002, p. 61). Pornification is therefore an exploration of boundaries, revealing how we characterize definitive categories and the politics of demarking the permeable spaces between such divisions.

Paasonen, Nikunen, and Saarenmaa observe that the boundaries that differentiate porn from other genres, and between genres of porn, are increasingly in flux, permeable, and difficult to map. They cite: celebrity flashings, sex-tapes, and tabloid scandals; the proliferation and 
increased prominence of hardcore and soft-core pornography and the legitimization of porn-stars in prime-time and mainstream media; communities defined by shared interests in porn; and explicit sexual references in music videos, advertising, and personal fashion as examples of pornification. Other examples include Ariel Levy, who in her Female Chauvinist Pigs (2005), talks about women perpetuating raunch culture - the aesthetics of pornography - and participating in amateur exploits like Girls Gone Wild in order to adhere to social standards of sexiness continually more defined by the adult entertainment industry. Paul Rutherford references exhibitions of erotic fashion in museums, food porn - where consuming images of food produces sensual responses similar to consuming images of sex - and commodity fetishism celebrated in pop art. These examples illustrate the diversity of forms under the domains of sexualization of culture and pornification, and the difficulty in articulating the tenuous difference between the two categories.

While each example is unique it is irrevocably tied to consumption and commerce. Commerce is the common denominator between pornography and all of the aforementioned industries it is cited as contaminating/influencing. Raunch culture, which is touted as sexually liberating by many of its industry practitioners, is argued by Levy to be "not essentially progressive, it is essentially commercial" (2005, p. 29). Sex is profitable and pornography provides sex in neatly packaged and commodified, proscribed, aesthetic forms for other commercial fields to consume and redistribute across dissolving industry borders.

\section{Sexually or commercially transmitted? The roots and range of pornification}

Understanding how pornographic conventions and material are able to penetrate into other media forms requires knowledge of the basic functioning of pornography industries. There 
are three factors identified by Paasonen, Nikunen, and Saarenmaa as causing pornification. The first is a technological determinist view, shared by Kovel, stating that pornography is ineluctably tied to media and media distribution, where there is a cyclical relationship between the development of media technologies and the expansion of the pornography industry. Paasonen, Nikunen, and Saarenmaa argue, "the birth of pornography can be traced back to the development of print technology," where increased availability correlated to higher affordability to an ever more literate populous $(2007$, p. 2). The creation of video led to increased opportunity for private viewing. The Internet has an even greater influence on the mass dissemination of pornography and the development of niche markets and non-normative perspectives. Katherine N. Kinnick shares this technological determinist view, writing: "the success of porn is built on digital technology, which has made porn cheaper, faster, and easier to produce, more widely available, and more profitable than ever before" (2007, p. 14). This highlights pornography's dependence on broad and affordable distribution models.

The second factor identified by Paasonen, Nikunen, and Saarenmaa as a cause of pornification is the deregulation of media policy. Deregulation allowed for pornography's legalization in the United States in 1957 (Williams, 1989, p. 88). Prior to its legalization, pornography could only be shown and distributed in secrecy, vastly limiting its availability. The anti-pornography feminists fought for tougher legislation, while free-speech activists and porn producers, famously exemplified by Hustler's Larry Flynt, fought against censorship throughout the 1970's and 1980's (Paasonen, Nikunen, and Saarenmaa, 2007, p. 7). Legalization ensures increased availability and visibility, which according to Kinnick, results in habituation - "a gradual desensitization and decline in reaction [to sexual stimulus]. As viewers become habituated to sexual content, more titillating, "harder core" fare is needed to arouse and interest 
them" (2007, p. 22). According to this line of thinking, the presence of porn causes its conventions to become acceptable and commonplace, either making regulations banning its presence appear unnecessary, or resulting in newer and harder versions pushing those boundaries. Relaxed regulations and the public's habituation to pornography arguably lead to increased production of more explicit content, which is then made available to a wider audience. As such, other industries, like television, film, and print, have followed suit, pushing their own boundaries in order to match pornography's aesthetics and appeal.

The sexualization of culture is the third factor named by Paasonen, Nikunen, and Saarenmaa as a necessary constituent for the trend of pornification. “... [T] he shifting boundaries of the pornographic and the mainstream can be associated with other diagnoses of contemporary media culture, such as tabloidization and intimization, namely the prioritization of the personal, the emotional and the sexual over information and education" (2007, p. 7). Rutherford expands on this shift in priorities in what he explains as the Eros project. He speculates on the social conditions that cause $A$ World Made Sexy (2007)', where a regime of stimulation, perpetuating capitalism, renders all products erotic. Based on Foucault's understanding of modern sexuality and social power structures, Rutherford argues that increased sexualization is social authority's response to the sexual body's resistance to the prohibitions inherited from Victorianism, exemplified in the 1960's. “By shifting from coercion to provocation... We find a new mode of investment [in the body] which presents itself no longer in the form of control by repression but that of control by stimulation" (2007, p. 3). Rutherford essentially describes a system of socialization through positive reinforcement and stimulus rather than repression and punishment.

\footnotetext{
${ }^{1}$ The title of Rutherford's book on the topic.
} 
This regime of stimulation organizes interest and excitement around certain symbols in the capitalist order, which are circulated for profit (expanded upon in Chapter Three). Levy extends this logic, stating "sex appeal has become synecdoche for all appeal" (2005, p. 30). Signs of 'sexiness' focus attention and arouse desire thus assigning correlative social value. "Sexual desire was always deferred and redirected in the world of consumption" (Rutherford, 2007, p. 139). Sex is therefore often the vehicle through which desire, as a sign of value, is attached to a given commodity. Pornography's expansion into the mainstream requires a system in which technology allows for affordable and easy mass dissemination through an unrestricted media distribution model to a society that is economically stimulated by sex.

\section{Implications of pornification}

Paasonen, Nikunen, and Saarenmaa state that debates over pornography are often oversimplified and polarized, "while some discuss pornography as a social problem, others depoliticize it as hip and fun. There is little in terms of middle ground" (2007, p. 15). In addition to the binary factions at each end of pornography's moral spectrum, pornification introduces those who are in support or indifferent to pornography, but do not want it infiltrating the mainstream. Controversy surrounding pornification largely centers on the context of sexually explicit material, and the resulting access to different audiences. While many critics do not object to pornography's content in private use, they object to its content being made available to minors. Critics, like Kinnick, identify with the Radical position and believe that there is a causal relationship between youths' exposure to sexual material and the likelihood of engaging in sexual activities, including intercourse (2007, p. 21). 
Some find pornography offensive regardless of context, and therefore view its increased prominence as dangerous and detrimental to society. Jane Caputi, whose definition of "everyday pornography" applies to any material that exploits, objectifies or denigrates the female body, states "the worldview of what I term 'everyday pornography' underlines not only the oppression of women and sex negatively, but infuses practices of consumerism, racism, homophobia, abuse of animals, militarism, and environmental devastation" (2003, p. 434). She differentiates erotica from pornography by casting erotica as artistic representations of sexuality and pornography as inherently violent and degrading because it reflects the patriarchal power structure of capitalism. Caputi's statements can be used to support either the Socialist or Radical feminist perspectives and so illustrate the lack of clear demarcation between positions on the feminist spectrum regarding pornography.

For Caputi, pornography is sexuality contaminated by mainstream morality that generally debases the body in a hierarchal "split between spirit and sex, mind and body," therefore, imperialistically colonizing the female body (2003, p. 435). Caputi argues that through the industry of pornography the body is cast as “'dirty,' that is, fertile, active, and exuberant, Nature is finally defeated and replaced by a shiny, man-made, and utterly controlled object" (2003, p. 448). Caputi's statement resembles descriptions of commodification, thus blaming pornography, as a sub-sect of consumer culture, for the standardization of sex and bodies through social, racial, and sexual stereotypes.

Levy agrees that pornography commodifies the female body and argues that it serves a normative role culturally and socially, as women have incorporated the aesthetics of commercial sex into their everyday presentation of selves. "A tawdry, tarty, cartoonlike version of female sexuality has become so ubiquitous, it no longer seems particular: What we once regarded as a 
kind of sexual expression we now view as sexuality" (Levy, 2005, p. 5). Levy says that raunch culture is "about endlessly reiterating one particular - and particularly commercial - shorthand for sexiness" (2005, p. 30). The standardization of heteronormative, patriarchal imagery is extremely limiting to the liberties of self-expression touted, by those like Wendy McElroy and Brian McNair, as by-products of pornography's increased acceptability. The same patriarchal limitations also extend to those marginalized by race and social class as well as gender. Levy argues that pornography is not a source of empowerment for women but a continuation of objectification.

McNair sees the proliferation of pornography as the potential democratization of desire, bringing sexual politics into public discourse. Like McElroy, McNair sees pornography as a right of sexual freedom and expression. Its emergence into the mainstream, rather than a sign of moral decline, is evidence of moral liberalism and the advance of feminism and queer rights. The democratization is evidenced by expanding "popular access to all means of sexual expression, mediated and otherwise ... and the emergence of a more diverse and pluralistic sexual culture than has traditionally been accommodated within patriarchal capitalism" (McNair, 2002, p. 12). McNair believes that by giving exposure to the divergent sexual tastes of women, queer, and fringe groups, the values of these groups will be deemed more acceptable. While it is true that hardcore pornographies have witnessed a pluralization, Jane Arthurs argues "soft-core and its mainstream variants have tended to reproduce rather predictable depictions of gender, desire and sexuality... pluralism does not guarantee democracy" (Paasonen, Nikunen, and Saarenmaa, 2007, p. 8). Hardcore pornography, while more pervasive, is still considered taboo. This periphery, outsider location allows it to not conform to mainstream social norms and standards of decency, which seem to reinforce the hetero, patriarchal order. 
Hardcore's peripheral social local marginalizes many of the individuals involved in its practices. McElroy sees the mainstreaming of pornography as beneficial to those working in the industry. Radical feminists claim that women are coerced into performing and are mistreated in the pornography industry. McElroy's investigation indicated that most abuse takes place because those working in pornography are denied the same working rights as individuals outside the industry due to social stigma. As such, performers have no recourse when contracts are broken, or they are otherwise mistreated. The moral judgments against working prostitutes leave them ostracized and vulnerable instead of protected. McElroy states, "to the extent that sex workers are battered, it seems to result from being denied the protection of law and legitimacy. Whenever porn is allowed to emerge from the underground, even into the shadows, the working conditions of the women improve tremendously, and they are safer" (1995, p. 190).

Reviewing the speculated repercussions of pornification, I feel we must acknowledge a crucial difference between the mainstreaming of pornography and the pornification of the mainstream. The increased visibility of pornography framed as pornography brings its working conditions and values into public discourse, potentially raising awareness, and possibly encouraging tolerance. The pornification of the mainstream however, as detailed by the above authors, appears to borrow pornography's aesthetics while maintaining normative mainstream values, emptying pomography's transgressive capacity while implementing its ability to provoke attention.

\section{My interest in pornification: Advertising, fashion, and sex}

My specific interest in pornification is the claim that mainstream fashion advertising is mimicking pornographic conventions. According to Diana Crane in "Gender and Hegemony in 
Fashion Magazines: Women's Interpretations of Fashion Photographs," fashion photography "has incorporated blatantly sexual poses from pornographic publications (Myers 1987; Steele 1996) that include sexual cues, such as closed eyes, open mouth, legs spread to reveal the genital area, and nudity or semi-nudity, particularly in the areas of breasts and genitals" (1999, p. 316). Crane identifies these features as being innately pornographic and their presence in other forms of media as evidence of pornification.

Merskin's 2006 study, "Where are the Clothes? The Pornographic Gaze in Mainstream American Fashion Advertising," is another such example that directly addresses my research question but only analyses fashion advertisements according to pre-accepted examples of pornographic conventions, without engaging with pornography itself as source material. I feel both of these studies failed to take an objective position in analyzing the relationship between pornography and fashion advertising by adhering to third party definitions of pornography biased by value judgments.

However, Merskin's study provides valuable rationalization as to why advertisements are sexualized and what the repercussions are on the female body by explaining how advertisements distribute value. Merskin argues, "through the use of branding, advertising is expected to do more than sell a product. Rather than simply telling consumers about the use-value of a product (what it can do for you), the emphasis is on a product's exchange-value (what you can do with it)" (2006, p. 203). Through branding, the audience learns to consume what the product stands for rather than its use value, the representation over the material, and the sign over the product. The representations are assigned meaning and value and ranked hierarchically. "Ultimately, the voice added by branding imbues an essentially neutral object with qualities and characteristics that are then transferred to the consumer" (Merskin, 2006, p. 204). Goods are linked to lifestyles 
and social status, and through the presence of the represented human body, positive associations are transferred to the viewer through their acquisition of those goods.

William Leiss, Stephen Kline, and Sut Jhally refer to this process as false symbolism. They cite Stuart Ewen who remarks that this trend emerged in the 1920s when advertising moved away from information and innate desires towards the manufacture of desires and persuasion. Advertisers flooded the market "with suggestions that individuals should buy products in order to encounter something in the realm of social or psychological experience that had been unavailable to them. Material objects thus came to play an increasingly important role in social interaction and everyday life as symbols of prestige and status" (1986, p 21). During this time, representations were being incorporated more and more in advertising and other media forms. Images were integrating the human body as a site for identification, allowing the viewer to relate to the figure depicted in the advertisement's picture. "The 1920's saw the progressive integration of people (via visual representation) into the message" (Jhally, 1990, p. 250). The amalgamation of visual representations, individuals, and the products for sale, led to what many view as the commodification of the body and reification.

Leiss, Kline, and Jhally, in a Marxist tradition, draw on Raymond Williams' structure of feeling, defining reification as material objects elevated as substitutes to gratify non-material human needs; "leisure, play, and other personal activities increasingly are absorbed by a kind of generalized 'fashion consciousness' that connects our activities with the inescapable presence of commercial objects" (1986, p. 26). Consumer goods, visually represented through advertisements, are framed as requisites and signifiers of personal happiness.

Laurie Ouellette in "Inventing the Cosmo Girl: Class Identity and Girl-Style American Dreams," elaborates on the importance of these material signifiers in structuring the female 
relationship to power, consumerism, and sex. Ouelette describes Helen Gurley Brown's 1965 transformation of Cosmopolitan from a "fledgling intellectual publication" into a self-help guide instructing women how to use their sexuality for material and social gain in a consumer society (1999, p. 118). "She [Gurley Brown] subverted the moral shame surrounding sex and reframed the sexual code as an individual ethic and commodity exchange... Her revised sexual contract promoted women's sexual freedom and financial independence, while also encouraging the exchange of sexual 'favors' for material comforts and luxuries" (1999, p. 124). According to Ouelette, feminine desirability was constructed through the women's lifestyle magazine according to the "cultural codes of the working-class prostitute" (1999, p. 123). These codes validate a system of exchange between products, sexual desirability, and social status, as bodies are exchanged for material goods and bodily representations are substituted as social signifiers through fashion.

Merskin, when studying how fashion pictorially directs these codes in advertisements, quotes John Berger: "The woman's beauty, her very desirability, becomes a function of certain practices of imaging - framing, lighting, camera movement, angle" (1972, p. 43). These practices are incorporated through fashion, and ineluctably linked to both commerce and the sexualized body. "'Fashionable' clothing can never be discussed in isolation form the bodies it drapes, shapes, and produces" (Harvey and Robinson, 2007, p. 66). Fashion functions socially to connote information about the body it selectively conceals and reveals. Merskin believes how fashion instructs conceptions of the body is heavily influenced by pornographic conventions.

Hannah B. Harvey and Karen Robinson concur and deduce from studying college women on their campus in "Hot bodies on campus: The Performance of Porn Chic" that "young women are caught up in a system of 'fashion' that convincingly induces human beings to commodify 
their own bodies," reducing their physical selves to the message a particular fashion promotes (2007, p. 73). They rationalize that, "pornography is a "dirty' practice, usually taking the form of women enticing men in exchange for money... 'fashion' elevates it above mere sexual fantasy into a "higher' realm of legitimized beauty" (2007, p. 68). Arguably then, fashion is a way of distracting from or purifying commercial exchanges around the body. Rutherford asserts that advertisements, and potentially anything mainstream, sanitize their imagery. In response to Jean Kilbourne's assertion in Killing Us Softly $(1979,1987,2000)$, that "the advertisers are America's real pornographers," Rutherford contends "the makers certainly did borrow a common porn image... but they also translated and cleansed that image, removing the 'dirtyness,' making it humorous" (2007, p. 152-3). The purpose is to evoke pornographic conventions without exactly replicating its imagery.

Rutherford references Marshal McLuhan's The Mechanical Bride (1951), in which McLuhan argues that the role of fashion is a "tool of discipline" that encourages continuous and constant consumption for both men and women (2007, p. 130). As styles change, new products must be obtained to convey acceptable signs of desirability. Fashion functions as does advertising, in what Christopher Lasch refers to as "“the propaganda of commodities' by which 'advertising serves not so much to advertise products as to promote consumption as a way of life"” (Leiss, Kline, and Jhally, 1986, p. 26). Fashion provides a viable outlet for the constant consumption and exchange of commodities and bodily representations.

As explored throughout this chapter there is a definite relationship between the exchange and interchangeability of visual representations of the body and commodities, as well as shared conventions between pornography and women's fashion and lifestyle advertising. Pornography understood as material manufactured with the intent to produce a particular effect can as easily 
be applied to advertisements as to pornography. Advertising imagery is also produced with the intention of inciting desire to encourage consumption. However with advertising, the producers' and consumers' desired effect requires the acquisition of additional products, while with pornography the product and subsequent effects have already been purchased. Advertising is intended to produce desire; pornographic editorial content is expected to temporarily satiate that desire. Accordingly, the framing of sex, through the female figure, as an active agent in creating or satisfying desire, should be drastically different between advertising and editorial content. This project sets out to determine how that content is different, and what these disparities and similarities can reveal about the relationship between visual representations, desire, and consumerism. 


\section{CHAPTER TWO: Quantitative Methodology}

The focus of this study is the aesthetic interpretation of the compositional characteristics of print pornography and women's lifestyle and fashion magazines. The resulting questions aimed at addressing this focus are: what formal and compositional techniques are used to portray the female figure in mass-market, pornography magazines; how are these visual practices similar and dissimilar to conventions used to represent the female figure in women's lifestyle and fashion magazines; and how can these images best be interpreted to understand the signification of the visual cues employed?

Because I am interested in the pornification of the mainstream, I am confining my research to the merging of market conventions and sexual representations manifest in mainstream, hetero-normative, mass media. As discussed in the last chapter, the female body is the figure most commonly sexualized and subjugated, and therefore must be present in all of the material I assess. I am limiting my scope to current North American publications all other time periods and markets are beyond the scope of this study. Psychological implications are relevant so far as they relate to how the viewer interprets images. Any correlation between depictions of sexuality and physical acts will not be explored including acts of sexual expression, violence, and consumerism. The study is confined to analyzing representations of desire and consumerism, not its practices.

Previous studies were referenced to ensure the validity of the parameters selected for this inquiry. Some studies have charted the level of female nudity in advertising (Beetles \& Harris, 2005); the overall occurrence and level of explicitness of sex in advertising (Reichert \& Lambiase, 2003; Reichert \& Carpenter, 2004; Monk-Turner et al., 2008); and how women are 
posed in pornographic material (Bogaert \& Turkovich, 1993). Others analyze the increased sexualization of fashion among college students, or pre-teens (Harvey \& Robinson, 2007; Bishop, 2007), or directly relate to my research question analyzing the similarities between fashion advertisements and pornography (Crane, 1999; Merskin, 2006).

When comparing these studies, it becomes evident that there is a lack of consensus on measuring instances of sexuality, and inconsistent conflation between the terms sex and pornography. Many of the studies are assumptive, relying on ideological arguments as the basis for defining criteria, or incorporating the results of previous studies as proven variables without making adjustments for changing contexts. I feel it is essential to simultaneously analyze the visual components of both the independent and dependent variables in a comparative study. As such, I will examine pornography alongside fashion and lifestyle magazines to determine if, and how, its visual methods are being incorporated.

One of my goals is to derive a working typology of sexual representations used in pornography and women's fashion and lifestyle advertising to be used in the exploration and creation of artistic visual critique. A multiple-part visual analysis will be used to fulfill the objectives of this study, while creative practice will be used to draw conclusions and comment on the resulting observations. The first part is an inductive, qualitative visual content analysis of the advertising and editorial content within three magazine genres: pornography, women's lifestyle, and women's fashion.

Content analysis is associated with investigations of how the mass media represents social issues and is equally well-suited for studies into formal qualities, both of which are topics of this study. "[Content analysis] can handle large quantities of data, typically in relation to confirming comparative hypotheses ('expectations')... But can equally well be applied to formal 
issues,... or indeed, to any issue that allows the formulation of clearly definable categories and comparative hypotheses" (Van Leeuwen and Jewitt, 2001, p. 2). Content analysis engages with primary sources - cultural artifacts - that, according to Shulamit Reinharz, can provide insight into the relationships between women and individuals, groups, identities, institutions, and ideas (1992, p. 155). Unfortunately, content analysis on its own in is not able to explain motive or meaning, but it is "an appropriate first step in studying them" (Buddenbaum and Novak, 200l, p. 194). The second step concerns "all kinds of visual information, its meanings, pleasures, and consumption (Van Leeuwen and Jewitt, 2001, p. 2). It is a combination of approaches under the umbrella of visual culture, including semiotics, to be elaborated on further in Chapters Three and artistic experimentation to be explained in Chapter Four.

It is necessary that the sample selections are mainstream, mass-produced and contain photographic representations of the female figure. Each sample must fit into the pre-determined genres of pornography, women's lifestyle, and women's fashion magazines. It is difficult to establish clear-cut boundaries between these genres, as many magazines are targeting audiences straddling these categories. As such, any magazine that defines itself through multiple categories was disqualified as a potential sample.

My selection is based on the most recent circulation figures of North American magazines. The top-ranking magazine within each genre was selected based on the results from the Audit Bureau of Circulation for the first half of 2006, resulting in the ranked ordering of: 17) Playboy, 18) Cosmopolitan, and 72) Vogue as the selected sample group. The unit of analysis is one page of advertisement or of photo-figurative editorial. Continuous photographic images that span double-pages or fold-out spreads are counted as a single unit. 
The seemingly straightforward task of defining advertising vs. editorial content is made more difficult by inconsistent visual layouts between the magazines. Cosmopolitan and Vogue are both quite similar to each other, with all editorial consisting of full color photographic images covering the entire page without borders, and a marginal to moderate amount of text superimposed, but rarely over the figure. Playboy, however, contains many full-page editorials divided into smaller photographs of figures stacked overtop and beside one another as in a vending machine. Similarly formatted pages in Cosmo and Vogue are typically advertorial, grouping numerous products and images together within an accompanying rationale. Advertisements are subsequently defined as full-page graphic with explicit and exclusive mention of a product or retailer excluding advertorial. Editorial is full-page pictures that may be made up of no more than 7 smaller images. Of the smaller images, only those containing no more than two figures per image, at least one of which must be female, are counted.

The December 2008 issue of each magazine was used as material for a grounded study-three magazines with a total of 773 pages (including front and back covers). Of these pages only full-page advertisements and photographic figurative editorials was used. The results are:

Table 1.1: Overview - magazine sample content

\begin{tabular}{|c|c|c|c|c|c|}
\hline Magazine & $\begin{array}{l}\text { Editorial - } \\
\text { single }\end{array}$ & $\begin{array}{c}\text { Editorial - } \\
\text { double }\end{array}$ & Ad - single & Ad - double & $\begin{array}{c}\text { Total page } \\
\text { count }\end{array}$ \\
\hline Playboy & 54 & 2 & 13 & 0 & $-69-$ \\
\hline & \multicolumn{2}{|c|}{56} & \multicolumn{2}{|c|}{13} & 185 \\
\hline \multirow[t]{2}{*}{ Cosmo } & 23 & 2 & 58 & 5 & $-88-$ \\
\hline & \multicolumn{2}{|c|}{25} & \multicolumn{2}{|c|}{63} & 231 \\
\hline \multirow[t]{2}{*}{ Vogue } & 28 & 13 & 82 & 24 & $-147-$ \\
\hline & \multicolumn{2}{|c|}{41} & \multicolumn{2}{|c|}{106} & 357 \\
\hline
\end{tabular}

The samples were exhaustive and inclusive, resulting in a total of 304 units containing 355 female figures. Figures were defined as any clearly identifiable females in part or in whole. 
Advertisements and editorials that did not make use of female representations are noted, but any in-depth textual analysis of these images or the representation of females non-realistically portrayed through cartoons, computer graphics, and other illustrations are beyond the scope of this study, as are male figures and children. The figures present in Playboy are primarily editorial content while those depicted in both Cosmopolitan and Vogue are mostly advertising. $81.4 \%$ of female figures in Playboy were in editorial spreads compared to $24.8 \%$ in Cosmopolitan and $23.4 \%$ of Vogue. Because of the incongruity between sample sizes it was decided to define and include both advertisements and editorial as sub-groupings within each genre, comparing trends within and between the magazines.

Another crucial difference between mainstream fashion, lifestyle, and pornography magazines is the difference in target audiences. As I have included the intention of creating a particular effect in the reader as a defining feature of pornography, the subjectivity of the viewer must be addressed. Masculine and feminine desires are framed differently in popular heteronormative media and the representation of the female figure should reflect this diversity. Racial, socio-economic, and sexual orientations are also contributing factors to shaping viewer desire and the subsequent market manipulations, but are beyond the scope of this study.

The sources are primary cultural artifacts and as such are internally valid. Merskin states "as a form of cultural text, advertising provides insight into the culture within which it resides and is a useful barometer for measuring sexual permissiveness of a particular era," and the case of this study, the level of permissiveness is compared to that of mainstream pornography (2006, p. 203). The samples are non-probability selected and will be employed over a short range of time, and so external validity (generalizability) is not applicable. The samples are internally valid for they are inclusive and exhaustive. Because this is a grounded study, analysis takes 
place in every instance that a category is defined throughout the coding process. Grouping visual observations together into categories is a form of assigning meaning, and the first stage of semiotics where denotative meaning is assigned to the signifier. Once meaning is assigned, the signifier becomes the signified and the process continues in what Roland Barthes describes as the "chain of associations" (Lester, 2000, p. 51). The first portion of analysis isolates formal features through semiotics to define categories within the typology.

This is a preliminary and exploratory study intended to create a typology of visual characteristics to be used as coding parameters for future studies and in the creation of artistic prints (elaborated upon in Chapter Four). The coding criterion is developed cumulatively throughout the process until saturation is reached and a comprehensive list of features is translated into exhaustive and mutually exclusive categories. The following month's edition is then analyzed to ensure that categories are valid and that no new trends emerged. Past studies are referenced in forming coding categories based on completeness of the figure, body positioning, camera angle, lighting, interaction with set, props, and other figures, instances of touch, level of dress/undress, and eye contact.

I began by describing each page of either advertising or editorial sequentially (as per the template in table 1.1, appendix 1) in each magazine (see examples in tables $1.2-1.4$, appendix 1). Items were depicted in detail focusing on the figure's pose and the overall compositional structure. The template evolved as new elements were discovered. This process proved to be too detailed and labor intensive, so was discontinued after the coding of ninety-seven items (forty in Vogue, forty-one in Cosmo, and sixteen in Playboy). My process was therefore refined to recording instances of full vs. partial figures, number of figures, camera angle, figure placement, visible exposure of body parts, eye visibility, focus, and direction of gaze, on 
multiple spreadsheets. ${ }^{2}$ The results were tabled into overviews (see appendixes 2-5), and compared (see appendix 6). The features were then grouped into categories that previous studies cite as instances of sex or examples of pornographic conventions. Reichert and Carpenter apply Courtney and Whipple's definition of sex in advertising as "sexuality in the form of nudity, sexual imagery, innuendo, and double entendre" (2004); this is evidenced by the models' level of undress, ranging from demure, suggestive, partially clad, or nude and their engagement in sexual behavior, based on levels of contact ranging from none, to simple, to intimate and very intimate contact.

Merskin combines conventions of cinematic pornography as defined by A. Kuhn (1985, 1995) with instances of "hierarchy, objectification, submission and violence," as set by Jensen and Dines (1998), as examples demonstrating pornography. These examples adhere to the radical feminist position, thus framing pornography as inherently negative. Derived from semiotic readings of Goffman, hierarchy is illustrated by the figures' posing and position relative to camera angle or other figures within the frame, their complacency established through eye contact (Merskin, 2006, p. 206-207). Merskin references fragmenting of the body as an element of objectification, and Bogaert and Turkovich refine this criteria to include any portrayal where the "individual or personal characteristics are minimized." This depersonalization is assessed through the model's eye clarity, facial clarity, and body posture (Merskin, 2006, p. 207-208). Examples of submission are similar to hierarchy in their framing of the body as vulnerable, but unlike hierarchy the model is caught unaware with the gaze directed anywhere but back at the viewer. There must be no eye contact and the body must be positioned to connote vulnerability often either viewed from above or behind, though any direction other than forward facing at eye

\footnotetext{
2 It would be useful for future studies to chart signifiers of race and social class, like hair and skin color and the engagement with sets and props, extending the inclusion of relevant variables.
} 
level is counted (Merskin, 2006, p. 208-210). Violence is defined as the convergence of all of these categories in a manner that highlights the powerlessness of the female figure, or portrays her as aggressive and domineering to other figures within the frame (Merskin, 2006, p. 210-211). Instances of these elements were recorded to ascertain the frequency and manner through which these components are employed in fashion, lifestyle, and pornographic publications.

Instances of sexual explicitness are denoted through visible exposure of body parts and figure positioning. Exposure of breasts, cleavage, nipples, pelvis, genitals, lower buttocks, and its crack are all coded as examples of explicit sexuality, while the presence of lower back, upper buttocks, inner thigh, upper thigh or hip, under arm, wrist, and abdomen are considered signs of availability and implicit references of sexuality. Elements such as the elevation of the legs, cocking of hips, and arching of back, that highlight these sexualized areas, are noted as examples of sexual display.

As expected, Playboy had by far the highest instances of sexual explicitness, with almost all of the figures represented exposing the entirety of their bodies. Editorial across genres tends to provide more examples of undress than advertising, varying from minor variations in Cosmo and Vogue, to double and triple the disparity in Playboy. Display is far more consistent between advertising and editorial within each magazine and varies in frequency and the body parts favored between each genre. Cosmo favored the display of décolletage and legs, Playboy highlights breasts, abdomens, and buttocks, while any instances of pelvic thrust, or elevated and parted legs potentially fully exposing the genitals occurred only when the models were dressed, and are by far most frequent in the fashion advertisements of Vogue. The pubic area and genitals are only nude in Playboy but are usually partially covered by a prop or the legs are closed. 
Hierarchy is primarily established through the figure's relationship to camera angle.

Depictions from any angle other than front facing at eye level convey a subservient relationship to the viewer, but shots from above looking down on the model or from behind, most thoroughly express this relationship. The models' complacency and acceptance of their arrangement must be established through eye contact in order to be considered hierarchy.

Examples of hierarchy are rampant across genres but are most frequent in Playboy. Only $30.8 \%$ of figurative material in Playboy is presented at eye-level compared to $43.4 \%$ in Vogue and $50.7 \%$ in Cosmo. $29.1 \%$ of figures in Playboy are front facing while Vogue and Cosmo have $48.3 \%$ and $55.4 \%$ respectively. The Playboy models maintain eye contact in nearly every single frame, inviting, legitimizing, and condoning the viewer's privileged position. $74.4 \%$ of Playboy's figures maintain eye contact while $61.4 \%$ of Cosmo's do, and only $48.3 \%$ return the viewer's gaze in Vogue.

Though examples of objectification are apparent in all three, it occurs differently and slightly less frequently in Playboy than in either Cosmopolitan or Vogue. Approximately only $1 / 3$ to $1 / 4$ of all figures were represented in their entirety in any of the magazines $-36.1 \%$ Playboy, $29.2 \%$ in Vogue, and $24.8 \%$ in Cosmo. Playboy's top rank is due to the high ratio of editorial vs. advertising content. Across the board, editorial has a minimum of $20 \%$ more full bodies than are present in advertising. If editorial is viewed in isolation, Vogue has the highest rate of complete figures at $47.8 \%$, Playboy has $40 \%$ and Cosmo has $36 \%$. If items with only one image of full figures are counted, then Playboy actually has the lowest instance of full bodies at $29 \%$ compared to Cosmo at $36 \%$ and Vogue at $41.5 \%$. This is due in large part due to Playboy's practice of dividing pages into smaller fragments that contain full and partial figures in a serialized manner potentially discounting their inclusion as representations of an entire person. 
Playboy has significantly higher instances of distinguishing markers such as eye visibility and contact, the lack of which is a determining factor of objectification, ranking Playboy as less objectifying than Cosmo or Vogue.

Both submission and violence are more frequent in advertising than in editorial and most evident in Vogue, followed by Cosmo. This is because in order to qualify as submission, the model needs to be "caught unaware" reassuring the viewer that there is no limit to prolonged gazing; the figure is unaware that she is being watched and weakened in her position of obliviousness. Vogue has significantly the lowest level of eye contact, and although Playboy has the highest percentage of submissive poses and positions, it also has the highest rate of eye visibility, direct gaze, and focus. The Playboy models are aware of their hierarchal position but seem to approve of it through their smiling recognition of the viewer. Fashion advertisements, however, often depict their characters indifferently self-absorbed or gazing longingly at the product or off into space. Instances of violence incorporate hierarchy, submission, and objectification but also seem to employ interaction either through touching others, self, or props. These dynamics exemplify restrictive and powerless relationships.

Sex functions more implicitly through advertising and mainstream media than through the explicit nature of pornographic editorial, but instances of so-called pornographic conventions, like submission, objectification, and violence occur more frequently alongside these implicit references. Only hierarchy occurs more frequently in conjunction with explicit sexual references. It follows logically - in Playboy explicit editorial is the product already purchased by the viewer. Ads make far more use of implicit sexual innuendo to illustrate what still needs to be obtained through the acquisition of additional goods. This suggests that consumerism is likely the root of the power dynamics attributed to sexual representations. 
My findings to date support that there are many shared representational elements between mainstream women's print media and soft-core pornography, but question the evidence of a causal relationship between pornography and advertising as purported by many heralding pornification. Mutual instances of an occurrence do not necessarily connote a causal relationship between the parties, and none of the previous studies established that the devices of hierarchy, objectification, submission, and violence originate with pornography. I suspect that the relationship between the mainstreaming of representations of sex and consumerist desire, at least in print advertising and editorial, is far more nuanced and multi-directional than many critics citing pornification imply. 


\section{CHAPTER THREE: Qualitative Interpretation and the Affect Economy}

There is at least one image on nearly every page in Playboy, Cosmopolitan, and Vogue. All but a few of these images are photographic, illustrating pornography and women's fashion and lifestyle magazines' reliance on photography as a means of expression. The studies analyzing these publications, detailed in Chapters One and Two, typically dissect their photographic content, but are deficient in their theoretical engagement with the visual elements they explore. Although the evocation of desire is the self-stated intent of the visual representations used as source materials for these studies, none speculate how lust is transmitted through pictures. Their analysis only engages with culturally dependent meaning read through semiotic analysis. They chart occurrences of sexually explicit conventions across media, but do not examine how these conventions operate. While they utilize photographic images, they do not probe into viewers' relationships to photographs and how these pictures are able to evoke and direct desire. They do not question the power of the photograph, as does Max Kozloff studying "the fascination of photography," or W. J. T. Mitchell's inquiry into "what pictures want" (1979, 2005). I believe that in order to understand the intricacies of how desire operates through photographic representations within these genres that promote consumer tendencies (advertising and pornography), we must first explore the operation of desire and the nature of photographs. What is the general operation of desire within photography?

Psychoanalysis argues that all desire originates from a wish to be united with the lost complement. The lost complement is associated with the infant's relationship to its mother's breast. At infancy, a time ruled entirely by the pleasure principle, the child does not distinguish itself from any other autonomous beings. With no concept of self or even ability to conceive the 
concept, the child feels analogous with its environment, exemplified by the fluid permeability in the relationship between the mother's breast and the infant's mouth. After the mirror stage and the introduction to the law of the father (symbolic order) that enables visual and verbal identification, the child has a sense of self and feels separated from its environment. The infant feels loss and desires to once again be united and whole with the mother/other who is now seen as distinct. The individual spends the remainder of his or her life wishing to be whole again, desirous of the lost complement, and searching for its retrieval in union with disparate entities. This original desire is necessarily insatiable; it can never be resolved, only transferred to potential symbolic stand-ins of the lost complement.

Sex is the physical union of individuals, and arguably as close as material beings can come to re-obtaining the lost complement. Desire thus inevitably correlates to displays of sex and sexuality. Products associated with sex are framed as unifying with the body to increase the desirability of the user and the possibility of obtaining the lost complement. Desire can therefore be transferred from object to object, as each promises the subject potential, but ultimately unobtainable, completion.

Roland Barthes is passionately engaged with the ontological essence of photography in his 1980 Camera Lucida. In the text, Barthes introduces the dual functioning of photographs to transmit both meaning - studium, and experiential poignancy - punctum. "If pictures teach us how to desire, they also teach us how to see - what to look for, how to arrange and make sense of what we see" (Mitchell, 2005, p. 72). This sense and arrangement is the photograph's studium, and is perceived and understood through one's cultural knowledge. It is the culmination of details and attributes. The studium is the divided units of signs, symbols, and icons organized into a syntax to both denote and connote a picture's meaning, "the semiotic 
content that it discloses" (Mitchell, 2005, p. 9). Studium is both the material and the result of deconstruction, where the interrelated signs of an image are read and strung together to derive a shared social significance.

All understanding takes place at the level of studium, the level Jacques Lacan refers to as the symbolic order. This is the field of all language - verbal and visual. When an object, feature, or entity is recognized it is incorporated into the structured order of the symbolic, shaping the subjects' worldview in relation to their concept of self. The gaze, structured by language, is one of division and hierarchy, which organizes nature into exclusive and sovereign categories that, in turn, validate their system of division and rank. Worth is applied along codified parameters determined by a language of the same parameters. The self-validating symbolic order ensures continuity and consistency in deciphering the worth or meaning of a given sign.

A codified system of meaning and value is necessary for the construction of commodities. A commodity is a product whose value is determined by an external system of exchange. A commodity's worth is not intrinsic, but directly correlated to its demand. The more a commodity is desired, the higher its worth. As such, the only required attribute of a commodity is that it be exchangeable/interchangeable and with value that is not inherent or fixed. In this sense, a commodity is similar to a sign; meaning is exchanged for a representation. Signs, unlike symbols and icons, are arbitrary. They are exchangeable stand-ins for an entity without any innate resemblance or connection to the original referent. Through visual linguistics a picture's image is reduced to code. This logic supports the argument that the gaze is objectifying with the potential to also commodify. Objectification occurs through the reduction 
of a referent through visual representation; commodification occurs when the representation is exchangeable or interchangeable without drastically altering the overall meaning of a picture.

The effective communication of meaning and worth are crucial to the success of pornography and advertising. As detailed in Chapter One, pornography and advertising are "particular content with an intention to produce a particular kind of effect" (McNair, 1996, p. 45). Pornography and advertising have increasingly similar sexualized content, with the intention of increasing consumption, but to divergent effects. Advertising is produced to encourage the acquisition of commodities while pornography aims to deliver sexual gratification through the consumption of the product already purchased by the viewer. The future purchase of pornography is dependent on its ability to satisfy past needs.

The aforementioned foundational studies all engage solely with their content's studium through semiotics. Semiotics analyzes the manifest/denotative meaning and the latent/connotative meaning of images - what images represent and the ideas and values the representations stand for (Van Leeuwen, 2001, p. 92-94). Denotative meaning is quite literal in photography as there is a point-to-point correspondence between representation and referent. Connotative meaning however, is culturally, and somewhat subjectively, contingent. Therefore, sociology, cultural studies, art history, and anthropology all contribute to semiotic readings that dissect the social significance of aspects such as body language, relative size and positioning, colour, and essentially all observable features in an image.

The previous chapter recorded instances of conventions defined as sexualized or pornographic by A. Kuhn, Jensen and Dines, Reichert and Carpenter, Courtney and Whipple, and most notably, Deborah Merskin. However, Merskin, and many of these other authors, only engage with defined pornographic practices qualitatively. The quantitative method used in 
Chapter Two only demonstrates the relative frequency of characteristics, but it is not able to provide insight into how those characteristics operate within specific examples. I will therefore analyze the previous chapter's findings through semiotics, drawing primarily on the techniques established by Roland Barthes and refined by Ervine Goffman.

The human figure is the subject of Goffman's Gender Advertisements (1976), and is the most commonly and consistently portrayed subject in pornography and advertising. The first step used in my content analysis is to study fashion advertisements to discern the visual conventions employed, concentrating on the female figure. All of the advertisements presented exemplify sexualized material and the potential merging of pornography and mainstream media. The majority of images are from the magazines used in my content analysis with a few external examples to show consistency with other publications.

Fashion advertisements use the body to create a structure of value, a site of exchange for goods, but not as goods itself. The body is used associatively to create a standard of equivalent values to connote a product's worth. Rutherford references Jean Baudrillard's 1968 The System of Objects stating the "capacity of advertising to gender any object, making the commodity a woman ready 'to be bought,' 'the woman-object being the advertisings world's most effective persuasive device and social myth" (2007, p. 136). Through the photograph, a model's sexual allure is transferred to the product, and can therefore be transferred to the viewer through the acquisition of that specified commodity.

As the products being promoted are distinctive, so are the methods used to convey the products' use and value. As a result, the conventions in advertising are less uniform with more variation between units and between the figure-to-product relationships than with pornography. 
Trends in presentation methods follow category distinctions of product type and target markets, such as fragrance, cosmetics, or jewelry, and between luxury and more plebian values.

The figure's interaction with a product is a key factor in establishing its general worth. Touching occurs far more frequently with high-end retailers, although the type of touching ranges with product type. Perfume ads tend to be the most sexualized instances of contact, employing what Goffman refers to as the feminine touch (see figures $1-4$ ). This type of touch involves caressing actions, barely engaged with surface, that are gentle and non-utilitarian. "Self-touching can also be involved, readable as conveying a sense of one's body being a delicate and precious thing" (Goffman, 1976, p. 31). Each of these examples also illustrates the vulnerability and permeability of the body through implied passivity and exposure. Each figure is presumably naked and revealing susceptible or suggestive parts of her body such as the inner wrist, underarm, or neck - also parts that connote sexual availability. The lips, in nearly every perfume ad observed, are parted and the eyes are often either visually obstructed, closed, or gazing off into space. These are examples of sexualized licensed withdrawal. Goffman defines licensed withdrawal as the character's psychological removal from the scene, depicted through the exhibition of intense emotions, the attempt to cover the character's face, touching the face, inverted gaze, fidgeting gestures, or shielding the self through visual barriers (1976, p. 57-83). Licensed withdrawal is considered a sign of submission.

Each of the models' heads are tilted back or turned away from their bodies in a canting gesture that Goffman refers to as a ritual of subordination and sign of appeasement or availability (1976, p. 46-47). The models' bodies are precious and desirable entities accessible to the viewer through the implied product use. The product is framed as able to transform the user through its positioning as a powerful phallic symbol between the subject and viewer, or in the case of figure 
2 , the subject's body becomes the product bound in its packaging. These fragrances promise to convert the purchaser into the sexualized figure in the advertisement.

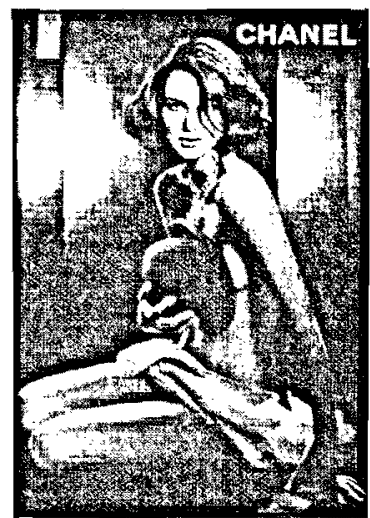

Figure 1

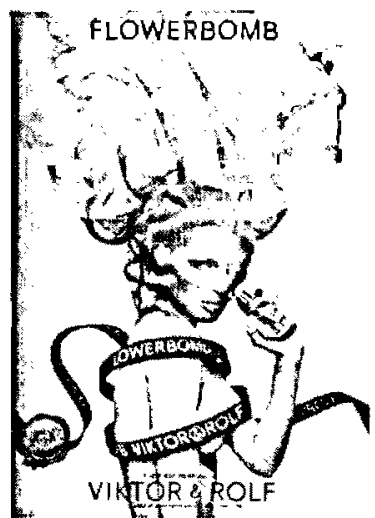

Figure 2

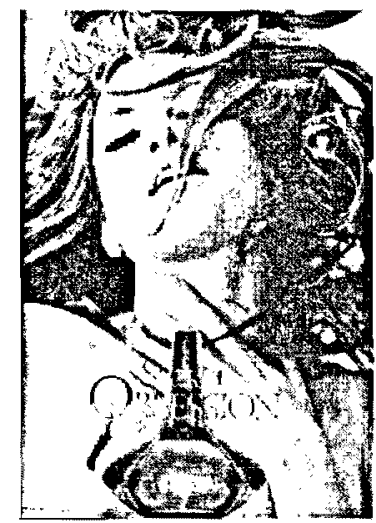

Figure 3

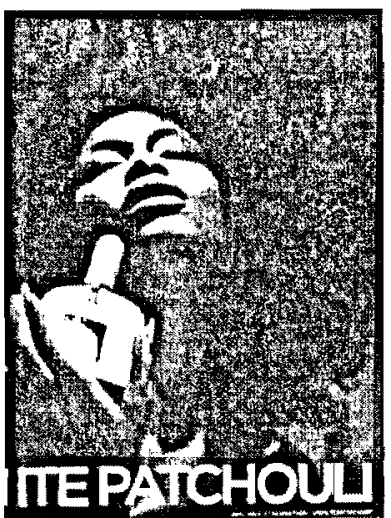

Figure 4

Jewelry is framed similarly to fragrance advertising, though somewhat less sexually

explicit (see figures 5-7). Vulnerable areas of the body that convey sexual availability are exposed to the viewer. Instances of licensed withdrawal are very common with the product positioned between the viewer and subject, or being used to touch the face in a playful, distracted way. The figures are more frequently portrayed facing forward at eye level and maintaining eye contact and are thus slightly less submissive than the majority of those portrayed in fragrance advertising. Both jewelry and cosmetics, however, tend to be more objectifying, never displaying the body in its entirety.

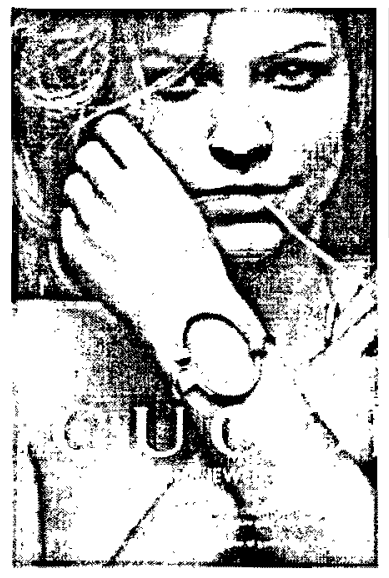

Figure 5

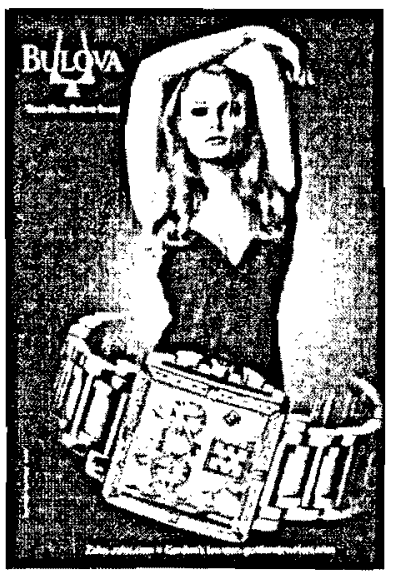

Figure 6

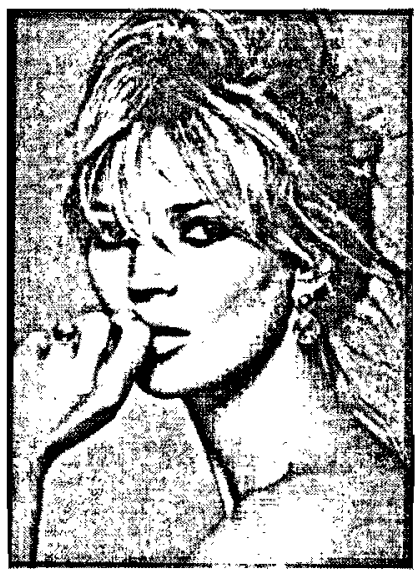

Figure 7 
Nearly all high-end and all luxury advertisers are found in Vogue (with additional examples from Vanity Fair), but not in Cosmopolitan. Higher-end retailers tend to focus on brand image, associating their products with the portrayal of a leisurely lifestyle exemplified through setting and props (see figures 8-12), or as fine art objects, by arranging the frame to aesthetically showcase the product (see figures 13-15). The models feign disinterest and/or disdain towards the viewer, either through confrontational and dismissive expressions or by a lack of eye contact altogether. The images from high-end retailers employing sets tend to be more narrative and often depict several products rather than exclusively showcasing one. The models are predominantly white and framed as upper class. When racial minorities are depicted in high-end advertisements, they are often either celebrities and/or portrayed more sexually explicitly (see figures 4,10 , and 15 ).

The body-posing in these ads are often more unnatural and awkward than in advertisements for lower-end retailers. The body is treated as a sculptural object arranged to complement the overall compositional structure of the image and not as a living organism meant to function and be comfortable. The products are portrayed as more valuable than the bodies willing to contort to hold and wear these commodities. The body language and gaze create an air of inaccessibility - the manufactured tone is that everyone wants these products but not everyone can have them. Figures 10,11 , and 12 depict bodies aggressively open to display, with the angled positioning of the legs and arms directing focus to the models' pelvis. Figures 13-15 operate similarly, employing hard angles and the lines of the body and background to draw attention to the products. Here the body is used as a decorative plinth to display merchandise. Figure 12 most effectively illustrates the body being used formally to direct attention simultaneously to the product and a sexualized area of the body. The shoe illustrates the 
transferal of erotic value exchanged from the sexualized body to the fetishized product, that is pointing to, and nearly puncturing the area. This is also a display of what Merskin refers to as violence in advertising. High-end advertisers tend to employ more aggressive and violent imagery depicting limited access to their products resulting in lust, envy, and competition that are often encouraged by the imagery in its advertisements.

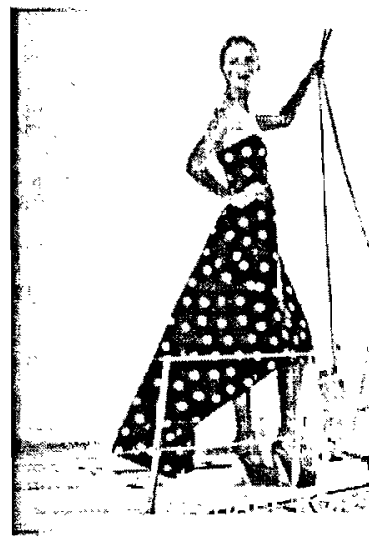

Figure 8

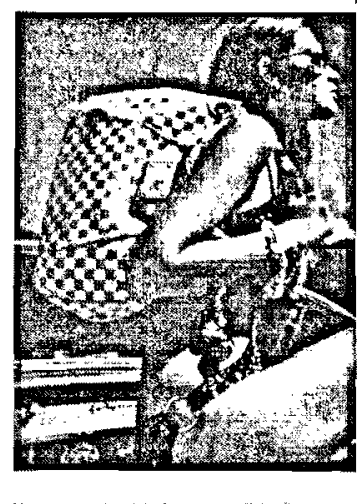

Figure 9

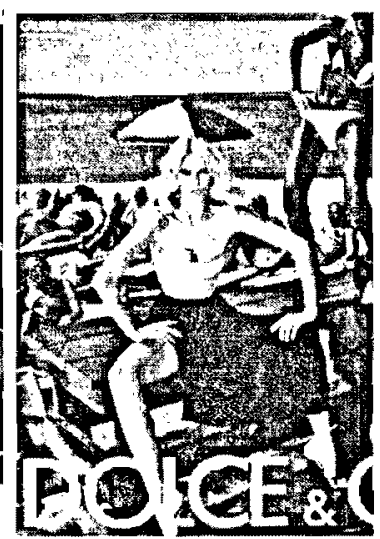

Figure 10

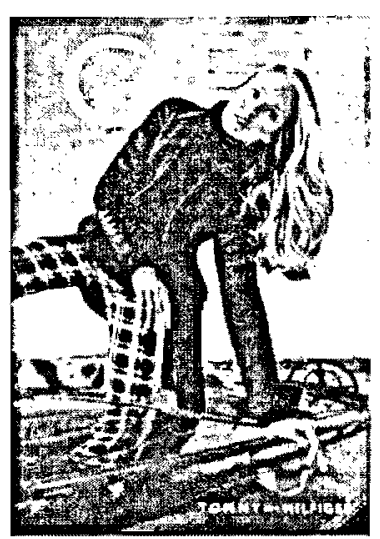

Figure 11

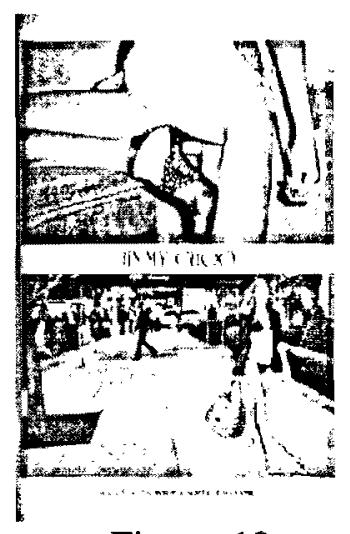

Figure 12

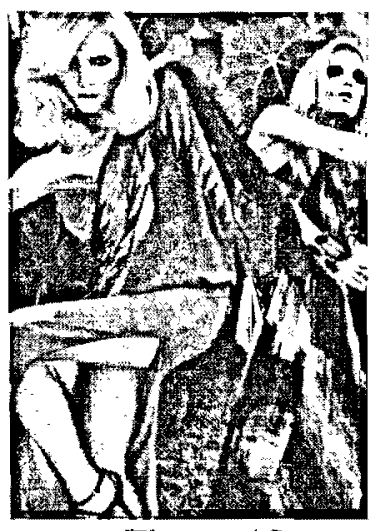

Figure 13

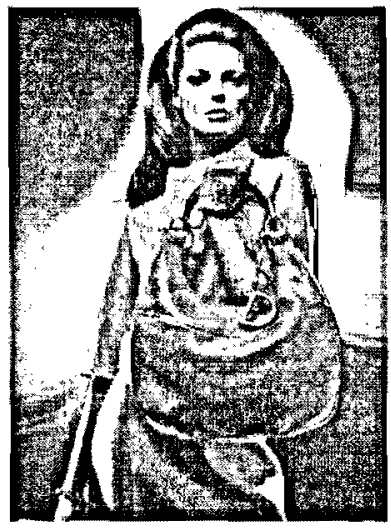

Figure 14

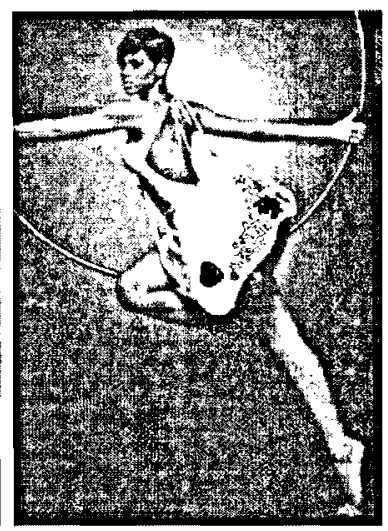

Figure 15

The models displaying lower priced commodities are more accessible through direct gazes and welcoming expressions, and are significantly less sexualized than with high-end retailers. The products depicted in these ads are usually cosmetics or low-end retailers. Less expensive retailers tend to depict their product's use-value through the model's engagement with the product (see figures $16-19$, note figure 17 is a mid to high-end brand of an inexpensive 
cosmetic product). Models are shown engaging with the product through touch or use, either implied or explicit. These ads are frequently more literal and practical, containing text describing the features and benefits of the product (see figures 16-18). Some ads attempt to mimic editorial conventions by providing mock-journalistic text to lend themselves an auspice of objectivity - note the advertisement label on figure 18 to ensure readers can tell the difference between types of magazine content that do not otherwise distinguish themselves visually. Repetitive visual elements are frequently employed in ads, highlighting associations between product and its effect through shared colors or patterns. In figures 16 and 19 the font and logo are the same color(s) as the products, while in figure 17 the red of the polish bottle, the fingernails, and the lips connect the product with sexualized, fetishistic areas of the body. Canting is very common, and the body is displayed to project comfort and ease. If there is more than one figure, the body language depicts jovial and intimate interaction. These ads are typically less overtly sexual, and more intimate and accessible.

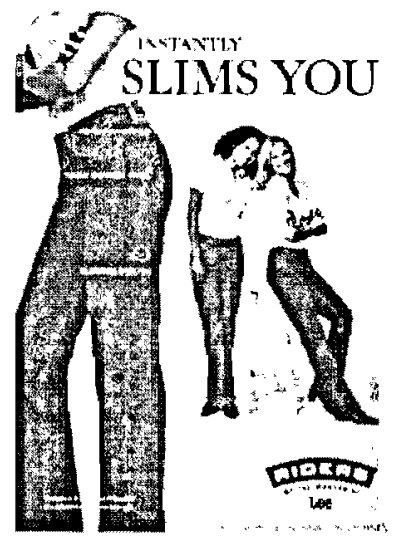

Figure 16

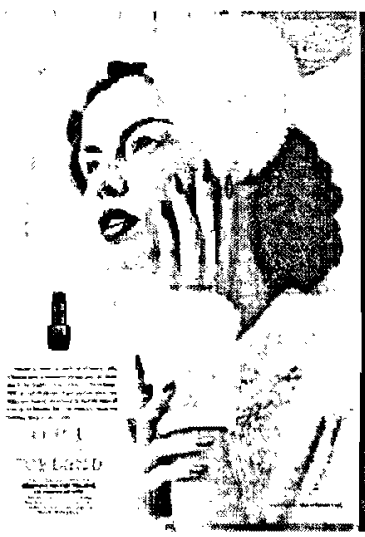

Figure 17

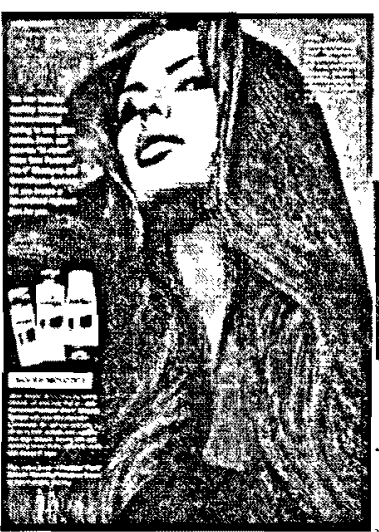

Figure 18

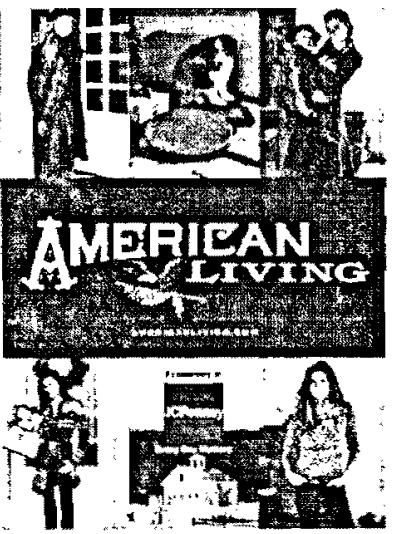

Figure 19

Lighting methods also correlate most obviously along lines of worth: the more expensive a product, the higher the level of contrast and artistic effects; lower-end products tend to be evenly lit, with little shadow, and occasionally over-exposed. Figures 20 and 21 are both for the same type of cosmetic, but figure 20 is an ad for a much more affordable brand. Figure 21 
adroitly illustrates that for high-end brands, the association between the model's allure and the brand logo is the most valued - product particularities are secondary.

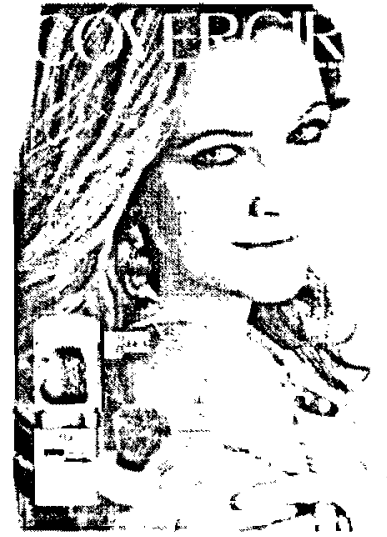

Figure 20

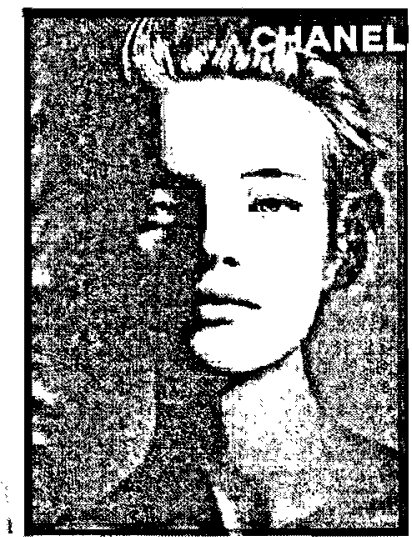

Figure 21

Bodies are represented in a variety of scales and levels of wholeness. Fragmented bodies are very common, most frequently depicting only the face. The selected figurative element corresponds to the area of the body where the product would be used. In advertising, the body acts as a marker of equivalence that denotes and connotes the value of a product through the sexual allure and/or the lifestyle its acquisition will afford.

The figures in fashion editorial are typically engaged with numerous products and, like the high-end advertisers, create desire narratively and associatively through the display of attractive lifestyles and bodies more often than depicting use-value (see figures 22-25). Singleimage, full-page editorials are most often displayed in spreads consisting of four to eight pages linked by an overarching theme. Editorials typically use the same models throughout the spread, which allows for greater individual characterization. Bodies are more often shown in their entirety and less prone to sexual explicitness, although instances of hierarchy and objectification are approximately equal to advertising. Because there are more multiple figures interacting in editorial, submission, licensed withdrawal, and violence occur slightly more frequently than in advertising, although high-end, fragrance, and jewelry advertisements, as a category 
distinguished from other advertising, have a higher frequency of these conventions than editorial content. Editorials contain the most diversity between examples, as they are often quite imaginative with elaborate sets and framing that convey themes like Romeo \& Juliet and retro Hollywood glamour. "Its [advertising's] hidden purpose was not so much to sell a brand, which was no more than a 'cover' to mask the really important job, namely to promote the social order" of perpetuating capitalist material gain through consumer consumption (Rutherford, 2007, p. 137-138). This quotation illustrates that advertising's hidden purpose is editorial's blatant purpose. Editorial is not about promoting any single object it displays, but rather establishing the belief that through the use and consumption of consumer goods, the viewer will acquire the same allure depicted in the image. Generally, throughout women's fashion and lifestyle magazines, the female figure is used as a sign of value to create desire for another commodity. Advertising presents the body as a commodified vehicle of exchange through which value can be transferred from the objectified body to other fetishised objects - sex allows for lubricated transference.

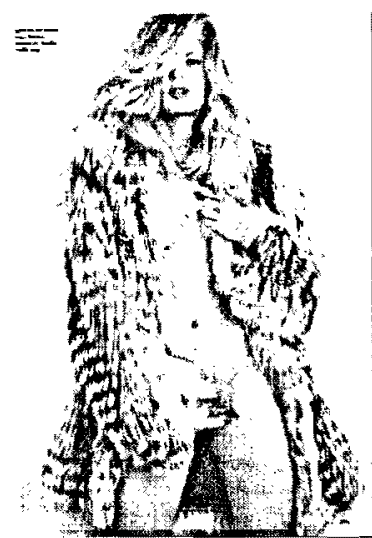

Figure 22

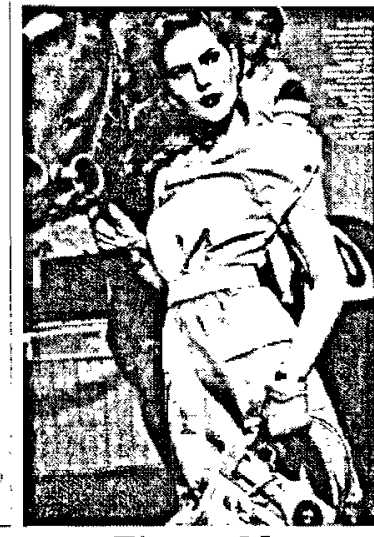

Figure 23

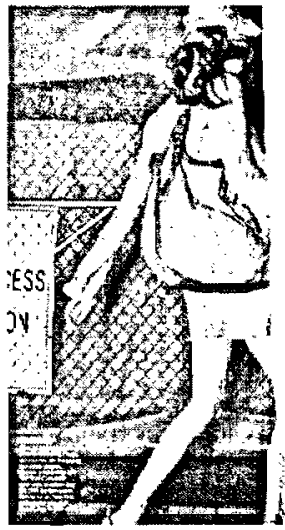

Figure 24
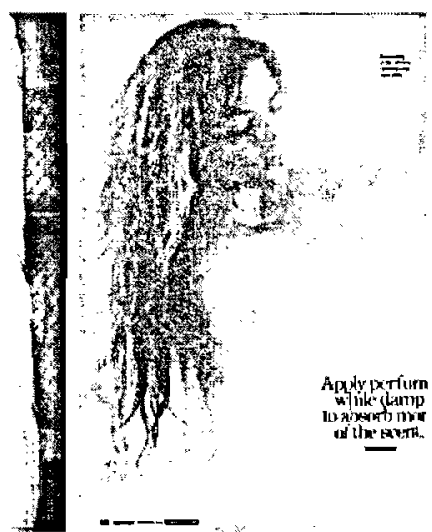

Figure 25

Pornography's visual conventions signify that the sexualized body on display is a commodity. Playboy establishes a soft-core, racially limited, middle class, hetero-normative aesthetic. While both male and female figures are portrayed, they are rarely together, though infrequent examples of males and females together occur mostly in advertising. Only the female 
figures, often on their own, are presented as commodities. Of the women depicted, approximately $80 \%$ are featured in editorial. Of these, nearly every female is in a state of undress, with either the breasts or buttocks exposed. These areas of the body are highlighted in advertisements but no nudity is shown.

Images from the December 2008 and January 2009 editions of Playboy were assessed. What is most remarkable about these images is the similarity between models and composition. Figures 26 and 27 are centerfold pages of the cover model from the December and January issues and employ similar layout, posing, and camera angle. Figure 28 illustrates Playboy's love of multiples in its frequent representation of twins and triplets. Figures 29-31 are composites of poses repeated throughout both issues to highlight the similarities in postures. Bodies are posed with shoulders back, backs arched, hips cocked, and with bent knees or elevated legs. These poses highlight breasts, abdomens, hips, and buttocks. The postures are submissive, maximizing visual access to the body, and often depicted from a vantage point looking down, to the side, or slightly behind the model. The models usually smile and maintain eye contact in nearly every frame, inviting, legitimizing, and condoning the viewer's privileged position.

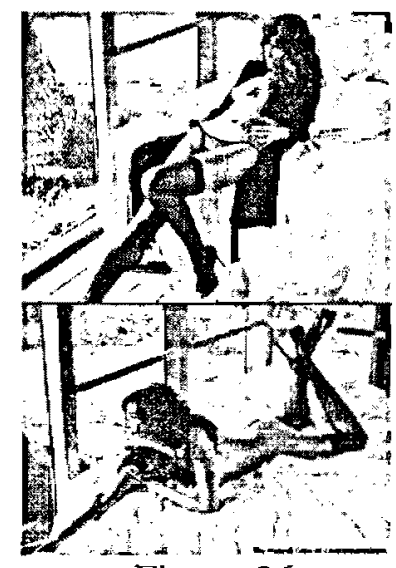

Figure 26

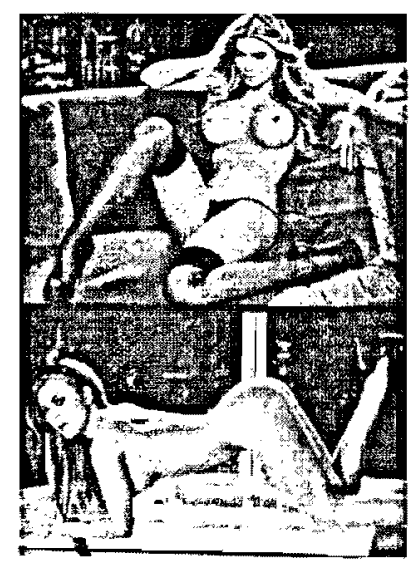

Figure 27

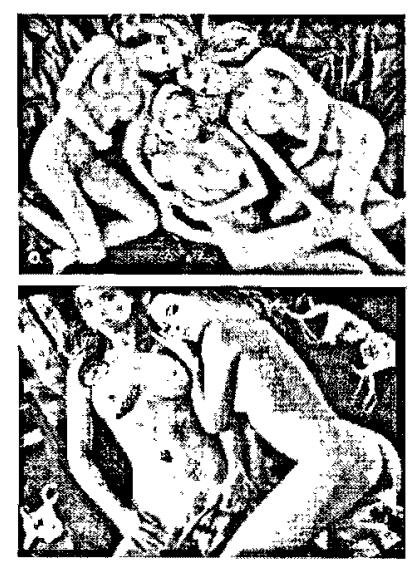

Figure 28 


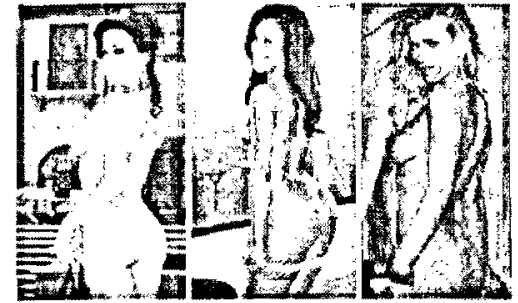

Figure 29

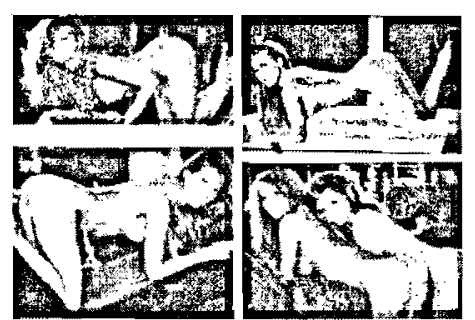

Figure 30

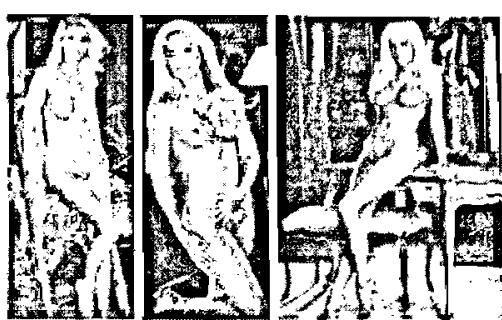

Figure 31

The lighting is warm, even, and nearly identical in every shot. Shadows are generally minimized through multiple light sources with additional key lighting on specified areas: eyes, breasts, and hips/buttocks. Often there is also backlighting, creating a halo effect on the models hair, which is inevitably long, loose, tousled, and blown away from the figure's face. The even lighting creates uniformity and a plasticized aesthetic of the skin, which appears smooth and impeccably groomed. There are no distinguishing marks and very little body hair. In contemporary examples, if any body hair is evident it is pubic and confined to a small, symmetrical strip or triangle. The body is adorned with jewelry or accessories, and is never without some form of ornamentation. The body is also rarely shown in its entirety. Even when the majority of the figure is depicted on the screen, there is often a hand or foot cropped out of the frame. This functions to leave the body open, penetrable, and vulnerable, as well as facilitating objectification by representing the whole being through isolated pieces.

The serialization of conventions and repetition of poses connotes interchangeability, as does the minimization of distinguishing factors. The body types are nearly identical creating a normalized aesthetic that suggests the presented figures are the ideal and that either no variation exists or is desired. The vast majority of models are white, and on the rare occasions when other races are depicted, physical characteristics that signify race are minimized. Rutherford names this standardization and streamlining of the body as a necessary attribute of the eroticization of popular culture. "What eroticism promoted was a body perfected as stimulus, a body that looked 
so good because it was smoothed, symmetrical, flawless, ordered, elevated indeed processed by fitness and fashion and photography... committed to lust and indulgence" (Rutherford, 2007, p. 8). The body becomes a commodity through its visual processing into a sign promoting lust. The compositional layout further commodifies the models; a single page will be divided into smaller photographs of figures stacked overtop and beside one another, as in a vending machine (see figures 32 and 33). The same figure will be displayed from multiple angles favoring physical features as defining criteria (see figures 26 and 27). The uniform aesthetic throughout the magazine creates a brand image, so the viewer will know what to expect from the product. All of these factors together present the models as interchangeable, desirable bodies that can be consumed and exchanged for sexual gratification.

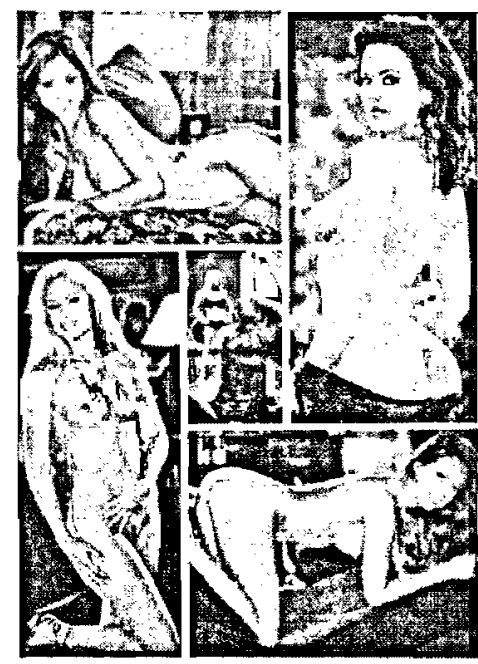

Figure 32

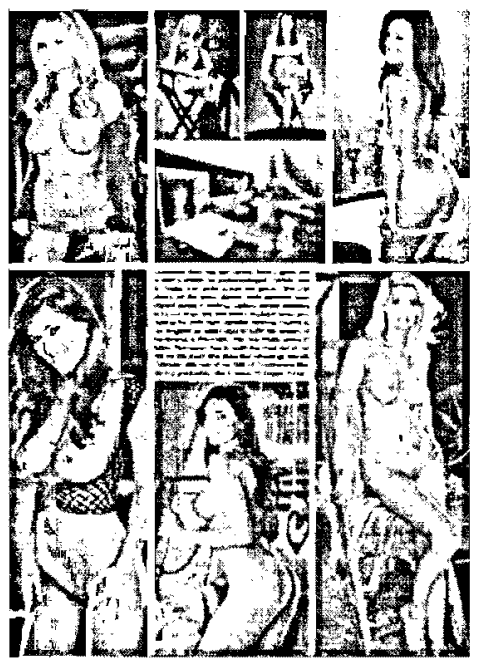

Figure 33

While semiotic understandings of how these genres create meaning are crucial to assessing the operations within the pornography and advertising industries, we must not forget that they require affect to actualize their purposes of creating desire promoting continued consumption. Like photographs, pornography and advertising function simultaneously within two economies - one of affect and one of meaning. This is likely why both industries rely heavily on photography in their production. 
I equate a photograph's ability to evoke affect with the punctum. Barthes defines the punctum as a punctuation that pricks or interrupts the studium - our conscious understanding of an image (1980, p. 26). The punctum can be thought of as a sign with surplus value that delivers an affective response beyond its semiotic or knowable meaning. It creates an emotional response that cannot be understood, defying logic by evading language and conscious thought. In this sense, the punctum is akin to the Lacanian Real, unknowable and intangible. It is fleeting and cannot be had, held, or contained. Like all non-material entities, it can only be felt by the effect of its presence, and so escapes conception.

This cognitive escape ensures that we can only relate or connect to affect through experience. According to Simon O'Sullivan, affect is "present experience - the moment, the event - [and] is inaccessible to consciousness" (2001, p. 127). Affect is accessed through its representation as a kind of echo. The instant an experience is pictured through memory and is described, it has entered the realm of the symbolic, of language and understanding, and is no longer felt in the same sense. Thinking of an emotion is not the same as feeling it. O'Sullivan elaborates on the intrinsic connection between matter, experience and affect stating: "affects are moments of intensity, a reaction in/on the body at the level of matter... They are certainly immanent to experience. Following Spinoza, we might define affect as the effect another body, for example an art object, has upon my own body and my body's duration" (O'Sullivan, 2001, p. 126).

Experience is perpetually present, but the photograph is a document of the past. The power of photographs, according to Geoffrey Batchen, is their contiguity (2001, p. 21). “...[P]hotography has never provided us a with the truthful appearance of things, but it has guaranteed, through the magic of contiguity, the possibility of a direct emotional empathy across 
an otherwise insurmountable abyss of space and time" (Batchen, 2001, p. 21). The particularities of a photograph that will emotionally transport the viewer to another time and place are unexpected, unpredictable, and somewhat subjective. Unarguably, such moments capture attention, signaling the presence of affect as we become aware of a feeling. These surprising moments of affective interruption often reveal a new perspective.

The punctum is what allows a given object to reveal another vantage point to affect the body. It is a puncture, a rupture that facilitates the transmission of feeling between disparate bodies. The punctum is the detail or point through which viewers can connect their own experiences to the experience represented in an image. Batchen argues that "what photography gave to modernity was not vision, but touch (or, more precisely, vision as a form of touch)" (p. 21). These touches are sites of contact through which both affect and meaning can flow creating a relationship between viewer and image.

Pornography and fashion advertising are dependent on these touch sites to create the required viewer response to their images. These industries drive to "produce images as content to feed the endless demand for images for use in circulating affective energy in an affect economy" (Wissinger, 2007, p. 233). This proliferating affect economy is described by Elizabeth Wissinger, in her article, "Always on display: Affective production in the modeling industry," as an economy that does not exchange commodities, but circulates attention. Attention was previously described as a consequence of the punctum, in which viewers are left vulnerable from their experience with an image. They are vulnerable to a flow of affect manipulated by images to produce or direct desire. Unlike the studium of images, which can be consciously engineered, the negotiation of an image's punctum is a much more troubling proposition. Affect is not a material entity that can be either easily exchanged or represented. 
Operating through the gaze, exchange occurs between fixed entities indexically represented through their images, while affect is not fixed to specific referents, but circulates between them and viewing bodies. Sequencing, correlation, and associations between entities become more important than the signs themselves.

Wissinger cites the works of feminist theorists Judith Bulter, Elizabeth Grosz, and Donna Haraway for developing a conception of the body that is fluid and continuous with its environment. This body is not exclusively bound by the containment of its skin, but permeable to its surroundings - a necessary precursor for an economy based on affective networks (2007, p. 231). Alernatively, a nebulous body is understood as a vessel with a given capacity to concentrate the affect in circulation. Bodies, both the consumers' and the models', become sites of capital investment and concentrations of affect translated economically into the accumulation of wealth (Wissinger, 2007, p. 234). "Within an attention economy, units of time spent attending to images are bought and sold in a 'flattening out' of affective intensities into calculated units of 'audiences' slated into 'demographic boxes"' (Wissinger, 2007, p. 235). This economy is thus based on the calibration and modulation of affective flows through nodes of interest to consuming bodies. Advertisements are sold throughout mainstream media based on the concentrations of affect they command.

The focus of many of these authors on the body, either literally or metaphorically, triggers the realization that every image in Camera Lucida, all of which Barthes identifies as containing a punctum, also contains a figure ${ }^{3}$. I wonder, then, if there is a correlation between representations of humans and the capacity for affect. Empathy is likely the conjoining factor, as the more we can identify with a being the more vulnerable we are to it. Identification can be

\footnotetext{
${ }^{3}$ With the exception of Niepce's The Dinner Table included for historical value as the first photograph.
} 
intuitive, or accumulated through experience. Sara Ahmed posits that affect is "only produced as an effect of its circulation," implying the more an image is in circulation the higher its affective potential (2004, p. 120). While Mitchell believes there is truth in the belief that "commodity fetishes are displayed for rituals or public veneration that are designed to produce surplus aesthetic and economic value," he argues that this view is incomplete (2005, p. 33). It is not only the image that must be in circulation, but also the viewer's attention. Affect is always an experience, potentially understood as a relationship between beings. Both beings must be engaged. Images that encourage this engagement are often those reinvested in circulation. This explains the repetition of conventions like similar posing, lighting conventions, coloring, and proscribed body types; these standards, along with the entities they modify, are signifiers of desire and value.

The models' bodies are traditional sites of investment and so become imbued with surplus value (Wissinger, 2007, p. 244). Advertisers hope that when casting a model, the model's surplus will be transferred to the product. All visual elements are coded to optimize this probability, but as affect occurs outside the realm of language and code, success is unpredictable. Citing Marshall McLuhan's critique of advertising, The Mechanical Bride, Rutherford states that ad agencies are not responsible for the trend of increased sexualization, but that they were only responding to popular mood. "Their success was the result of their particular skill, the ability to plumb the psyche of consumers" (2007, p. 133). This argument frames practitioners of the industry as reactionary, essentially barometers able to intuitively identify and manipulate potential punctums. Such does not acknowledge the industry's formative influence, as images deemed successful are copied and re-circulated through media, thus perpetuating the proliferation of trends introduced by advertising, and thereby altering the consumer psyche. 
Brian Massumi would consider this and similar processes "apparatuses of actualization and implantation that plug into them and transformatively relay what they give rise to" (Wissinger, 2007, p. 247). Rutherford considers this process of cultivation and concentration the "libidinal economy... that involve[s] a double operation: a portion of the economy was eroticized, a portion of the libido was commodified. The result was a marketplace organized around exploiting and satisfying the erotic dimensions of the body situated in various social settings" (2007, p. 5-6). Economics modulated by the sensual body led to diminishing divisions between the body and commodities evidenced by the body portrayed as a commodity in pornography and commodities presented as affective portents able to transform the body in advertising. "In the world of publicity women were transformed into standardized and processed machines... whose legs, hair, lips, look, walk, and so on, were all objects that commodities might enhance to engender the sexual excitement of male victims" (Rutherford, 2007, p. 132133). The very nature of commodities transformed into less material entities as the conception of the body became less fixed and static. "The meaning and utility of [the] commodity was informed by an aura of sensing excitement or its role as an instrument of sexual desire or its function as a catalyst for some erotic narrative" (Rutherford, 2007, p. 6). In the libidinal economy, both the body and the commodity are not so much entities as they are permeable concentrations of affect, where value, as well as feeling and meaning, can accumulate.

According to Wayne Booth's "The Company We Keep," advertising is a form of pornography that does not endeavor to satisfy want but to "rouse appetites and refuse to gratify them within the form" (Mitchell, 2005, p. 78 notes). Pornography, however, is the form gratification takes by transforming the body into a commodity already acquired by the viewer; while advertising is intended to direct affect, and therefore desire, towards a specific product, 
pornographic editorial is expected to accumulate and temporarily satiate desire. Barthes believes that this single aim of pornography to represent and satisfy sexual desire destroys pornography's erotic potential, and arguably its ability to effectively control affect. Barthes describes the unary photograph as one without punctum that functions singularly at the level of studium. For Barthes, the pornographic photograph falls into the category of unary because it is "without intention and without calculation completely constituted by the presentation of only one thing: sex" (p. 41). It does not engage with any other point of interest that could distract from its presentation of sex, and reduces sexual organs to fetishes (p. 59).

I argue that pornography is not merely consumed with sex, but with selling sex. Joel Kovel states that pornography is erotica contaminated by mass-culture aesthetics (p. 161). Similarly, Jennifer Wicke defines Kovel's reading of pornography as "proof of the penetration of capital into yet another legitimate conduit of desire" (p. 69). Pornography restricts the potential reading of erotic symbols in its contrived attempt to channel and codify desire into easily consumable products. In this fashion, it may very well limit its affective potential, but its coded signs are still potential receptacles of attention and experience. Barthes distinguishes pornography from the erotic on the basis that erotica is a pornographic photo that has been fissured or disturbed (p. 41). The punctum, in Barthes' view, is not single minded.

The classification of pornography as without punctum is problematic to my argument. As I have previously defined, the punctum is the rupture through which affect can flow. Pornography is defined as material created to elicit a sexual response from its viewer - a response I would classify as affective. If pornography is without punctum how can it produce the necessary affect upon which its definition depends? The classification of sexually stimulating material is arbitrary, as one's cause for pleasure is another's repulsion. It seems that 
for Barthes, sexually explicit material must be complex to elicit an affective response, but this is apparently not the case for all consumers of pornography, as evidenced by its propagation. Barthes' qualification between erotica and pornography seems to be based on whether or not he deems it successful in its aim to arouse. This highlights the subjective nature of the punctum. The punctum is not something inherent to the photograph, but something shared between the photograph and the viewer. It is the puncture that becomes the point of connectivity through which affect can unite subjects. The discord over pornography and non-commercial, erotic material, like the punctum, is largely subjective and semantic.

An understanding of the semantics and syntax of pornography and advertising is crucial to undertake critical readings of meaning through semiotics and the manipulations of affective channels. The increasing similarity between advertising and pornography can be largely understood through Wissinger's description of affect economy. With the advent of immaterial labor employed along the lines of affective potential "all of social life can become a force of production, as all kinds of activities formerly coded as gendered and private, and lying outside of the domain of capitalist investment, are increasingly pulled into its domain" (2007, p. 234). The permeability of bodies and our environment has led to a flux, de- and re- territorializing our conceptions of self and our social existence.

Perhaps this fluidity, especially evident between genres, and in the collapse of public and private, is in part due to the emergence and proliferation of photography. "Photography corresponds precisely to the explosion of the private into the public, or rather into the creation of a new social value, which is the publicity of the private: the private is consumed as such, publicly" (Barthes, p. 98). The photographic image is the private representation of its referent available for public dissemination. It is the conflation of intimate and social touch, transmitting 
both meaning and feeling, and forever altering the viewer's experience of seeing and reading images, resulting in conceptions of a less contained self. The ability of a photograph to perceptually conjoin disparate moments and objects through visual representations is mobilized in pornography and advertising in the hope of transmitting meaning and affect to the subjective body. Commodities and human bodies become more permeable and interchangeable though visual representation, as sexual desire is circulated through these representations and the viewer to profit the pornographic and advertising industries. 


\section{CHAPTER FOUR: Speaking Through Images - Art as research}

The previous chapter explores the affective capacity of images, but it does so entirely through words. The impotence of verbal explanations is their exclusive engagement with interpreting material meaning - the studium. These types of studies focus on exhaustive and mutually exclusive categories consciously organized as part of the symbolic order. Charts of the frequencies of ordered autonomic entities are unable to qualify the less tangible flow of attention circulated through an affect economy. The punctum of any image analyzed in this manner is disregarded, explaining why statistics largely fail to evoke an emotional response and personal resonance from an audience.

Artists such as Nancy Burson and Chris Jordan are aware of an image's power to make affective statements relatable to a broader audience and they utilize this ability in their artistic practices through composite photographs. I also work with composites, which I define as an image constructed through visual phrasing, from multiple separate photographs representing or (re) presenting something that does not exist as a representational object/entity in reality. Composites allow for the realistic, and somewhat more literal, representation of abstract concepts, immaterial relationships, and imaginary projections.

Burson uses composites of the human figure to increase subjective identification with her visually supported and arranged arguments. For example, Burson's Human Race Machine, is a high-tech photo booth that records the viewer's image and manipulates it according to physical conventions of race. The individual is portrayed in sequence depicted as multiple races in conjunction with the phrase "there is no gene for race" (see Figure 34), demonstrating the social construction of ethnicity based on the patterns of commonly grouped physical markers. While 
this message can be communicated through words, the realistic representation of surrogate selves allows for greater individual identification and understanding on a personal and emotional level. Burson harnesses the visual syntax of composite imagery, to visualize and increase the tangibility of an impossible condition to engage with the feeling necessary to promote her goal of tolerance.

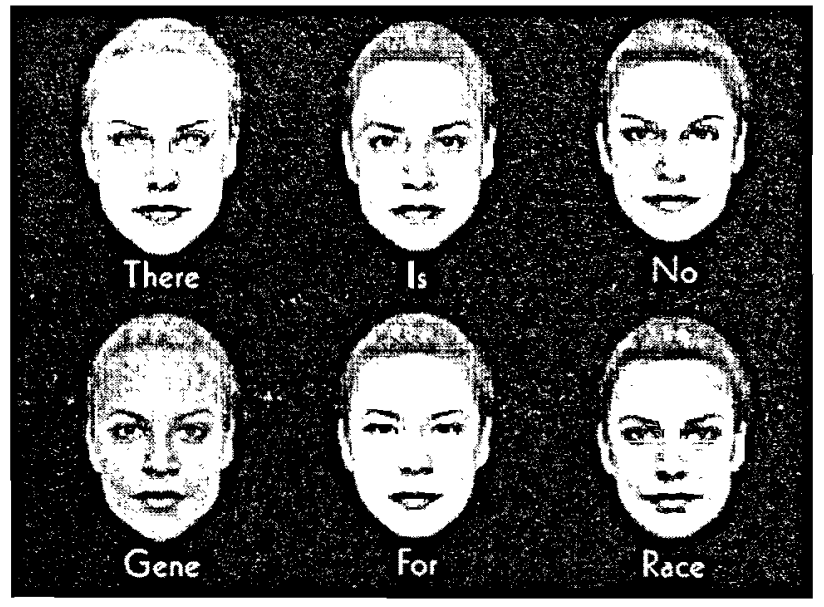

Figure 34

Jordan represents statistical data in a manner that makes its often-enormous scale more palpable and personally relatable to the viewer. His Running Numbers are series of digitally assembled photographs presenting empirical data realistically depicted in a one to one ratio. An example is his 2006, Barbie Dolls, $60 " \times 80$ ", presenting 32,000 Barbie dolls oriented to resemble a woman's breasts and to equal the number of elective breast augmentation surgeries performed monthly in the US in 2006 (see Figures 35-37). Figure 34 is the full-size image while 35 and 36 are close-ups of the larger picture. Meaning shifts as scales adjust and the focus changes from the constituent details to what the minutiae create when lost in the patterned shadings of the whole, as the viewer moves nearer and further from the gallery hung imagery. Jordan reminds the viewer of the relationship between individual units and large groups, details and patterns, and the image's ability to express both simultaneously. 


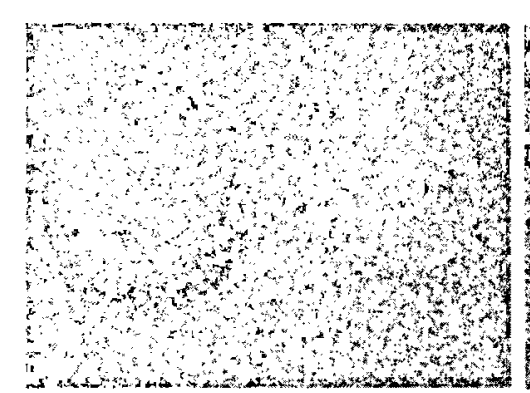

Figure 35

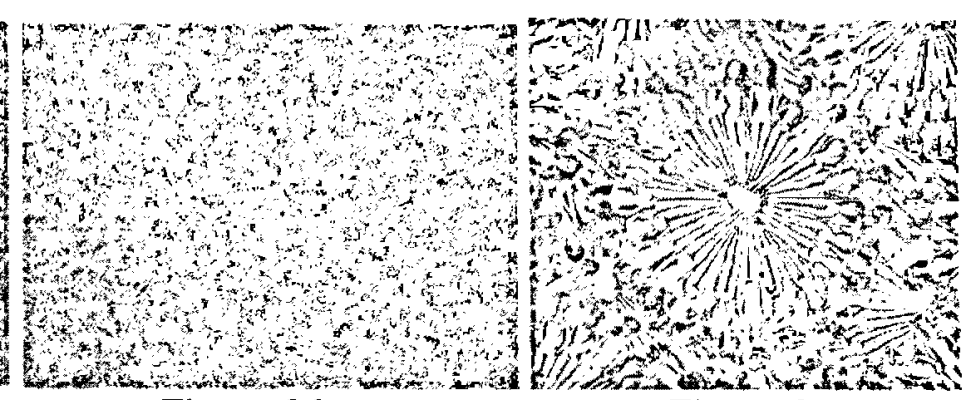

Figure 36
Figure 37

Both artists display how images are able to absorb the viewer, framing them relationally to their pictorial content. I also express the results from my study visually through digital prints that convey my affective response to the sexualization of consumerism manifest in women's magazines and pornography. This is in hope of both gaining insight into the transmission of desire through consumer representations of the body by dissecting my own affective response, and engaging the audience in a similar affective reaction that allows them to relate to my findings both rationally and emotionally.

This intuitive response to the use of images through images, avoids any loss in translation from visual imagery to verbal meaning. Also, by reflecting upon my practice as an artistic, autoethnographic study, I am able to analyze my creative response to further understand the visual representations and the human body's ability to visually direct desire through my own attempts at manipulation. Following Norman Denzin's model as set out by Harvey and Robinson, I frame myself as a "universal singular - unique in [my] own individual experience yet also able to speak for the wider culture [artistic practitioner and female consumer] from which [I] come" (2007, p. 58-59). Graeme Sullivan supports this form of inquiry arguing that artistic practice is a valid form of research in scholarly, cultural, and social circles. "What is common is the attention given to rigor and systematic inquiry, yet in a way that privileges the role imagination and intellect plays in constructing knowledge that is not only new but has the capacity to transform 
human understanding" (Sullivan, 2005, p. xii). Artistic practice is an inductive and self-reflexive approach that is heavily guided and grounded by intuition.

The DVD that accompanies this project visually outlines my creative process, and displays finished pieces within a growing body of work. All of the images are constructed using Photoshop in a manner similar to Jordan's. The prints draw from a previous body of work based on thematic interpretations of Gustav Klimt's paintings, where I collapse several images into an allegorical composite. The composition requires a template to maintain boundaries and provide a framework around which I organize smaller photographic images repeated and reduced into fields of pattern. Each of the photographic images relates to the overall theme and composition of the image. The prints for this series conflate commodities and the human body; their compositions modeled after either fashion advertisements or centerfolds, and tessellated with patterns of sexualbody parts and consumer products extracted from the same source material.

Throughout my engagement with more traditional humanities and social science research, I was eager to begin artistic production. I had been imagining and sketching collages, mock-ads, and elaborately constructed photographs into potential templates. However, upon completing the content analysis and subsequent interpretation of each magazine, I found the sketches trite and discarded each of the templates. I realize now in retrospect, that they were too contrived, consciously constructing meaning through the arrangement of symbols that resembled a paintby-numbers checklist of genre conventions. Unable to begin my work as I had envisioned it, I revised my process, and instead of working deductively to execute a resolved image, I would 'play' with the source material unconsciously, and unsure of the final result.

The images I use are intuitively selected from my sample. I cannot explain the particular drawing power of an image; it was something I felt. Like Barthes in Camera Lucida, a specific 
detail within a particular image would strike me. These were the images I scanned into Photoshop where I could extract the visual element that caught my attention (see example in Figures 38 to 39). I used my own attention as the gauge for instinctively selecting a palette that, while likely unconsciously informed by my content analysis, did not make explicit reference to its findings.

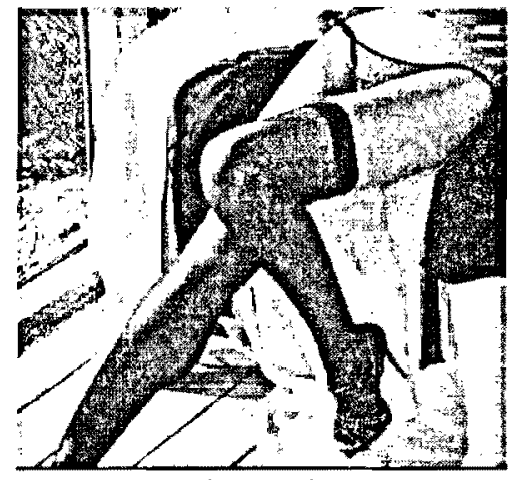

Figure 38

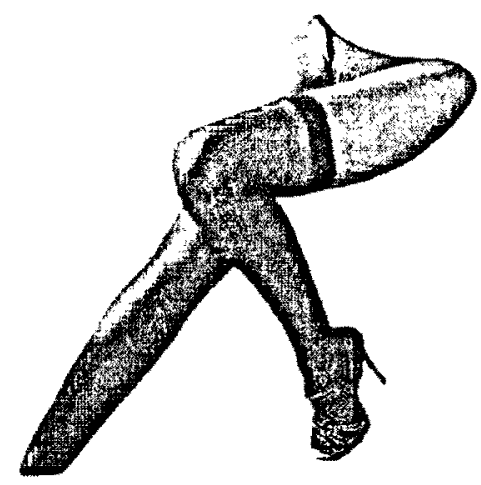

Figure 39

My practice of visually isolating a particular from the whole is extremely telling in reference to Naomi Schor's Reading in Detail: Aesthetics and the Feminine (1987). Schor argues that the detail has been doubly gendered as feminine through its association with ornamentation, traditionally noted as effeminate and decadent, and through its correlation to the particular or everyday (1987, p. 4). Schor tracks the debasement and feminine gendering of the detail throughout art history and literary criticism highlighting Sir Joshua Reynolds' Discourses on Art (1769-1790). William Hazlitt summarizes Reynolds' position stating "the great style in painting consists in avoiding the details, and peculiarities of particular objects" (Schor, 1987, p. 12). According to Reynolds, this is achieved by championing ideal beauty and the sublime in art. Enlisting a patriarchal gendered mind/body split, Reynolds exalts the artist who perceives with his mind and represents the generality of a form over the artist who perceives with his eyes and renders the form as it appears in the particular (Schor, 1987, p. 15). Reynolds' generalized 
ideal can also be thought of as a mental or psychological imago "the visual content of dreams, memories, and perception" (Mitchell, 2005, p. 2).

The imago is the imagined visual signification of the signifier - all that is pictured when we think of something, anything that can be named, including a platonic preconception of classes of objects. The imago is the result of the Gestalt - the psychological ability to recognize the whole form as an entirety beyond the sum of its constituents, typically pertaining to visual recognition. Imagos inform our perception and understanding of our reality, arguably to the extent that we conform our vision to our expectations. "We see things that fit well within our preconceived notion of how things should appear, not necessarily as they actually do appear" (Solso, 1994, p.187). We have an idealized conception of beauty and sexual appeal, and expect reality to conform to those ideals; something is often only considered beautiful when it adheres to a pre-established convention that can be recognized in the particular. Common measures of beauty gauge the extent to which the particular is able to exemplify the ideal. The pleasure felt when looking at an object of beauty can largely be attributed to validating a sense of control and order provided by the recognition of expectations.

Consumption is manipulated through a series of commonly arranged signs establishing expected rituals. There are many variants of these rituals to satisfy divergent tastes, but they are all similar in their need to institute a proscribed set of expectations, that will grant the viewer gratification upon their fulfillment. There is a great deal of pleasure derived from the validation of expectations as viewers feel a sense of control in their ability to view what they expect and desire to see. "Pornography pivots on sex and works in specific ways that target particular audiences by cultivation control and desire and the promise of sexual power through the viewing of available bodies" (Merskin, 2006, p. 202). I believe this cultivated control is also extended to 
advertising where viewers are promised social power through the information garnished from viewing bodies made available to them through products. This control is likely derived from the viewer seeing what they expect to see before them, and the illusion of mastery over reality that view provides. In application of Rutherford's analysis of the libidinal economy, I argue that this is an example of how the viewing subjects are in truth controlled by their desires that have been socially shaped for that very purpose. Viewers' sense of mastery over systems of consumption is an illusion that causes the misrecognition of consumer literacy and involvement as political and personal agency.

Art's history of prioritizing the generalized ideal over the individual detail lends legitimacy to the practice of objectification in mass media imagery. Objectification occurs when the complexities of the singular are reduced to a marker of the universal. The repetitive poses in Playboy and the reduction of distinguishing factors translate each figure into a normative sign. The reoccurrence of signs regulates what is considered sexually attractive through the circulation and re-circulation of only those particulars that reinforce the hegemony of the idealized general. The unique characteristics of the models are obscured in favor of depicting the individual generalized into an idyllic version of current beauty standards that are predominantly slim, ablebodied, white, and upper-class.

Signs often portray aspects of visible reality, but like composite images, signs can also refer to immaterial entities and processes that are not physically apparent in nature. Signs are relative, their meaning dependent on neighboring signs and the resulting associations. The apparent reliance on the interconnectivity of signs to convey meaning highlights the functioning of pattern in establishing expectations and imparting a given message. All meaning derived from language is a form of pattern recognition. A particular interpretation of a sign is dependent upon 
a given context, which is subsequently linked with those signs to form a commonly related set of identifiers. The symbol or sign itself is auxiliary to the repetition of associations that is necessary to communicate significance. Recognition of chains of signifiers and the seeming naturalness of their relationship correlates positively to the frequency of their circulation. The sign of the proscribed female body circulated through Playboy, always in conjunction with posing, lighting, and set conventions, connotes that the body is to be read as a commodity when those signifiers are present. In this sense, as proposed by Rutherford, the commodity is as much image as it is product. In a marriage of combined aesthetic and utilitarian purpose, the spectacle determines "the fate of this commodity, now a unit of the knowledge created, distributed, and altered by publicity as erotica" (Rutherford, 2007, p.6). The body and equivalent commodities are links in a relative circuit of knowledge and affective signification.

In this associative system of circulating value, desire, and image, the body has multiple roles. Chapter Three discusses representations of the body as simultaneously a sign, as a streamlined and standardized commodity, and as an adaptable conduit able to transmit and collect feeling and relative value. The required flexibility of bodily conception to be all of these concurrently leads to, and results from, the general increase in networks and interconnections between previously distinct categories, evident in the destabilized distinction between sign and referent, and between genres of media.

The amplified permeability between formerly distinct bodies leads to what Giles Deleuze and Félix Guattari term assemblages (1987). Rutherford explains assemblages, with regard to the body and sexualized media in the libidinal economy, as "complicated and extensive formations of bodies, technologies, and signs designated to achieve certain ends" (2007, p. 8). Rutherford references McLuhan's The Mechanical Bride where McLuhan speaks of the growing 
correlation between the body, understood as a living machine and machines cast as "vibrant and attractive organisms" (2007, p. 132). The body understood in this manner is entirely relative, "extended in space and in time to connect with a material world of goods that [are] in turn eroticized" (Rutherford, 2007, p. 8). As such, no single sign can be read exclusive of its context. The body, body part, or commodity can be either signifier or signified, in either chorus or consequence, dependent on its surroundings.

The use of the detail as a sign in my art is paradoxical. In one sense, highlighting the detail is reclamation of the feminine gendered particular. It is selecting a unique characteristic and framing it synecdochically as important as the idealized general. Contradictorily, my use of the detail is also an objectifying re-assimilation of the particular into the general through isolation. When extracted from its larger context, the detail becomes a new subject in its entirety on a smaller scale referencing a more specialized ideal. However through patterning, the detail is reproduced until its unique characteristics dissolve into aesthetic qualities. The detail becomes indistinguishable from its surroundings; it is re-appropriated into the whole but in a manner that does not reconstruct the original. The sum of all parts does not necessarily equal the whole as illustrated by the impossibility of reintegrating isolated parts back into the original once taken out of context. The detail is first isolated, valorized, until ultimately destroyed in order to disrupt the archetypal imago.

The relationship between detail and composite reveals certain tendencies inherent to the nature of representation. Suppositionally, all representation is a reductive process of objectification that converts an entity into a referent of itself, either as an icon, a symbol, or a sign. As explored in Chapter Three, it can also produce the commodification of its referent. Any method of representation is incomplete; it cannot give as full of an account of itself as the 
original object or subject. Representation portrays an aspect of the subject presented in an isolated context as a depiction of its entirety. This abstraction necessarily creates a hierarchy between attributes, favoring the characteristics illustrated over those omitted.

The details I isolate are emphatically feminine regardless of art history's gendering; they are either derived from products intended for use by women, or are pieces of women's bodies. The details are primarily legs, breasts, and torsos, all interchangeable signifiers of sexuality and those most frequently highlighted in the magazines assessed. I duplicate these details experimenting with scale, position, and orientation. The body portrayed as divided and mutable, illustrates its technologically permeable and relativistic nature in a commodity market. Fragmented pieces of figures and products are repeated and repositioned into forms and geometric sequences (see Figures 40-44, and 48). The detail, once isolated, is decontextualized from its surroundings, its iconic signification further disrupted by its replication and subsequent distortion. Lipsticks, shoes, and other commodities are reduced to shapes. Nipples, vaginas, and parted lips become swirling fields of color and pattern, no longer recognizable as signs of sexuality.

Through the experimentation of developing patterns, I realized the similarity between the patterns I created and textiles. One example is a stocking-clad leg reproduced, rotated, and mirrored to create herringbone, checkers, and fringe-like patterns (see Figures 40-44), another is a torso replicated and rotated around a center-point mimicking floral arrangements (see Figure 48). I started arranging these patterns to impersonate designer logos, patterns, and textures. I then selected commodities from advertisements that exemplify fetishistic representations and covered them in a pattern of fragmented and objectified body parts (see Figures 45-47). The result is a product made from the image that is typically used to sell it. 


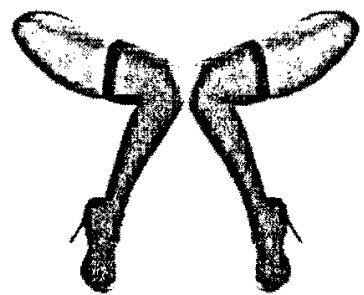

Figure 40

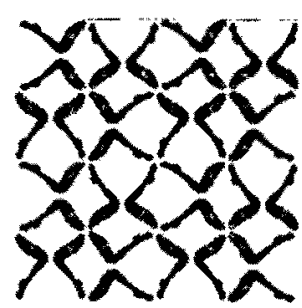

Figure 41

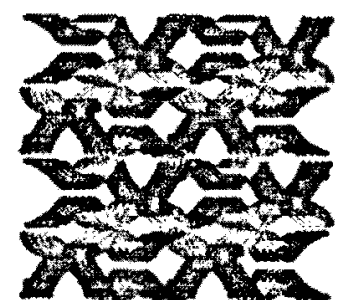

Figure 42

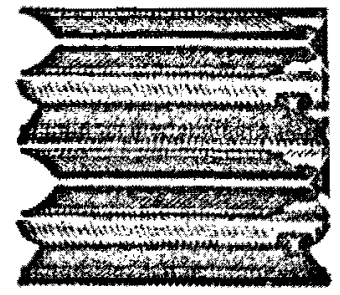

Figure 43

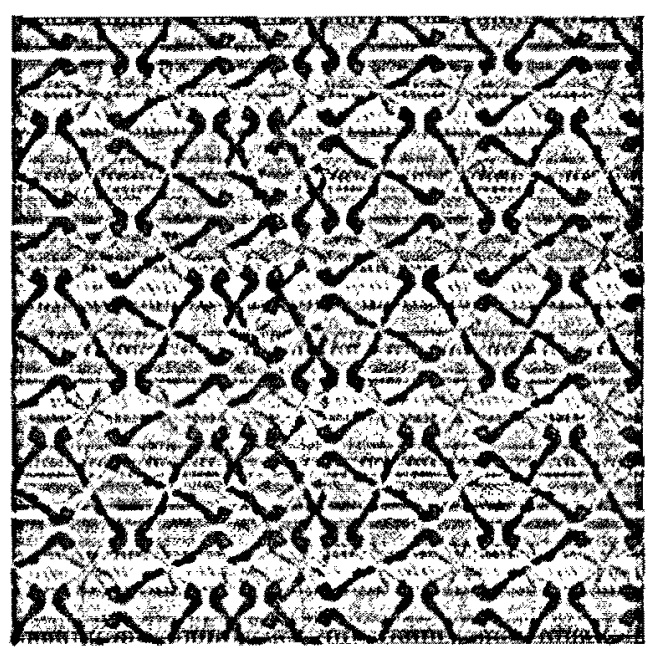

Figure 44

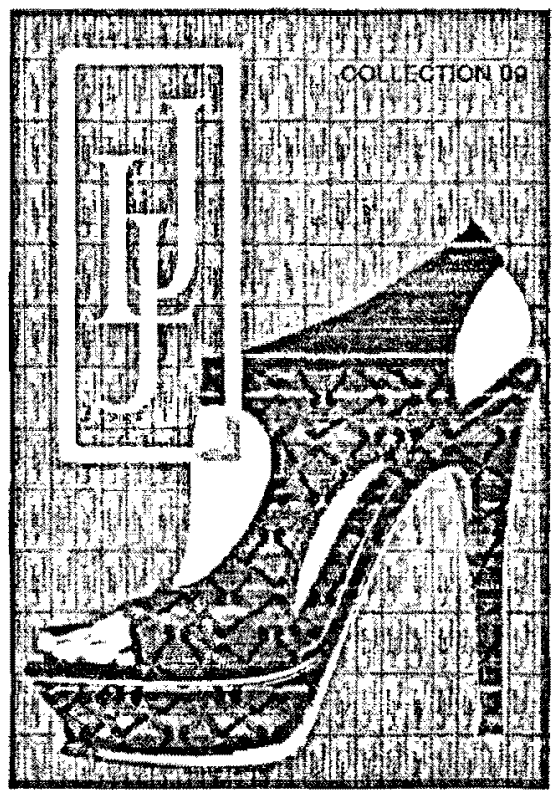

Figure 45

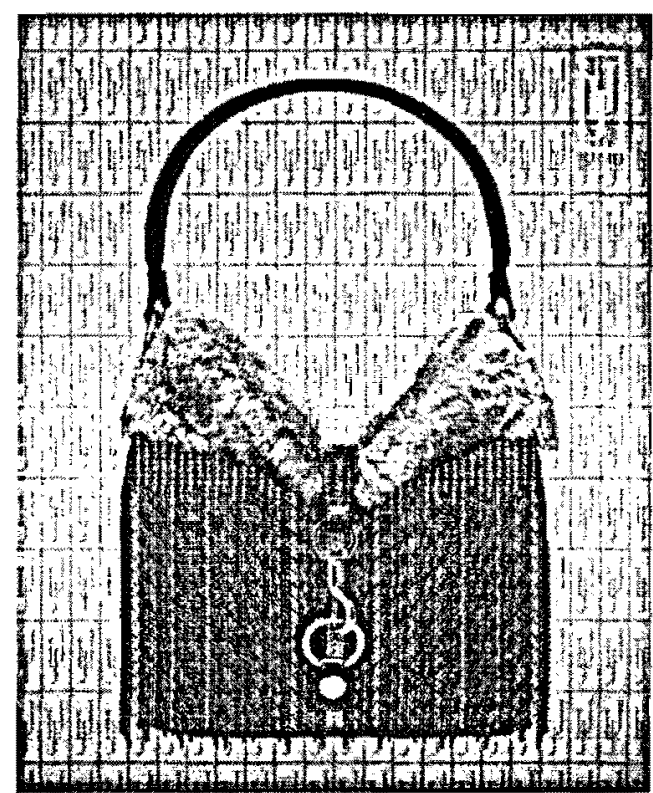

Figure 46 


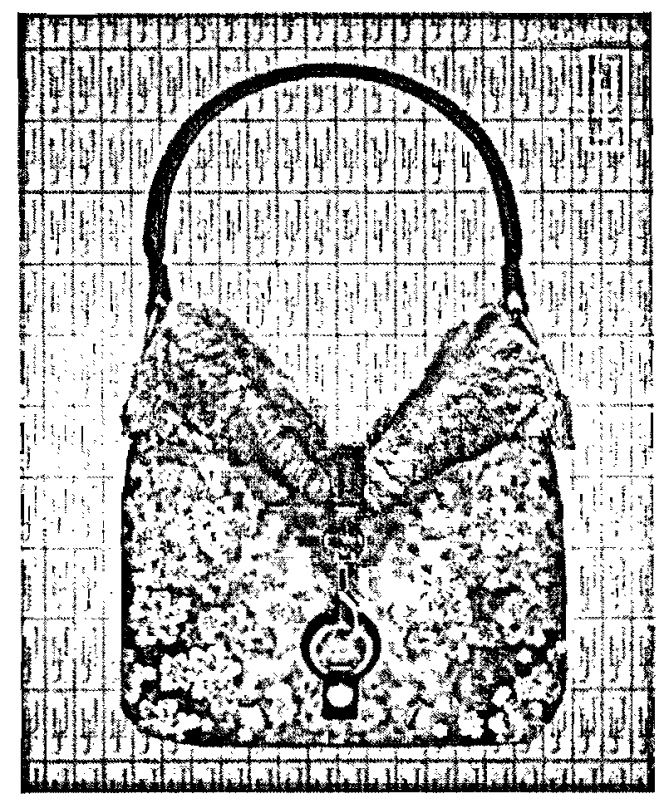

Figure 47

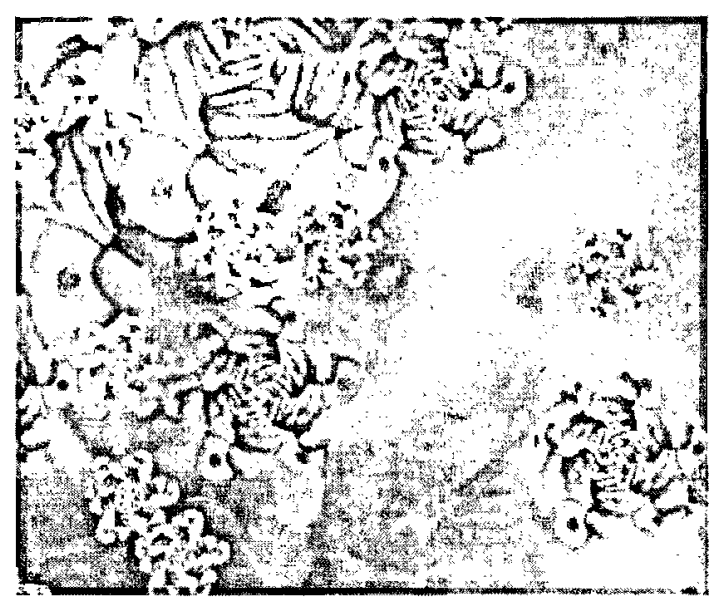

Figure 48

The commodities I studied are usually assigned value through their association with the sexual appeal of the model with which they are posed and their purported ability to transfer that allure to their purchaser. My products parody this process of transference by making it blatant and vulgar, and highlight the normalized aesthetic of slender, upper-class whiteness. Merskin quotes Schroeder and Borgerson stating, "the fetish 'replaces human relations with commodified object relations' and promises satisfaction of desires" (2006, p. 202). My figurative commodities make no such promises; by resituating an objectified female form onto the product they force the recognition that, in fashion, the body is often presented as a byproduct or framed as an accessory. Advertising's convention of using the figure as a disposable indicator of worth beneath the actual brand value is made offensively clear. Prized commodities, like designer handbags and shoes, are no longer ranked according to the model's sexual appeal, but made from it. It is a pun to say the model has been objectified, but more accurate to say she has been assimilated. She is no longer a sign of herself; she is a sign of what she is reduced to during the process of commodification and in advertising. 
My commodities, while still handsome or pretty, are also strange, uncanny, and somewhat grotesque. The isolated details are referents of idealized beauty, but as the product's skin they take on a peculiar cannibalistic dimension, appearing dismembered and abject, while contradictorily still attractive. Mainstream fashion and soft-core pornography present a very limited range of body types used as variant signs, resulting in the homogenous aesthetic of its examples and my art work. That each of my pieces is made from the Western ideal of default white models is meant to encourage the recognition of the uniformity of fashion and pornography's forms. This tension of being simultaneously recognizable and appealing while strange and unappealing aligns with what Sigmund Freud refers to as the uncanny. Freud posits the uncanny as a gestalt reaction of mixed fear and fascination that "occurs when something that is familiar is alienated, through a process of repression, and then returns to us in an uncanny form" (Grenville, 2002, p. 20). The body is certainly recognizable, so what about it is repressed or hidden?

Bruce Grenville argues that obstruction can occur through ubiquitous visibility and subsequent misrecognition; perhaps "the greatest threat of all, [is] the threat that we cannot see a danger even as it stands before us because it is too familiar and, worse yet, we may be unnaturally attracted to it" $(2002$, p. 21$)$. I posit that the body's mechanized serialization has proliferated universally to the extent that its integration is invisible and its presence is completely naturalized. That the body has largely been converted into a commodity and sign goes unnoticed. Grenville chides that "we are unable (or unwilling) to see that which is in front of our eyes; we repress the recognition of its real form and instead remain fascinated by its beauty. Occasionally that uncanny body may be doubled in such a way that it becomes unacceptably visible" (2002, p. 21). Such is the case with my products that makes the body's absorption into 
commodity culture undeniable, exposing the mechanisms of cooption, the presence of which challenges any claims of naturalism. The uncanny is the mutation of patterns of consumption without interruption, as illustrated by my Frankensteinian creations that coextensively reaffirm and challenge contemporary advertising techniques and pornographic conventions through mimicry and extension to monstrous extremes.

Any entity that can be visually represented can be converted into a sign and absorbed into circulation within the commodified strata of visual culture. The sign's flow through the circuit forms associations with other signs and recognizable patterns of transmission that result in a variable network of meaning and value. In this sense it is movement that creates affect and meaning. I realized that although I am studying static images, I am attempting to illustrate a process that is dependent on movement. As such, I found it is necessary to animate my prints.

The description of my process makes it sound as though my decision to animate my prints was consciously made - it was not. As the selection of the details I extracted, as source material, was entirely intuitive, so too was my determination to see my creations move. My desire for movement first became apparent as I was creating a check-pattern from a partially bent leg. I felt the urge to see that leg kick (see Figures 49-51). As I was repeating the same leg in sequence, I was doubly struck to see all of the legs kick in succession like in a chorus line. In an instantaneous flash of associations I envisioned a handbag doing the can-can, as it grew excited by its owner's approach. I suppose like Dr. Frankenstein, I wanted my creation to have a life of its own, and so I set about sorting out how to manifest my apparition. 


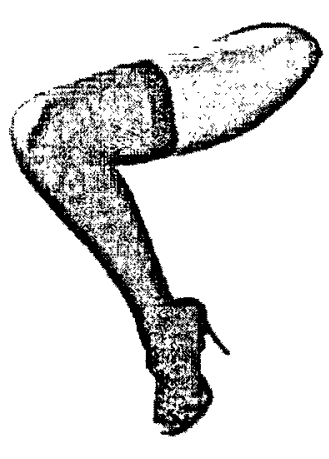

Figure 49

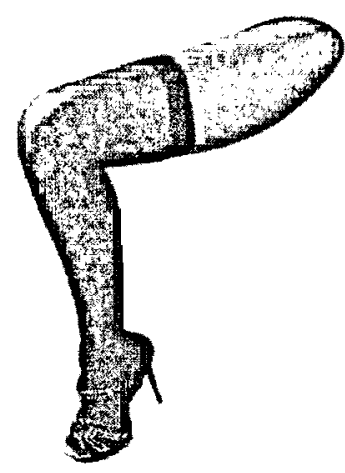

Figure 50

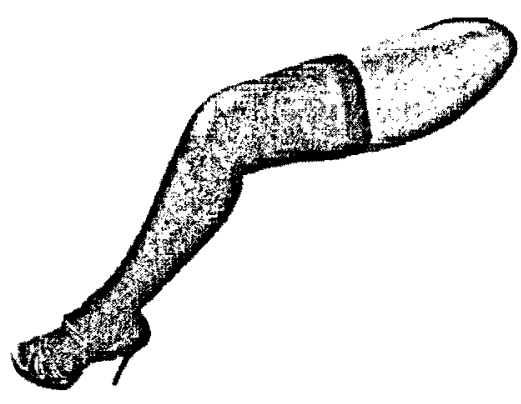

Figure 51

Movement can only be represented in certain media, and so it was necessary to revise my original plan of creating photographic prints to imitate the magazines used as source material. I did not want to abandon the magazine aesthetic though as this inquiry deals specifically with that data. The final iteration of this project is beyond the scope of this study, and as such, is discussed hypothetically. The DVD demonstrates the pilot development and illustrates the final version aside from its interactive gallery installation, although I am discussing how I plan to install it in a gallery setting.

In researching other new media artists and through trial and error, I settled on a design that appears to be a high-end catalogue image animated by viewer stimulus. The picture is displayed on a framed LCD screen to resemble a light-box advertisement, but is in fact a video frozen on a particular frame. The image appears to be a static print that becomes animated upon the viewer's approach. Proximity sensors trigger animations that play overtop of the still image. The sensors cue different video animations at specified intervals, and the commodity becomes more and more frenzied at the viewer's advance. The result is pulsing, turning, and breathing fields of pattern playing overtop of the previously still product, making it seem alive and responsive. The animated movement is accompanied by heavy breathing and moaning sounds that also intensify upon the viewer's approach. The closer the viewer draws, the more excited 
the image becomes until finally as the spectator comes directly before it and the screen blacks out stating in white print - SOLD OUT. As in all advertising, the viewer is denied full viewing satisfaction without purchase.

The first image animated is the can-can kick purse, that kicks at higher and higher intensities as the viewer draws near. Each product is constructed with different possible patterns to further mimic catalogue conventions and again echoes the prevalence of a mass produced, idealized form with only slight variation between particular models. The manufacturing process of these images is itself a commentary on the automated mechanics of commodity culture. The animations are constructed frame by frame from a series of composite images that are reproduced with minor and gradually increasing modulations. When played sequentially, the images create an effect similar to the flipbook. In order to maintain image continuity, I had to develop automated scripts in Photoshop to align each detail exactly, converting my creative practice to a repetitive assembly-line production. Multiple identical animations are constructed at varying speeds to play at each distanced increment to create the illusion of increased agitation at signs of audience attention. The automated product response reflects the equation-like manipulation undergone by advertisers to create proscribed viewer reactions, and is similar to the contrived recirculation of pornographic tropes used to elicit a specific user response.

The reduction of the body through aestheticization contributes to the personification of my commodities through imaging. The pulsing of pattern represents the flow of affect as feeling and attention circulate through the body-ridden surface of the commodity, visually manifesting the metaphor of McLuhan's desiring machines. The personified commodity reacts to the viewer's presence. It desires to be desired, and demands audience attention. Mitchell explores exactly this relationship, animatizing pictures as autonomous beings with drives and desires of 
their own. Mitchell questions what it is that pictures want, rather than the more conventional "what do they say," positing that pictures would not have the hold over humanity that is illustrated in culture's masterpieces, religious idols, tribal totems, and iconoclastic wars, if they simply made didactic statements. Mitchell posits that pictures cannot be trusted to disclose their sources, or to understand their wants, and that it is crucial that we do not confuse their desires with those of

the artist, the beholder, or even the figures in the picture. What pictures want is not the same as the message they communicate or the effect they produce; it's not even the same as what they say they want. Like people, pictures may not know what they want; they have to be helped to recollect it through dialogue with others. (2005, p. 46).

Mitchell postulates whether what pictures ask of us is really our own desires projected back upon us made visible and distorted through the image's lack that we fill with our own wants and needs (2005, p. 25). Throughout his query into the desires of images, Mitchell frames an image's wants in relation to the viewer's experience, speaking of our Heideggerian understanding of the world and everything in it as a picture of itself. If this is true, do we understand ourselves also as a picture mediated by our own consciousness? A world-view of pictures and representations explains the increased permeability between entities, as with pictures, beings are conceptualized less as closed systems and more as networks of associated signs. In this hypothetical world we are fascinated and somewhat apprehensive towards pictures, with the simultaneous wish " to penetrate them [images] and our fear of being swallowed up by them" (Mitchell, 2005, p. xvii).

My commodities that show signs of life when viewed, illustrate a picture's need for an audience. In the entertainment and advertising industries, audience attention is the commodity in circulation. Potential consumers become the consumed as the product requires interchangeable supplies of desire to circulate interest around its brand image, quite literally portrayed through 
my prints and animations fabricated from consumed and assimilated bodies. The brand is essentially shorthand for a grouping of signifiers that connote a particular image and a correlative value - a set of product expectations. As such, I decided I needed a brand name to unify my bodies of work. Most of the editorial and advertisements I had been studying use designer names in a designated font, and logos to identify their brand. I toyed with invented names, with etymological roots relating to themes of body, circulation, icons, patterns, and other areas explored during this study. Nothing appealed as a suitable avatar, until I finally decided to use my own initials as a reified signature mimicking the LV - Louis Vuitton logo that greatly affected my patterning.

My subsequent series will illustrate the body already consumed and commodified through images. The J'adore print is the demo for this upcoming series and depicts a hard-core pornographic image of female body, highlighting genitalia made from Louis Vutton handbags, and framed as a magazine advertisement (see Figures 52-54). Her body is made entirely from products while the automated series of commodities is made from female figures conflating the relationship between bodies and commodities negotiated through visual representations. Figure 54 emphasizes the illusion of plurality and diversity evident in the slight variations of a standardized form in a Warholesque print series. 


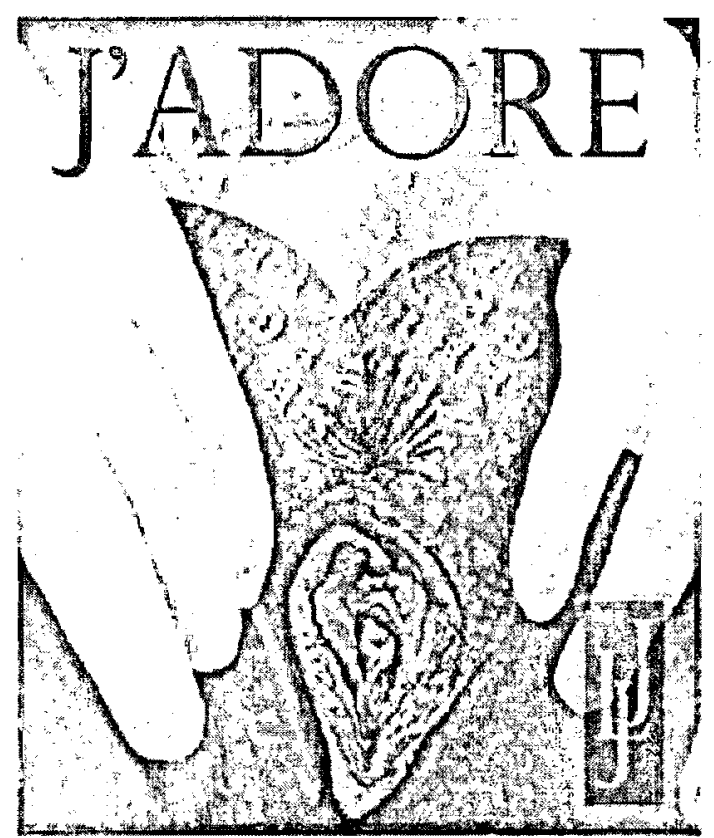

Figure 52

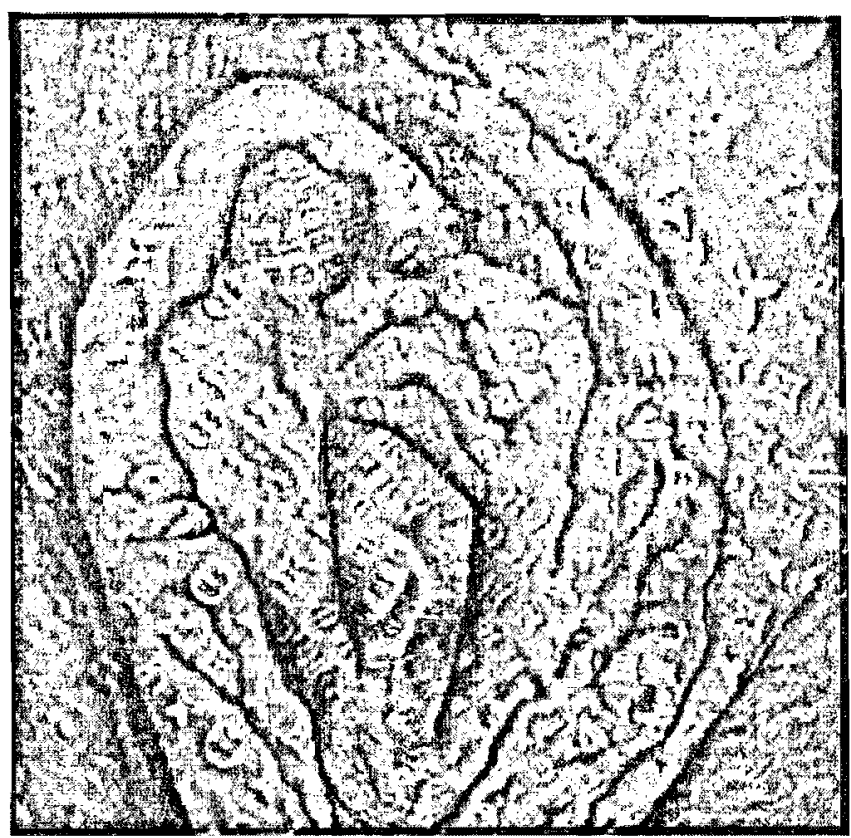

Figure 53

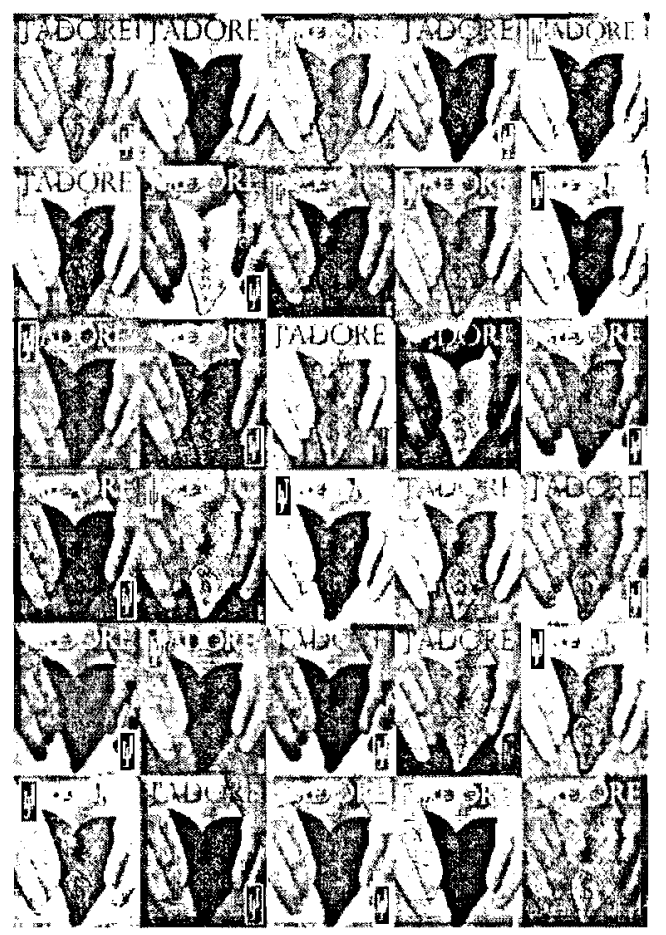

Figure 54

My intuitive play allowed for the exploration of areas I may have missed with conscious thought alone, and I believe, provided a more sincere representation of how these images relate to the viewer affectively by analyzing my own experience. My use of the detail and the resulting rationale of its use in advertising and pornography, came from my unconscious draw to the 
particular, and illustrates a direction I may not have explored, artistically and theoretically, if not for my practice. The images I created not only provide a forum to express and communicate my affective understanding of the operations of pornography and advertising, but also expanded my comprehension of how images function to direct desire within these genres. Through my art I exaggerate the means through which pornography and fashion advertising manipulate desire by highlighting their own representational practices. This reveals the mechanics of their construction and ironically diffuses the power of their symbols through mass (re)production.

I situate my work within the art-making practices of third-wave feminism, which combines feminist social and political agendas with artistic production. The chief concerns of third-wave feminism revolve around how to "respect the diversity in feminist thought and practice" regarding issues of sexuality, new technologies, and popular culture's impact on gender identities and perceptions (Brayton, 2006, p. 337). My project contributes to this discourse by analyzing how the representation of women in mainstream publications helps to establish a feminine identity of commodity and consumer. It is my goal to recontextualize patriarchal techniques of feminine representation in such a way that their mechanics become visible and obvious. I contend that the blatancy of my visual parody will translate to an increased visual literacy and awareness of the hegemonic conventions prevalent in pornography and fashion advertising. I hope my work challenges current cultural equations of consumerism with desire in an innovative and visually appealing manner. 


\section{CONCLUSION}

"Where everylhing is transformed into images: only images exist and are produced and are consumed."

(Barthes, 1980, p. 118).

Images are fully integrated into most individuals' daily lives, already present through their mind's eye, and constantly reintroduced across forms of media. Fashion, advertising, and pornography all operate within an economy of images, with the differences between their pictures' content not always apparent. These industries produce profit primarily by circulating representations, rather than by trading goods. This system reduces the portrayed subject to a referent of itself; metaphorically, the subject is destabilized. Representation renders its subject somewhat transposable as the gestalt of the whole is deconstructed into a system of interchangeable signifiers. The body is transformed from an autonomous being to an imago constructed from a group of signs, from a fixed entity to a permeable network of associations that connote the attributes of the depicted subject.

The pictured entirety of the representation is the archetypal standard against which newly perceived images are understood and measured, while concurrently the culmination of additional visions inform and renegotiate the original imago. With the imago of the human figure as it is depicted in mass media, the viewer identifies with the image of a body that is permeable and derives meaning from its portrayed surroundings. This inevitably results in the viewer seeking to assimilate and recreate the representation's image by seeing themselves as integrated with the signs of their physical world. In a reality understood through and as images, there is less division between an entity's representation and referent.

Fashion, advertising, and pornography count on this process of viewer identification and boundary diffusion. They manipulate representational structures of equivalence to promote 
consumer imitation and consumption through tactics that are often sexual. Images of sex can stimulate, transfer, and satiate desire. The purpose of this study has been to ascertain how these sexualized images function to direct desire for commercial purposes, and how these strategies vary between the fashion, advertising, and pornography industries. Comparison between common conventions of several genres provided a much more complex view of how visual representations, desire, and consumerism interrelate, much as making comparisons through multiple methodologies also presented a much more complete analysis.

Each of the previous chapters describes a particular aspect of my research topic explored through a selected mode of study that isolates specified data. The use of multiple methodologies revealed the relative strengths and weaknesses of each approach, and the type of knowledge ascertained by varying methods of inquiry. The order of the chapters correlates to the general sequence in which each methodology was applied although, in practice, there was more interaction between methods than the chapter divisions imply.

Chapter One, via a thorough literature review, explains the general social, political, cultural, and economic environment of pornography and its permutations throughout the mainstream. The landscape of divergent perspectives is described and assessed. I emphasized the spectrum of feminist positions because I situate the art resulting from this study in feminist third-wave practices. Much of the chapter discussed the difficulty in defining pornography, the debate surrounding its definition, and the repercussions of implementing a given definition over another. Special attention was given to pornography's relationship to social divisions of power. The debate was whether pornography is a cause, an indicator, or a symptom of gender politics within the current social landscape, and whether its presence has a liberating, normalizing, or 
violent effect. Indisputably evident from these divergent interpretations of pornography was its ability to illicit strong opinions from subjective and culturally contingent perspectives.

In compiling the criticism around the trend of pornification, two observations took precedence. Firstly, that definitive borders between media, industries, and genres have become more diffuse and fluid. Boundaries in general are more permeable, as distribution models have become more networked and less centralized, collapsing the space between public and private sectors. Secondly, I spoke of the ideological difference between the mainstreaming of pornography and the pornification of the mainstream. Most of the authors in Chapter One that champion the benefits of pornification cite the importance of pornography opening a dialogue about the multiplicity of sexual practices and forms of personal expression, resulting in increased awareness and tolerance, and improved working conditions for industry practitioners. These were all named as potential side effects of the mainstreaming of pornography. Most of the negative criticism levied at pornification has been at media adopting pomographic aesthetics while maintaining mainstream audiences and practices. The alleged pornification of heteronormative mainstream media was the dimension addressed in this study, and it was explored particularly in terms of how fashion conventions relate to pomographic tropes, and question the assumption of unidirectional influence.

Chapter Two analysed how these claims could either be challenged or substantiated through engagement with the visual material of primary sources. A quantitative approach provided an objective, topographical overview of general relationships and comparative statements between recorded factors, and was used to evaluate the perspectives given in Chapter One. Content analysis was used to isolate distinct attributes and chart their frequency in relation to all other recorded features. Arranging these features essentially derived patterns, that 
monitored the frequency and intensity of varying compositional techniques defined as pornographic by the studies referenced Chapter One.

The results of the content analysis exposed the assumptive nature of a number of the studies upon which this inquiry was based. Several of the devices defined as pornographic in sample studies, were found to be more prevalent in advertising and fashion editorial than in pornography, challenging the claim of a causal relationship. In particular, Merskin's qualitative analysis showed shared practices between pornography and advertising, but was unsuccessful in establishing pornography as point of origin for the sexualization of fashion editorials and advertisements. It was difficult to prove a causal relationship when the frequency of several factors framed as connoting pornographication was higher in the dependent variable than in their supposed originator. Either Merskin's hypothesis and conclusions were invalid, should not have been generalized beyond her sample, or - most likely in my opinion - the variables selected, as necessary attributes of pornography, were not inherent or exclusive to the genre.

What is at stake in conducting this, or any form of visual analysis, is the degree to which the resulting statements about the field analyzed can be said to describe features that are, in fact, semantically significant for viewers/spectators/'readers' of the images (van Leeuwen and Jewitt, 2001, p.25).

The validity of any study is dependent on precise and complete definitions, and the relevance of the variables selected. My content analysis illustrated the benefits of a grounded approach to selecting and defining variables.

Quantitative data gives factual accounts only of observed variables. While meant to provide an accurate overview of all active factors, it only described the attributes of which it was aware. In this sense, content analysis can run the risk of being two-dimensional. Similar to drawing a figure study, each perspective offers a partial view inevitably giving preference to visible characteristics over those omitted. As with a figure study, in order for content analysis to 
ensure that it provides an accurate overview it must engage multiple perspectives and be cognizant of its vantage point at any given time. Content analysis is best used in conjunction with other methods that can read meaning into its data, as quantitative information cannot provide nuanced interpretations or explanations as to why the relationships it charts occur. Qualitative analysis engages with the functioning of particularities to ascribe meaning to the trends observed quantitatively.

Chapter Three qualitatively addressed how meaning and desire are understood, exchanged, and circulated through advertising, fashion, and pornographic images. The chapter engaged theoretically with Lacanian principles of desire and perception, and with Marxist readings of affect theory to conjecture on the relationship between consumerism and desire evident in visual representations. The chapter began with a semiotic analysis to discern meaning, followed by an exploration of how desire, as a form of affect, is transmitted through pornographic and advertising images.

Semiotic analysis was used to read meaning into the trends observed throughout the content analysis. Contrary to noting particular independent attributes, the semiotic interpretation revealed patterns of traits commonly linked together. In advertising, it was observed that groups of signs are frequently arranged around product types or brands. Repetitive visual elements and chains of signifiers highlighted associations between the product and its effect. The figure was typically displayed as a decorative element to connote social worth through sexual appeal. Highend retailers and fragrances had the highest instances of explicit sexuality and alleged pornographic conventions, while low-end retailers were much less sexually blatant and promoted the products' use value. In pornography, however, the figures were portrayed systematically in nearly identical poses to present the body as a commodity. Body types, positions, lighting 
conditions, and camera angles were uniformly standardized with little variation or distinguishing factors to promote an idealized standard to which each model must adhere. Images portraying the same model from different privileged vantage points and pages divided into multiple views of different models presented the individuals as serialized product options within a catalogue.

Affect was explained as relative and immaterial, only discernible through movement as it flows between entities. It escapes cognition, making it only possible to speak of the effects of affect. Because it operates through feeling, outside of the realm of language, it cannot be manipulated in the same sense that meaning can be constructed through a series of organized signs. Affect can be transmitted through images as purported by Barthes, who names the punctum as a detail within an image that is able to puncture the viewer. This rupture allows for affect to flow through from the represented subject into the viewer's perception. It was noted that although it was the detail that provided access to affective channels through which desire could be transferred, it was the patterned sequences of correlated signs that created the network through which affect flows.

Economies that function largely through affect, like pornography, fashion, and advertising, specialize in calibrating affect to flow through designated patterns and to concentrate around certain signs. As affect is actualized in circulation, the more a sign is disseminated the higher its affective potential. Affect generally correlates to publicity along recognizable patterns of signs. Advertisements used recognizable patterns in conjunction with brands and product types to concentrate attention and desire on specific commodities, while mainstream pornography circulated proscribed images of the body to produce immediately recognizable and easily digested archetypes of sex appeal. Simply put, advertisers used the sexualized body to 
transfer desire to a commodity while pornography portrayed the body as a commodity to be consumed by the viewer.

Because this was a study about the similarities between images, as well as how to chart and interpret those images, I felt compelled to respond through images. The creation of affective channels, through the organization of details/signs described in Chapter Three, was actualized through my creative practice. Chapter Four outlines the rational for addressing the similarities between pornography, fashion, and advertising artistically, and my process for doing so. Images are far more slippery than words, evading simple categorization and illustrating the equivocacy of systems of visual classification. My own pieces have an uncertain identity, vacillating between aestheticized objects, social criticism, and erotic art, appropriately highlighting the ambiguity upon which they are based. Working creatively was a largely intuitive process, through which I first became consciously aware of many of the observations I explored in earlier chapters. Theo van Leeuwen and Carey Jewitt have an excellent description of the benefits in combining creative and systematic analysis:

Conclusions lie beyond information and description: as such they entail creative and artistic processes. It is both necessary and legitimate to allow ourselves to respond artistically or intuitively to visual images in research, both during earlier stages of analysis and as we articulate conclusions. However, while creative processes are essential to discovery, artistic process may produce only fictitious statements if not combined with systematic and detailed analysis" (2001, p. 59).

Intuitive practices are best served when produced and understood in concert with conscious rationalization.

Together, the perspectives gained from each of these methods provide an overview of the complex and ambiguous terrain of aspects of fashion, advertising, and pornographic industries. Every one of these industries is far more complicated than this study is able to elaborate upon, with far more examples illustrating the diversity of its forms. The limitations of 
this study were due to its small scope and individual nature. I was the sole practitioner in this study resulting in subjective coding criteria and semiotic readings. No other individuals checked the validity of coding. However, I did randomly recode units from each magazine throughout the process to maintain reliability. This study was not meant to be generalizable. The specificity and size of my samples are far too narrow to be indicative of larger trends, making the findings only valid for each magazine. Future studies should draw from less exhaustive examples extracted through probability sampling from a larger sample pool over a broader period in time. It would also have been interesting to apply my multi-disciplinary approach to other media including online content. Framed as a pilot study, this exercise provides useful insight into the benefits of employing particular methods in an interdisciplinary approach to subjects that are not easily housed within one field of study.

Magazine publishing, advertising, fashion, and pornography are all industries within the entertainment and information service sectors that function simultaneously in an exchange economy and affect market. They trade between goods and signs, circulating attention through established sign patterns to concentrate desire on recognizable forms. In the mainstream, the form evident in the soft-core pornography of Playboy is a normalized ideal of an availably posed female body. Cosmopolitan and Vogue present the form of the female body either augmented by a portrayed commodity's use, or contorted to display the commodity valued above her. The only constant variation between pornography and mainstream media is the level of nudity among all models in Playboy, with posing resembling product prototypes and is less sexually aggressive than the fully clothed, explicit and implicit innuendo found in Cosmo and Vogue.

I suspect in the image based economy, exclusive signs will likely be less and less common, with proscribed pattern sets dictating material classification of increasingly permeable 
categories. In order to actively engage within a society of increasingly fluid relationships between media genres and their creators, users, and regulators, we must determine how we as academics and/or makers can best understand and contribute to these interactions. I believe it is through the self-reflexive, mimicry and parody evident in my art. Normalized conventions are carried to their logical, yet ridiculous, extremes, making their customs blatant and questionable. The blurring of industry visual conventions and boundaries is mirrored by the integration of academic methodologies and creative practices. Similar yet askew images of consuming figures are born from a permeable and sexualized world of pictures that cyclically encourage their own consumption through pictures. 


\section{APPENDIXES}

\section{Appendix 1: Content analysis - method one}

Item 1.1: Template data collection form -method one

Page(s): series:

- figure(s): 1

- pose description:

exposed:

level of dress:

adornment/markings:

touch/interaction:

- parts hair:

eyes:

mouth:

- Composition: text ratio:

logo:

background and notable props:

color:

lighting:

camera:

- Product: type:

spread: continuous:

Full/partial:

Type:

continuous: single/multiple:

- size prominence:

presentation/relation to figure:

Item 1.2: Example of method one - Cosmopolitan (full sample available on DVD)

Page(s): 4-5 Description: JC Penny American living Type: Ad series: $\mathrm{N}$ spread: $\mathrm{Y}$ continuous: $\mathrm{N}$ single/multiple: $\mathrm{M}$

multiple layout: 55 split into 3 rows, top and bottom rows contain 3 equal sized images, there are figures in the corner image of each M1-4 that are small overall but high to mid within their frames, $\mathrm{p} 6$ is a single full page image M5.

M1

- figure(s): 1 Full/partial: partial, head to calf - size prominence: mid

- pose description: standing $3 / 4$ front to camera, facing forward

exposed: hands and face

level of dress: full

adornment/markings: none visible

touch/interaction: none visible

- parts hair: long, loose, covering right shoulder -dark blond/light brown

eyes: open, direct gaze -blue

mouth: large smile, teeth visible

M2

- figure(s): 2 (1 female, other child) Full/partial: partial, head to mid-leg - size prominence:

high 
- pose description: $3 / 4$ front view, hip cocked, leaning back twisting, back right shoulder higher than left, arms crossed in front holding child, head turned in $3 / 4$ towards camera

exposed: face, neck and part of forearm

level of dress: full, wide skirt, collared shirt and sweater

adornment/markings: small pearl earrings

touch/interaction: holding child against waist -implicit, clothing covers contact

- parts hair: pulled back - black

eyes: open, direct gaze -brown

mouth: wide smile, teeth visible

M3

- figure(s): 1 Full/partial: partial, head to mid-calf - size prominence: mid

- pose description: standing legs apart, right hip slightly cocked, left hand on hip arm slightly

bent, head tilted slightly down and to left, left arm obscured by props.

exposed: face, neck, part of décolletage, hands

level of dress: full, pants, long belted sweater and shirt

adornment/markings: pearl necklace

touch/interaction: implied holding of props (presents) and left hand on hip with thumb in pocket

- parts hair: long, loose, neat - brown

eyes: open, gaze direct, looking slightly up -not visible

mouth: wide smile, teeth visible

M4

- figure(s): 1 Full/partial; partial, head to above knee - size prominence: high

- pose description: standing facing forward, legs apart, left slightly forward, right hip slightly

cocked, arms down at sides slightly bent at elbows, with hands at hip, head forward

exposed: face and forearms

level of dress: full, turtle-neck sweater and pants

adornment/markings: none visible

touch/interaction: hands at hip half in pockets

- parts hair: long, loose, slightly tousled, covering right shoulder -dark blond/light brown

eyes: open, direct gaze -blue

mouth: wide smile, teeth visible

M5

- figure(s): 1 Full/partial: partial, head to knees - size prominence: $\mathrm{mid} / \mathrm{high}$

- pose description: standing $3 / 4$ forward with left hand side away from camera, straight but leaning very slightly back, right leg slightly forward, arms relaxed by sides, head turned slightly facing almost straight to camera.

exposed: face, neck, shoulders, arm

level of dress: full, sleeveless shit top and full above knee skirt and sheer tights

adornment/markings: pearl earrings

touch/interaction: right hand grazing skirt

- parts hair: pulled back - brown

eyes: open gazing to left side - brown

mouth: lips slightly parted, full, soft smile

- Composition: text ratio: high/mid placement: centered in center row contrast: high logo: large, part of brand name 
background and notable props: set location, interior/exterior doorway, white boards and wood staircase

color: white, navy, red, black and hunter green

lighting: even, little shadow

camera: direct frontal

- Product: type: merchandise brand (likely clothing)

presentation/relation to figure: in shoot - wearing, same scale

Item 1.3: Example of method one - Vogue (full sample available on DVD)

<note: same as item 10 in Cosmo>

Page(s): 2\&3 - Description: Gucci by Gucci perfume Type: ad

series: no spread: yes continuous: yes single/multiple: $\mathbf{S}$

- figure(s): $1 \quad$ Full/partial: partial, hips to head - size prominence: high

- pose description: lying down on side, arms bent, leaning on elbows with head resting on

clasped hands. Head slanted to right corner.

exposed: hands, forearms, decolatage, face, partial left ear

Level of dress: full: dress

adornment/markings: gold chain-choker necklace, French-manicure nails, brown smokey

eye

bottle

touch/interaction: jaw resting on right hand, resting on left hand, all draped over perfume

- parts hair: long, loose, middle part, blown away from face-brown, more gold by face

eyes: open, gazing up, mid-direct -brown

mouth: pursed and pouting, slightly open

- Composition: text ratio: mid/low placement: bottom left, off of figure contrast: high background and notable props: diffused solid color, no visible ground line

color: gold, taupes, warm tans and browns, white, clear

lighting: studio, warm, consistent

camera: front, looking down

- Product: type: designer brand, perfume

presentation/relation to figure: in shot, touched/supporting by model, display

(large version) of product

Item 1.4: Example of method one - Playboy (full sample available on DVD)

Page(s): 101 - Description: centerfold page 2 Type: ed - centerfold series: $\mathrm{Y}$ spread: $\mathrm{Y}$ continuous: $\mathrm{N}$ single/multiple: $\mathrm{S}$

- figure(s): 2 Full/partial: full - size prominence: high

- Fig1) pose description: weight on hands and knees/lower leg, diagonal profile to camera, lower legs obscured, buttock over feet, back slightly arched, arms bent, head turned to face front.

exposed: pubis and left leg obscured

level of dress: nude

adornment/markings: gold dangle earrings and long gold necklace

touch/interaction: touching surface covering

- parts hair: long, loose, tousled

eyes: open, direct gaze looking slightly up

mouth: partially open, slight smile, upper teeth visible, tongue slightly visible 
Fig 2) pose description: kneeling with legs out behind, leaning to side, twisted torso, $3 / 4$ front, left arm crossed over body, right arm up supporting body, head tilted back to side

exposed: pubis, buttocks and left leg obscured

level of dress: nude

adornment/markings: gold drop earrings and long gold necklace and belly-button ring touch/interaction: holding bed frame in each hand

- parts hair: long, loose, tousled

eyes: open, direct gaze, looking slightly up

mouth: slightly pursed

- Composition: text ratio: none placement: n/a contrast: $\mathrm{n} / \mathrm{a}$

logo: not visible

background and notable props: interior studio, domestic cabin scene, bed foreground

clear focus, back -softblurry focus

color: warm wood tones, tan skin, dark blues and green plaid

lighting: warm studio key and ambient

camera: direct, looking slightly down

- Product: type: n/a

presentation/relation to figure: $n / a$

\section{Appendix 2: Content analysis - method two - sample tables}

Each figure is a table completed for each of the magazines used - full sample available on DVD

Table 2.1: Instances of full vs. partial display of figures

\section{Ad}

$\begin{array}{llllll}\text { Single } & \text { Multiple } & \text { Full } & \text { Partial } & \text { Both } \\ \text { Full } & \text { Partial } & \text { Both } & & \\ \begin{array}{l}\text { Editorial } \\ \text { Single } \\ \text { Full }\end{array} & \text { Partial } & \text { Both } & \text { Multiple } & \text { Full } & \text { Partial }\end{array}$

Table 2.2: Camera position

Ad

Editorial

$\begin{array}{lllll}\text { Eye level } & \text { Slight above } & \text { Above } & \text { Slight } & \text { below } \\ \text { Front } & \text { Slight side } & \text { Side } & \text { Slight back } & \text { Back }\end{array}$

Table 2.3: Body placement
Ad Editorial
(F)iront $3 / 4$ pro $F$
facing
(R)right
$3 / 4$ pro
$3 / 4$ pro $B$
(L) left Profile L FL
(L) left $\quad$ Profile L $\quad$ FL
$3 / 4$ pro
Profile R (B)back R Back 
Table 2.4 Body parts - visible exposure - full and partial

$\begin{array}{llllll}\text { Ad } & \text { Editorial } & \text { Figure \# } & \text { Exposure } & \\ \text { Head } & \text { Face } & \text { Neck } & & \\ \text { Chest } & \text { Cleavage } & \text { Breasts } & \text { Nipple } & \\ \text { Abdomen } & \text { Hips } & \text { Pubic } & \text { Genitalia } & \\ \text { Back } & \text { Buttocks } & \text { Crack } & \text { B. Cleavage } & & \\ \text { Thigh(s) } & \text { Inner thigh } & \text { Knee } & \text { Calf(ves) } & \text { Feet } & \\ \text { Shoulders } & \text { Upper-arm(s) } & \text { Forearm(s) } & \text { Hand(s) } & \text { Inner wrist } & \text { Under arm }\end{array}$

Table 2.5 eyes and gaze

\begin{tabular}{|c|c|c|c|c|c|}
\hline $\mathrm{Ad}$ & Editorial & Figure \# & & & \\
\hline & & & $\begin{array}{l}\text { Visible } \\
\text { Both }\end{array}$ & Ronly & L only \\
\hline $\begin{array}{l}\text { Open } \\
\text { Direct }\end{array}$ & Partially. & Closed & & & \\
\hline $\begin{array}{l}\text { Front } \\
\text { Un-direct }\end{array}$ & Side & Side up & Upward & Side down & Downward \\
\hline Front & Side & Side up & Upward & Side down & Down cast \\
\hline $\begin{array}{l}\text { Shadowed } \\
\text { Slight }\end{array}$ & Heavy & Focused & Unfocused & & \\
\hline
\end{tabular}

Appendix 3: Overview of advertising and editorial content analysis: Cosmopolitan

Table 3.1: Instances of full vs. partial figures

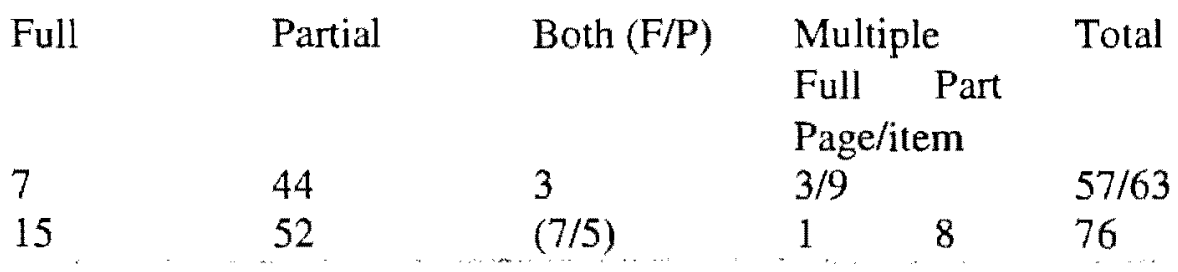

\section{Editorial}

Ed item

Figures

916

16

$\begin{array}{lll}-- & -- & 25\end{array}$

Items

60

3

68

(7/5)

$3 / 9$

1
25

$82 / 88$

101 
Table 3.2: Camera position (increments of items)

Ads

$X-$ full ad

M - multi

Fronl

$\begin{array}{ll}\text { Eyc-level } & \begin{array}{l}\text { Slight } \\ \text { above }\end{array} \\ 17 / 23 & 9 \\ 8 / 9 & 5 / 6 \\ \cdots & \cdots\end{array}$

$\begin{array}{ll}\text { Above } & \text { Slight } \\ 1 & \text { below } \\ 1 & 7 / 8 \\ & 2\end{array}$

Below
1
$-\cdots$
1
1
-3

$\begin{array}{ll}\text { Multi Ad } & \text { Total } \\ & 35 / 42 \\ & 16 / 18 \\ & 1 \\ & \\ & 2 \\ -- & 3 /(9) \\ 3 /(9) & 57 / 63\end{array}$

\section{Editorial}

Front

Slight side 5

Side

Slight

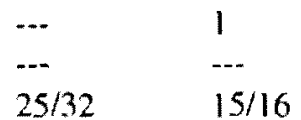

$\cdots$

$\cdots$

$\begin{array}{ll}\cdots- & 2 \\ \cdots- & -- \\ \cdots & - \\ \cdots & - \\ \cdots & - \\ \cdots & 2\end{array}$

$\begin{array}{ccc}\cdots & & 15 \\ \cdots & & 8 \\ \cdots & & - \\ \cdots & & 1 \\ \cdots & \ldots & 1 \\ \cdots & -- & 25\end{array}$

Table 3.3: Figure placement (increments of figures)

Front 3/4FR Pro R 3/4 BR Back 3/4 BL ProL 3/4 FL N/A Total

$\begin{array}{lllllllllll}\text { Ad } & 39 & 12 & 2 & 3 & 2 & 2 & 2 & 12 & 2 & 76\end{array}$

$\begin{array}{lllllllllll}\text { Ed } & 17 & 0 & 3 & 1 & 0 & 0 & 1 & 2 & 1 & 25\end{array}$

Table 3.4: Visible exposure of body parts (increments of figures)

$\begin{array}{llll} & \text { Head } & \text { Face } & \text { Neck } \\ \text { Ads } & 69 & 69 & 62 \\ \text { Full Exposure (I) } & 54 & 51 & 46 \\ \text { Partial Exposure (P) } & 15 & 18 & 16 \\ \text { Editorial } & 25 & 25 & 25 \\ \text { Full Exposure (I) } & 19 & 17 & 20 \\ \text { Partial Exposure (P) } & 6 & 8 & 5\end{array}$

\begin{tabular}{|c|c|c|c|c|c|c|c|}
\hline & Chest & Cleavage & Breast & Nipple & Abdomen & Pubic & Genital \\
\hline Ads & 43 & 25 & 3 & -- & 11 & --- & -- \\
\hline Full (I) & 24 & 18 & --- & --- & 7 & -- & --- \\
\hline $\begin{array}{l}\text { Partial } \\
\text { (P) }\end{array}$ & 19 & 7 & 3 & --- & 4 & --- & -- \\
\hline Editorial & 15 & 9 & 2 & -- & 2 & $\ldots$ & $\ldots$ \\
\hline Full (I) & 9 & 4 & $\cdots$ & $-\cdots$ & 1 & -- & -- \\
\hline $\begin{array}{l}\text { Partial } \\
\text { (P) }\end{array}$ & 6 & 5 & 2 & -- & 1 & $\cdots$ & $\cdots$ \\
\hline
\end{tabular}




$\begin{array}{llllll} & \text { Back } & \text { Hips } & \text { Buttocks } & \text { Crack } & \text { B. Cleavage } \\ \text { Ads } & 7 & 7 & 1 & -\cdots & 2 \\ \text { Full (I) } & 2 & 2 & 1 & --- & 1 \\ \text { Partial (P) } & 5 & 5 & -- & -- & 1 \\ \text { Editorial } & 3 & 1 & 1 & --- & --- \\ \text { Full (I) } & 1 & 1 & -- & --- & -- \\ \text { Partial (P) } & 2 & --- & 1 & --- & -- \\ & & & & & \\ & \text { Thigh } & \text { Inner Thigh } & \text { Knee } & \text { Calves } & \text { Feet } \\ \text { Ads } & 17 & 9 & 17 & 20 & 15 \\ \text { Full (I) } & 10 & 2 & 14 & 13 & 5 \\ \text { Partial (P) } & 7 & 7 & 3 & 7 & 10 \\ & & & & & \\ \text { Editorial } & 8 & 1 & 7 & 6 & 4 \\ \text { Full (I) } & 1 & --- & 5 & 5 & -- \\ \text { Partial (P) } & 7 & 1 & 2 & 1 & 4\end{array}$

$\begin{array}{lllllll} & \text { Shoulder } & \text { Upper arm } & \text { Forearm } & \text { Hand(s) } & \text { Inner wrist } & \text { Under arm } \\ \text { Ads } & 39 & 38 & 45 & 58 & 3 & 8 \\ \text { Full (I) } & 33 & 23 & 26 & 41 & 2 & 1 \\ \text { Partial (P) } & 6 & 15 & 19 & 17 & 1 & 7 \\ & & & & & & \\ \text { Editorial } & 11 & 12 & 19 & 22 & 2 & -\cdots \\ \text { Full (I) } & 6 & 9 & 11 & 17 & 2 & -- \\ \text { Partial (P) } & 5 & 3 & 8 & 5 & -\cdots & --\end{array}$

Table 3.5: Figure eye visibility (increments of figures)

Ad

\begin{tabular}{|c|c|c|c|c|c|c|}
\hline Both Eyes & & & R Only & R Eye & L Onl & LEye \\
\hline total & Shade & DShade & 3 & 3 & 3 & 3 \\
\hline 48 & 7 & 3 & 3 & -- & 4 & --- \\
\hline 7 & --. & 2 & 1 & 1 & 1 & --- \\
\hline
\end{tabular}

Visibility

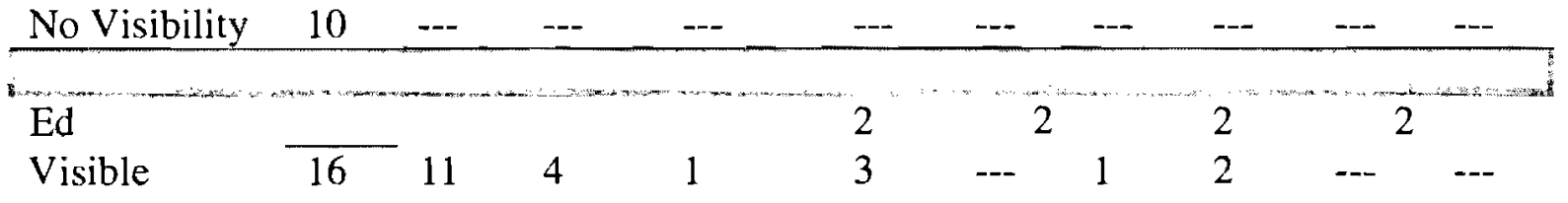

Partial

Visibility

No Visibility $1 \quad---\quad---\quad--$ 
Table 3.6: Figure gaze direction and focus (increments of figures)

\begin{tabular}{|c|c|c|c|c|c|c|c|c|c|}
\hline & $(\mathrm{I} / \mathrm{P})$ & Front & Side & $\mathrm{S}$ up & Up & Sdown & Down & Focus & $\mathrm{XF}$ \\
\hline Open & $\begin{array}{l}59 \\
(52 / 7)\end{array}$ & $\begin{array}{l}29 \\
(25 / 4)\end{array}$ & $\begin{array}{l}10 \\
(7 / 3)\end{array}$ & 11 & 7 & 1 & 1 & 49 & 10 \\
\hline O Direct & $\begin{array}{l}45 \\
(41 / 4)\end{array}$ & $\begin{array}{l}28 \\
(24 / 4)\end{array}$ & 3 & 7 & 6 & --- & 1 & 42 & 3 \\
\hline $\begin{array}{l}\mathrm{O} \\
\text { Indirect }\end{array}$ & $\begin{array}{l}14 \\
(11 / 3)\end{array}$ & 1 & $\begin{array}{l}7 \\
(4 / 3)\end{array}$ & 4 & 1 & 1 & --- & 7 & 7 \\
\hline Partial & $\begin{array}{l}3 \\
(2 / 1)\end{array}$ & $\cdots$ & -.. & --. & -- & 1 & $\begin{array}{l}2 \\
(1 / 1)\end{array}$ & 3 & -- \\
\hline P Direct & 2 & --. & -.. & --. & --- & 1 & 1 & 2 & $-\ldots$ \\
\hline $\begin{array}{l}\mathrm{P} \\
\text { Indirect }\end{array}$ & $\begin{array}{l}1 \\
(/ 1)\end{array}$ & --- & $\cdots$ & -- & --- & --- & $/ 1$ & 1 & --- \\
\hline $\begin{array}{l}\mathrm{P} \\
\text { unclear }\end{array}$ & & $\cdots$ & $\cdots$ & -- & -- & -- & -- & -- & $\cdots$ \\
\hline Closed & $\begin{array}{l}4 \\
(3 / 1)\end{array}$ & --- & --- & --. & -- & -- & -- & -- & -- \\
\hline $\mathrm{Ed}$ & & & 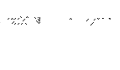 & & . & $\ldots$ & . & & \\
\hline Open & $\begin{array}{l}18 \\
(16 / 2)\end{array}$ & $\begin{array}{l}9 \\
(8 / 1)\end{array}$ & 2 & $\begin{array}{l}4 \\
(3 / 1)\end{array}$ & 3 & -.. & -.- & 13 & 5 \\
\hline O Direct & $\begin{array}{l}15 \\
(13 / 2)\end{array}$ & $\begin{array}{l}8 \\
(7 / 1)\end{array}$ & 1 & $\begin{array}{l}3 \\
(2 / 1)\end{array}$ & 3 & $\cdots$ & -.- & 13 & 2 \\
\hline $\begin{array}{l}\text { O } \\
\text { Indirect }\end{array}$ & 3 & 1 & 1 & 1 & --- & -- & -- & --- & 3 \\
\hline Partial & 3 & 1 & $\cdots$ & 1 & -- & --- & 1 & & \\
\hline P Direct &.-- & -.. & -.- & $\ldots$ & --. & --- & -.. & -.. & -.. \\
\hline $\begin{array}{l}\mathrm{P} \\
\text { Indirect }\end{array}$ & 3 & 1 & $\cdots$ & 1 & $\cdots$ & - & 1 & 1 & 2 \\
\hline Closed & 3 & --- & -.. &.-- & --- & -.. & -- & $\ldots$ & - \\
\hline
\end{tabular}




\section{Appendix 4: Overview of advertising and editorial figure analysis - Vogue}

Table 4.1: Instances of full vs. partial figures

full

partial

Both

multiple

Total

Full Part

Ads

19

80

Page/Item

Ad Figures

27

91

3

$(8 / 8)$

$2 / 4$

$104 / 106$

\begin{tabular}{l} 
Editorial \\
Ed Figures \\
\hline
\end{tabular}

Items

17

24

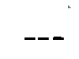

1

122

Figures

$\begin{array}{lll}36 & 104 & 3 \\ 49 & 115 & (8 / 8)\end{array}$

41

24

$2 / 4$

4

$145 / 147$

168

Table 4.2: Camera position (increments of items)

Ads

\begin{tabular}{|c|c|c|c|c|c|c|c|}
\hline & Eye-level & $\begin{array}{l}\text { Slight } \\
\text { above }\end{array}$ & Above & $\begin{array}{l}\text { Slight } \\
\text { below }\end{array}$ & Below & Multi Ad & Total \\
\hline Front & $28 / 29$ & $14 / 15$ & 11 & 15 & 1 & & $58 / 61$ \\
\hline Slight side & $14 / 15$ & 14 & 4 & 7 & --- & & $39 / 40$ \\
\hline Side & 1 & --- & --- & 3 & --- & & 4 \\
\hline \multicolumn{8}{|l|}{ Slight } \\
\hline back & -.- & 1 & --- & -- & -- & & 1 \\
\hline \multirow[t]{2}{*}{ Back } & --- & --- & $-\cdots$ & --- & --- & & -- \\
\hline & $44 / 46$ & $28 / 29$ & $4 / 5$ & 25 & 1 & $(2 /)$ & $104 / 106$ \\
\hline \multicolumn{8}{|l|}{ Editorial } \\
\hline Front & 13 & 2 & --- & 1 & --- & & 16 \\
\hline Slight side & 11 & 8 & 2 & 2 & -- & & 23 \\
\hline Side & -.. & 1 & --- & --- & --- & & 1 \\
\hline \multicolumn{8}{|l|}{ Slight } \\
\hline back & 1 & -- & -- & $\cdots$ & $\cdots$ & & ] \\
\hline \multirow[t]{2}{*}{ Back } & $-\cdots$ & $-\cdots$ & $\cdots$ & $\cdots$ & $\cdots$ & & $\cdots$ \\
\hline & 25 & 11 & 2 & 3 & --- & --- & 41 \\
\hline
\end{tabular}

Table 4.3: Figure placement (increments of figures)

$\begin{array}{lllllllllll} & \text { Front } & 3 / 4 \text { FR } & \text { Pro R } & 3 / 4 \text { BR } & \text { Back } & 3 / 4 \text { BL } & \text { Pro L } & 3 / 4 \text { FL } & \text { N/A } & \text { Total } \\ \text { Ad } & 62 & 23 & 6 & 1 & --- & 2 & 4 & 20 & 4 & 122 \\ \text { Ed } & 19 & 11 & 2 & 2 & -- & -- & 2 & 9 & --- & 45\end{array}$


Table 4.4: Visible exposure of body parts (increments of figures)

\begin{tabular}{llll} 
& Head & Face & Neck \\
Ads & 119 & 119 & 116 \\
Full Exposure (I) & 89 & 80 & 64 \\
Partial Exposure (P) & 30 & 39 & 52 \\
\hline & & & \\
Editorial & 46 & 46 & 38 \\
Full Exposure (I) & 37 & 26 & 24 \\
Partial Exposure (P) & 9 & 20 & 14
\end{tabular}

$\begin{array}{llllllll} & \text { Chest } & \text { Cleavage } & \text { Breast } & \text { Nipple } & \text { Abdomen } & \text { Pubic } & \text { Genital } \\ \text { Ads } & 65 & 23 & 7 & --- & 12 & --- & --- \\ \text { Full (I) } & 34 & 19 & 4 & --- & 5 & --- & --- \\ \text { Partial } & 31 & 14 & 3 & -- & 7 & --- & -- \\ \text { (P) } & & & & & & & \end{array}$

\begin{tabular}{|c|c|c|c|c|c|c|c|}
\hline Editorial & 22 & 10 & 1 & --- & & --- & --- \\
\hline Full (I) & 8 & 5 & --- & -- & & --- & --- \\
\hline Partial & 14 & 5 & 1 & -- & & -- & --- \\
\hline & Back & & Hips & Buttocks & Crack & & B. Cleavage \\
\hline Ads & 9 & & 10 & 2 & --- & & 3 \\
\hline Full (I) & 2 & & 3 & 1 &.-- & & 1 \\
\hline Partial (P) & 7 & & 7 & 1 & --- & & 2 \\
\hline Editorial & 6 & & 2 & $\ldots$ & -- & - & 1 \\
\hline Full (I) & --- & & 2 & --- & --- & & --- \\
\hline Partial (P) & 6 & & --- & --- & -- & & 1 \\
\hline
\end{tabular}

\begin{tabular}{llllll} 
& Thigh & Inner Thigh & Knee & Calves & Feet \\
Ads & 39 & 10 & 32 & 31 & 21 \\
Full (I) & 18 & 7 & 27 & 19 & 3 \\
Partial (P) & 21 & 3 & 5 & 12 & 18 \\
\hline & & & 8 & 10 & 12 \\
Editorial & 6 & 3 & 8 & 4 & 1 \\
Full (I) & 4 & -3 & 5 & 6 & 11 \\
Partial (P) & 2 & 3 & 3 & &
\end{tabular}




\begin{tabular}{lllllll} 
& Shoulder & Upper arm & Forearm & Hand(s) & Inner wrist & Under arm \\
Ads & 62 & 53 & 75 & 97 & 10 & 14 \\
Full (I) & 38 & 31 & 44 & 48 & 5 & 8 \\
Partial (P) & 24 & 22 & 31 & 49 & 5 & 7 \\
\hline & & & & & & \\
Editorial & 17 & 24 & 27 & 30 & 1 & 1 \\
Full (I) & 11 & 13 & 8 & 11 & 1 & 1 \\
Partial (P) & 6 & 11 & 19 & 19 & -- &
\end{tabular}

Table 4.5: Figure eye visibility (increments of figures)

Ad

\begin{tabular}{|c|c|c|c|c|c|c|c|c|c|}
\hline \multicolumn{2}{|c|}{ Both Eyes } & & & R Only & & R Eye & \multicolumn{2}{|c|}{ L Only } & L Eye \\
\hline total & & Shade & DShade & 9 & & 15 & 2 & & (15) \\
\hline 78 & 66 & 11 & 1 & 11 & $\cdots$ & 1 & 7 & 4 & 1 \\
\hline 7 & 4 & --- & 3 & 6 & 4 & 2 & 4 & -- & 1 \\
\hline
\end{tabular}

Partial

Visibility

No Visibility $11 \quad 8 \quad 1--\quad 3$

Ed

Visible

Partial

$\begin{array}{llll}26 & 19 & 6 & 1 \\ 3 & 2 & -\cdots & -\cdots\end{array}$

35

6

(5)

Visibility

No Visibility

$3 \quad 3$


Table 4.6: Figure gaze direction and focus (increments of figures)

Ad

Open 84

$(78 / 6)$

O $\quad 57$

Direct $\quad(53 / 4)$

O

Indirect $(25 / 2)$

$\begin{array}{lll}\text { Partial } & 19 & 3\end{array}$

P $\quad 9$

Direct

$\begin{array}{ll}\mathrm{P} & 8 \\ \text { Indirect } & (5 / 3)\end{array}$

Indirect $(5 / 3)$

unclear
(I/P) Front
Focus Unfocus

Down

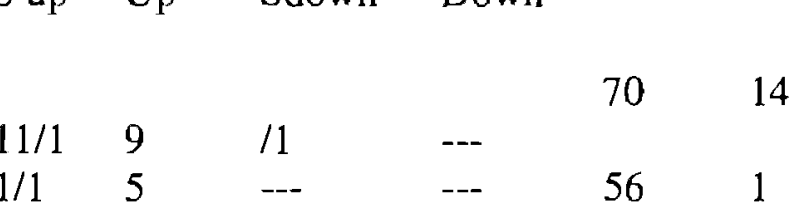

\section{Consuming Figures}

\begin{tabular}{|c|c|c|c|c|c|c|c|c|}
\hline Open & $\begin{array}{l}84 \\
(78 / 6)\end{array}$ & $42 / 3$ & $16 / 1$ & $11 / 1$ & 9 & $/ 1$ & --- & 70 \\
\hline $\begin{array}{l}\text { O } \\
\text { Direct }\end{array}$ & $\begin{array}{l}57 \\
(53 / 4)\end{array}$ & $38 / 3$ & 9 & $1 / 1$ & 5 & -- & --- & 56 \\
\hline $\begin{array}{l}\mathrm{O} \\
\text { Indirect }\end{array}$ & $\begin{array}{l}27 \\
(25 / 2)\end{array}$ & 4 & $7 / 1$ & 10 & 4 & $/ 1$ & --- & 14 \\
\hline Partial & $\begin{array}{l}19 \\
(16 / 3)\end{array}$ & 3 & $3 / 2$ & 3 & $1 / 1$ & 2 & 2 & 14 \\
\hline $\begin{array}{l}\mathrm{P} \\
\text { Direct }\end{array}$ & 9 & 1 & 2 & 2 & 1 & 1 & 2 & 9 \\
\hline $\begin{array}{l}\mathrm{P} \\
\text { Indirect }\end{array}$ & $\begin{array}{l}8 \\
(5 / 3)\end{array}$ & 2 & $1 / 2$ & 1 & $/ 1$ & 1 & $\cdots$ & 5 \\
\hline $\begin{array}{l}\mathrm{P} \\
\text { unclear }\end{array}$ & 2 & --- & --- & --- & --- & -- & --- & \\
\hline
\end{tabular}

Closed 8

\begin{tabular}{|c|c|c|c|c|c|c|c|c|c|}
\hline Open & $\begin{array}{l}34 \\
(31 / 3)\end{array}$ & $14 / 2$ & $5 / 1$ & 6 & 6 & --- & -- & 27 & 7 \\
\hline $\begin{array}{l}\text { O } \\
\text { Direct }\end{array}$ & 14 & 11 & 1 & -- & 2 & --- & -- & 12 & 2 \\
\hline $\begin{array}{l}\mathrm{O} \\
\text { Indirect }\end{array}$ & $\begin{array}{l}20 \\
(17 / 3)\end{array}$ & $3 / 2$ & $4 / 1$ & 6 & 4 & --- & --- & & 5 \\
\hline Partial & $\begin{array}{l}6 \\
(4 / 1)\end{array}$ & & & & & & & 3 & 2 \\
\hline $\begin{array}{l}\mathrm{P} \\
\text { Direct }\end{array}$ & 1 & --- & 1 & --- & --- & -- & $\cdots$ & $\cdots$ & 1 \\
\hline $\begin{array}{l}\mathrm{P} \\
\text { Indirect }\end{array}$ & $\begin{array}{l}5 \\
(3 / 1)\end{array}$ & 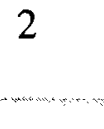 & --- & --- & $\cdots$ & $2 / 1$ & $\cdots$ & 3 & $\ldots=\ldots$ \\
\hline Closed & $\begin{array}{l}3 \\
(2 / 1)\end{array}$ & --- & --- & -- & -- & $\cdots$ & $\cdots$ & & \\
\hline
\end{tabular}


Appendix 5: Overview of advertising and editorial figure analysis - Playboy

Table 5.1: Instances of full vs. partial figures

$\begin{array}{llll}\text { Full Partial } & \text { Both (F/P) } & \text { Multiple } & \text { Total } \\ & \text { Full Part }\end{array}$

Ads

\begin{tabular}{|c|c|c|c|c|c|c|}
\hline Ad item & --- & 7 & --- & $3 / 6$ & & $10 / 13$ \\
\hline Figures & --- & 8 & --- & 3 & 5 & 16 \\
\hline Editorial & & & & & & \\
\hline Ed item & 8 & 11 & 1 & $11 / 36$ & & $31 / 56$ \\
\hline Figures & 14 & 15 & $(1 / 1)$ & 14 & 27 & 70 \\
\hline Items & 8 & 18 & 1 & $14 / 42$ & & $41 / 69$ \\
\hline Figures & 14 & 23 & $(1 / 1)$ & 17 & 32 & 86 \\
\hline
\end{tabular}

Table 5.2: Camera position (increments of items)

Ads

\begin{tabular}{|c|c|c|c|c|c|c|c|}
\hline & Eye-level & $\begin{array}{l}\text { Slight } \\
\text { above }\end{array}$ & Above & $\begin{array}{l}\text { Slight } \\
\text { below }\end{array}$ & Below & Multi Ad & Total \\
\hline Front & $2 / 4$ & $1 / 2$ & --- & 1 & --- & & $4 / 7$ \\
\hline Slight side & --- & $1 / 3$ & $1 / 2$ & 1 & --- & & $3 / 6$ \\
\hline Side & --- & --- & --- & --- & --- & & -- \\
\hline \multicolumn{8}{|l|}{ Slight } \\
\hline back & --- & $\cdots$ & $\cdots$ & $\cdots$ & --- & & $\cdots$ \\
\hline \multirow[t]{2}{*}{ Back } & $-\cdots$ & -- & $\cdots$ & $-\cdots$ & --- & & -- \\
\hline & $2 / 4$ & $2 / 5$ & $1 / 2$ & 2 & --- & $3 /(6)$ & $10 / 13$ \\
\hline \multicolumn{8}{|l|}{ Editorial } \\
\hline Front & $8 / 14$ & $1 / 5$ & 3 & $2 / 4$ & --- & & $14 / 26$ \\
\hline Slight side & $1 / 9$ & $2 / 9$ & $1 / 4$ & $1 / 6$ & $\cdots$ & & $5 / 28$ \\
\hline Side & 1 & $/ 1$ & --- & --- & --- & & $1 / 2$ \\
\hline \multicolumn{8}{|l|}{ Slight } \\
\hline back & --- & -- & --- & --- & -- & & --- \\
\hline \multirow[t]{2}{*}{ Back } & --- & --- & $\cdots$ & $\cdots$ & --- & & -- \\
\hline & $10 / 24$ & $3 / 15$ & $4 / 7$ & $3 / 10$ & --- & $11 /(36)$ & $31 / 56$ \\
\hline
\end{tabular}

Table 5.3: Figure placement (increments of figures)

$\begin{array}{lllllllllll} & \text { Front } & 3 / 4 \text { FR } & \text { Pro R } & 3 / 4 \text { BR } & \text { Back } & 3 / 4 \text { BL } & \text { Pro L } & 3 / 4 \text { FL } & \text { N/A } & \text { Total } \\ \text { Ad } & 5 & 4 & --- & --- & 1 & 2 & 2 & 1 & 1 & 16 \\ \text { Ed } & 20 & 14 & 1 & 3 & 1 & 8 & 4 & 19 & --- & 70\end{array}$


Table 5.4: Visible exposure of body parts (increments of figures)

\begin{tabular}{llll} 
& Head & Face & Neck \\
Ads & 16 & 16 & 12 \\
Full Exposure (I) & 14 & 11 & 8 \\
Partial Exposure (P) & 2 & 5 & 4 \\
\hline & & 70 & 65 \\
Editorial & 70 & 57 & 54 \\
Full Exposure (I) & 70 & 13 & 11 \\
Partial Exposure (P) & --- &
\end{tabular}

\begin{tabular}{llllllll} 
& Chest & Cleavage & Breast & Nipple & Abdomen & Pubic & Genital \\
Ads & 9 & 10 & 3 & -- & 5 & --- & --- \\
Full (I) & 5 & 8 & 1 & -- & 3 & -- & -- \\
$\begin{array}{l}\text { Partial } \\
\text { (P) }\end{array}$ & 4 & 2 & 2 & --- & 2 & --- & -- \\
\hline Editorial & 49 & 64 & 57 & 53 & 50 & 22 & 8 \\
Full (I) & 42 & 47 & 43 & 39 & 35 & 14 & 4 \\
Partial & 7 & 17 & 14 & 14 & 15 & 8 & 4
\end{tabular}

(P)

\begin{tabular}{llllll} 
& Back & Hips & Buttocks & Crack & B. Cleavage \\
Ads & 3 & 5 & 2 & 2 & 3 \\
Full (I) & 2 & 5 & 2 & --- & -- \\
Partial (P) & 1 & --- & --- & 2 & 3 \\
\hline & & & & & 16 \\
Editorial & 20 & 51 & 21 & 15 & 16 \\
Full (I) & 10 & 44 & 14 & 14 & 12 \\
Partial (P) & 10 & 7 & 7 & 1 & 4
\end{tabular}

\begin{tabular}{|c|c|c|c|c|c|}
\hline & Thigh & Inner Thigh & Knee & Calves & Feet \\
\hline Ads & 10 & 2 & 6 & 6 & 4 \\
\hline Full (I) & 5 & 1 & 4 & 4 & 2 \\
\hline Partial (P) & 5 & 1 & 2 & 2 & 2 \\
\hline Editorial & 63 & 17 & 44 & 40 & 28 \\
\hline Full (I) & 40 & 9 & 26 & 16 & 3 \\
\hline Partial (P) & 23 & 8 & 18 & 24 & 25 \\
\hline
\end{tabular}




\begin{tabular}{lllllll} 
& Shoulder & Upper arm & Forearm & Hand(s) & Inner wrist & Under arm \\
Ads & 11 & 11 & 12 & 14 & 3 & 2 \\
Full (I) & 8 & 7 & 10 & 6 & 3 & -- \\
Partial (P) & 3 & 4 & 2 & 8 & --- & 2 \\
\hline & & & & & & \\
Editorial & 63 & 58 & 58 & 61 & 7 & 17 \\
Full (I) & 54 & 52 & 49 & 45 & 6 & 5 \\
Partial (P) & 9 & 6 & 9 & 16 & 1 & 12
\end{tabular}

Table 5.5: Figure eye visibility (increments of figures)

\begin{tabular}{|c|c|c|c|c|c|c|c|c|c|c|}
\hline \multirow{3}{*}{$\begin{array}{l}\text { Ad } \\
\text { Visible }\end{array}$} & \multicolumn{4}{|c|}{ Both Eyes } & \multicolumn{2}{|c|}{ R Only } & \multirow{2}{*}{$\frac{R \text { Eye }}{1}$} & \multicolumn{2}{|c|}{ L Only } & \multirow{2}{*}{$\frac{\text { L Eye }}{1}$} \\
\hline & total & & Shade & DShade & 1 & & & 1 & & \\
\hline & 11 & 8 & 1 & 2 & -.. & --- & --- & - & -- & -. \\
\hline $\begin{array}{l}\text { Partial } \\
\text { Visibility }\end{array}$ & --- & $-\cdots$ & $\cdots$ & --- & 1 & 1 & --- & 1 & -- & 1 \\
\hline No Visibility & 2 & --- & --- & --- & --- & -- & --- & -- & -- & --- \\
\hline Ed & & & & & 3 & & 4 & 3 & & 4 \\
\hline Visible & 50 & 48 & 1 & 1 & 5 & 1 & --- & 3 & -- & --- \\
\hline Partial & 9 & 5 & 1 & 3 & 1 & $\ldots$ & -- & 1 & 2 & 1 \\
\hline
\end{tabular}

ility

No Visibility 1 
Table 5.6: Figure gaze direction and focus (increments of figures)

\begin{tabular}{|c|c|c|c|c|c|c|c|c|c|}
\hline & $(\mathrm{I} / \mathrm{P})$ & Front & Side & S up & Up & Sdown & Down & Focus & $\mathrm{XF}$ \\
\hline Open & 11 & 5 & 3 & 1 & 1 & 1 & & 8 & 3 \\
\hline $\begin{array}{l}\mathrm{O} \\
\text { Direct }\end{array}$ & 9 & 5 & 2 & 1 & 1 & --- & --- & 8 & 1 \\
\hline $\begin{array}{l}\mathrm{O} \\
\text { Indirect }\end{array}$ & 2 & -- & 1 & --- & --- & 1 & --- & --- & 2 \\
\hline Partial & 2 & $/ 1$ & 1 & & & & & --- & $\begin{array}{l}2 \\
(1 / 1)\end{array}$ \\
\hline $\begin{array}{l}\text { P } \\
\text { Direct }\end{array}$ & --- & --- & -- & --- & --- & -- & -- & --- & -- \\
\hline $\begin{array}{l}\mathrm{P} \\
\text { Indirect }\end{array}$ & $\begin{array}{l}2 \\
(1 / 1)\end{array}$ & $/ 1$ & 1 & --- & --- & --. & --- & --- & 2 \\
\hline $\begin{array}{l}\mathrm{P} \\
\text { unclear }\end{array}$ & --- & -- & --- & --- & --- & -- & --- & -- & -- \\
\hline Closed & 1 & --- & $-\cdots$ & --- & --- & --- & $\ldots$ & --- & --- \\
\hline \multicolumn{10}{|l|}{$\mathrm{Ed}$} \\
\hline Open & 62 & & & & & & & 58 & $\begin{array}{l}4 \\
(3 / 1)\end{array}$ \\
\hline $\begin{array}{l}\text { O } \\
\text { Direct }\end{array}$ & $\begin{array}{l}52 \\
(47 / 5)\end{array}$ & $\begin{array}{l}23 \\
(20 / 3)\end{array}$ & $\begin{array}{l}14 \\
(13 / 1)\end{array}$ & $\begin{array}{l}9 \\
(8 / 1)\end{array}$ & 5 & --- & 1 & 51 & 1 \\
\hline $\begin{array}{l}\mathrm{O} \\
\text { Indirect }\end{array}$ & $\begin{array}{l}10 \\
(5 / 5)\end{array}$ & $\begin{array}{l}5 \\
(2 / 3)\end{array}$ & $\begin{array}{l}4 \\
(2 / 2)\end{array}$ & 1 & --- & --- & --- & 7 & $\begin{array}{l}3 \\
(2 / 1)\end{array}$ \\
\hline Partial & 5 & --- & 3 & --- & --- & 1 & 1 & 3 & 2 \\
\hline $\begin{array}{l}\text { P } \\
\text { Direct }\end{array}$ & 3 & --- & 1 & -- & --- & 1 & 1 & 2 & 1 \\
\hline $\begin{array}{l}\mathrm{P} \\
\text { Indirect }\end{array}$ & 2 & --- & 2 & --. & --- & --- & --- & 1 & 1 \\
\hline Closed & 2 & --- & --- & $\cdots$ & --- & --- & --- & $\ldots$ & --- \\
\hline
\end{tabular}


Appendix 6: Comparative overview of advertising and editorial figures between Cosmo, Vogue, and Playboy

Table 6.1: Instances of partial and full figures

\begin{tabular}{llllll} 
\% & Full item & Partial item & Both & F Figure & P Figure \\
Vogue & 24.5 & 73.5 & 2 & 29.2 & 70.8 \\
Ads & 17.9 & 79.3 & 2.8 & 22.1 & 77.9 \\
Editorial & 41.5 & 58.5 & --- & 47.8 & 52.2 \\
\hline & & & & & \\
Cosmo & 19.4 & 77.2 & 3.4 & 24.8 & 75.2 \\
Ads & 12.7 & 84.1 & 4.8 & 21.1 & 78.9 \\
Editorial & 36 & 64 & --- & 36 & 64 \\
\hline & & & & & \\
Playboy & 24.4 & 53.7 & 21.9 & 36.1 & 63.9 \\
Ads & 7.7 & 92.3 & -- & 18.6 & 81.4 \\
Editorial & 29 & 48.4 & 22.6 & 40 & 60
\end{tabular}

Table 6.2: Camera positions

\begin{tabular}{|c|c|c|c|c|c|c|c|c|c|}
\hline \multirow[t]{2}{*}{$\%$} & \multicolumn{3}{|c|}{ Vogue } & \multicolumn{3}{|c|}{ Cosmo } & \multicolumn{3}{|c|}{ Playboy } \\
\hline & $\mathrm{Ad}$ & Ed & & $\mathrm{Ad}$ & Ed & & $\mathrm{Ad}$ & Ed & \\
\hline Eye-level & 43.4 & 61 & 48.3 & 50.7 & 48 & 50 & 30.8 & 42.9 & 40.6 \\
\hline Slight above & 27.3 & 26.8 & 27.2 & 25.4 & 44 & 30.7 & 38.4 & 26.8 & 28.9 \\
\hline Above & 4.7 & 4.9 & 4.8 & 3.2 & --- & 2.3 & 15.4 & 12.5 & 13.1 \\
\hline Slight below & 23.6 & 7.3 & 19 & 15.9 & 8 & 13.6 & 15.4 & 17.8 & 17.4 \\
\hline Below & 0.9 & --- & 0.7 & 4.8 & $-\cdots$ & 3.4 & $\cdots$ & $\cdots$ & $-\cdots$ \\
\hline Front & 57.5 & 39.1 & 52.4 & 66.7 & 60 & 64.8 & 53.8 & 46.4 & 47.8 \\
\hline Slight side & 37.7 & 56.1 & 42.9 & 28.6 & 32 & 29.5 & 46.2 & 50 & 49.3 \\
\hline Side & 3.8 & 2.4 & 3.4 & 1.6 & --- & 1.1 & --- & 3.6 & 2.9 \\
\hline Slight back & 1 & 2.4 & 1.3 & 3.1 & 4 & 3.4 & --- & $\cdots$ & --- \\
\hline Back & --- & --- & --- & --- & 4 & 1.1 & --- & --- & --- \\
\hline
\end{tabular}


Table 6.3: Figure placement

\begin{tabular}{llllllllll} 
\% & Front & 3/4 FR & Pro R & $3 / 4 \mathrm{BR}$ & Back & $3 / 4 \mathrm{BL}$ & Pro L & $3 / 4 \mathrm{FL}$ & $\mathrm{N} / \mathrm{A}$ \\
Vogue & 48.3 & 20.3 & 4.8 & 1.9 & -- & 1.3 & 3.6 & 17.4 & 2.4 \\
Ads & 50.8 & 18.9 & 4.9 & 0.8 & -- & 1.6 & 3.3 & 16.4 & 3.3 \\
Editorial & 42.3 & 24.5 & 4.4 & 4.4 & $\cdots$ & -- & 4.4 & 20 & -- \\
\hline & & & & & & & & & \\
\hline Cosmo & 55.4 & 11.9 & 5 & 4 & 1.9 & 1.9 & 3 & 13.9 & 3 \\
Ads & 51.3 & 15.9 & 2.6 & 3.9 & 2.6 & 2.6 & 2.6 & 15.9 & 2.6 \\
Editorial & 68 & --- & 12 & 4 & -- & -- & 4 & 8 & 4 \\
\hline Playboy & 29.1 & 20.9 & 1.2 & 3.5 & 2.3 & 11.6 & 6.9 & 23.3 & 1.2 \\
Ads & 31.25 & 25 & -- & --- & 6.25 & 12.5 & 12.5 & 6.25 & 6.25 \\
Editorial & 28.6 & 20 & 1.4 & 4.3 & 1.4 & 11.4 & 5.8 & 27.1 & ---
\end{tabular}

Table 6.4: Visible exposure of body parts

\begin{tabular}{llllllllll} 
\% & Head & & \multicolumn{3}{c}{ Face } & & & Neck & \\
Vogue & 98.2 & Full & Part & 98.2 & Full & Part & 91.7 & Full & Part \\
Ads & 97.5 & 72.9 & 24.6 & 97.5 & 65.6 & 31.9 & 95.1 & 52.5 & 42.6 \\
Editorial & 100 & 80.4 & 19.6 & 100 & 56.5 & 43.5 & 82.6 & 52.2 & 30.4 \\
\hline & & & & & & & & & \\
Cosmo & 93.1 & 72.3 & 20.8 & 93.1 & 67.3 & 25.7 & 86.1 & 65.3 & 20.8 \\
Ads & 90.8 & 71.1 & 19.7 & 90.8 & 67.1 & 23.7 & 81.6 & 60.5 & 21.1 \\
Editorial & 100 & 76 & 24 & 100 & 68 & 23 & 100 & 80 & 20 \\
\hline & & & & & & & & & \\
Playboy & 100 & 97.7 & 2.3 & 100 & 79.1 & 20.9 & 89.5 & 72.1 & 17.4 \\
Ads & 100 & 87.5 & 12.5 & 100 & 68.75 & 31.25 & 75 & 50 & 25 \\
Editorial & 100 & 100 & --- & 100 & 81.4 & 18.6 & 92.9 & 77.2 & 15.7 \\
& & & & & & & & & \\
\% & Shoulders & & Chest & & & Back & & \\
& & Full & Part & & Full & Part & & Full & Part \\
Vogue & 47 & 29.2 & 17.9 & 51.8 & 25 & 26.8 & 8.9 & 1.2 & 7.7 \\
Ads & 50.8 & 31.1 & 19.7 & 53.3 & 27.9 & 25.4 & 7.3 & 1.6 & 5.7 \\
Editorial & 36.9 & 23.9 & 13 & 47.8 & 17.4 & 30.4 & 13 & $-\ldots$ & 13 \\
\hline & & & & & & & & & \\
Cosmo & 49.5 & 38.6 & 10.9 & 57.4 & 32.7 & 24.7 & 9.9 & 3 & 6.9 \\
Ads & 51.3 & 43.4 & 7.9 & 56.6 & 31.6 & 25 & 9.2 & 2.6 & 6.6 \\
Editorial & 44 & 24 & 20 & 60 & 36 & 24 & 12 & 4 & 8 \\
\hline & & & & & & & & \\
\hline Playboy & 86 & 72.1 & 13.9 & 56.25 & 31.25 & 25 & 26.7 & 13.9 & 12.8 \\
Ads & 68.75 & 50 & 18.75 & 56.25 & 31.25 & 25 & 18.75 & 12.5 & 6.25 \\
Editorial & 90 & 77.1 & 12.9 & 70 & 60 & 10 & 28.6 & 14.3 & 14.3
\end{tabular}




\begin{tabular}{|c|c|c|c|c|c|c|c|c|c|}
\hline \multirow[t]{2}{*}{$\%$} & \multicolumn{3}{|c|}{ Cleavage } & \multicolumn{3}{|c|}{ Breast } & \multicolumn{3}{|l|}{ Nipple } \\
\hline & & Full & Part & & Full & Part & & Full & Part \\
\hline Vogue & 19.6 & 14.3 & 11.3 & 4.8 & 2.4 & 2.4 & --- & --- & --- \\
\hline Ads & 18.9 & 15.6 & 11.5 & 5.7 & 3.3 & 2.4 & --- & --- & --- \\
\hline Editorial & 21.7 & 10.9 & 10.8 & 2.2 & --- & 2.2 & --- & --- & -- \\
\hline Cosmo & 33.7 & 21.8 & 11.9 & 4.9 & -- & 4.9 & --- & --- & $\cdots$ \\
\hline Ads & 32.9 & 23.7 & 9.2 & 3.9 & -- & 3.9 & --- & $\ldots$ & --- \\
\hline Editorial & 36 & 16 & 20 & 8 & --- & 8 & -- & --- & -- \\
\hline Playboy & 86 & 63.9 & 22.1 & 69.8 & 51.2 & 18.6 & 61.6 & 45.3 & 16.3 \\
\hline Ads & 62.5 & 50 & 12.5 & 18.75 & 6.25 & 12.5 & --- & --- & --- \\
\hline Editorial & 91.4 & 67.1 & 24.3 & 81.4 & 61.4 & 20 & 75.7 & 55.7 & 20 \\
\hline \multirow[t]{2}{*}{$\%$} & \multicolumn{3}{|c|}{ Abdomen } & \multicolumn{3}{|c|}{ Pubic } & \multicolumn{3}{|c|}{ Genital } \\
\hline & & Full & Part & & Full & Part & & Full & Part \\
\hline Vogue & 8.9 & 4.2 & 4.8 & -- & --- & --- & --- & -- & $\ldots$ \\
\hline Ads & 9.8 & 4.1 & 5.7 & --- & --- & $-\ldots$ & -- & --- & --- \\
\hline Editorial & 6.5 & 4.3 & 2.2 & --- & --- & --- & --- & --- & --- \\
\hline Cosmo & 12.9 & 7.9 & 5 & --- & --- & --- & -- & --- & --- \\
\hline Ads & 14.5 & 9.2 & 5.3 & --- & -- & --- & --- & --- & --- \\
\hline Editorial & 8 & 4 & 4 & --- & --- & $\ldots$ & --- & --- & $-\cdots$ \\
\hline Playboy & 64 & 45.3 & 19.8 & 23.2 & 16.3 & 9.3 & 9.3 & 4.7 & 4.7 \\
\hline Ads & 31.25 & 18.75 & 12.5 & --- & $-\cdots$ & --- & --- & --- & -- \\
\hline Editorial & 71.4 & 50 & 21.4 & 31.4 & 20 & 11.4 & 11.4 & 5.7 & 5.7 \\
\hline \multirow[t]{2}{*}{$\%$} & \multicolumn{2}{|c|}{ Buttocks } & & \multicolumn{2}{|c|}{ B Crack } & & \multicolumn{3}{|c|}{ Buttocks Cleavage } \\
\hline & & Full & Part & & Full & Part & & Full & Part \\
\hline Vogue & 1.2 & 0.6 & 0.6 & --- &.-- & --- & 2.4 & 0.6 & 1.8 \\
\hline Ads & 1.6 & 0.8 & 0.8 & --- & --- & --- & 2.5 & 1.6 & 0.8 \\
\hline Editorial & -- & --- & --- & --- & -- & -- & 2.2 & -- & 2.2 \\
\hline Cosmo & 1.9 & 0.9 & 0.9 & --- & -- & -- & 1.9 & 0.9 & 0.9 \\
\hline Ads & 1.3 & 1.3 & --- & --- & --- & --- & 2.6 & 1.3 & 1.3 \\
\hline Editorial & 4 & --- & 4 & -- & --- & -- & --- & $--\cdot$ & --- \\
\hline Playboy & 25.6 & 18.6 & 8.1 & 19.8 & 16.3 & 3.5 & 22.1 & 13.9 & 8.1 \\
\hline Ads & 12.5 & 12.5 & -- & 12.5 & --- & 12.5 & 18.75 & --- & 18.75 \\
\hline Editorial & 30 & 20 & 10 & 21.4 & 20 & 1.2 & 22.8 & 17.1 & 5.7 \\
\hline
\end{tabular}




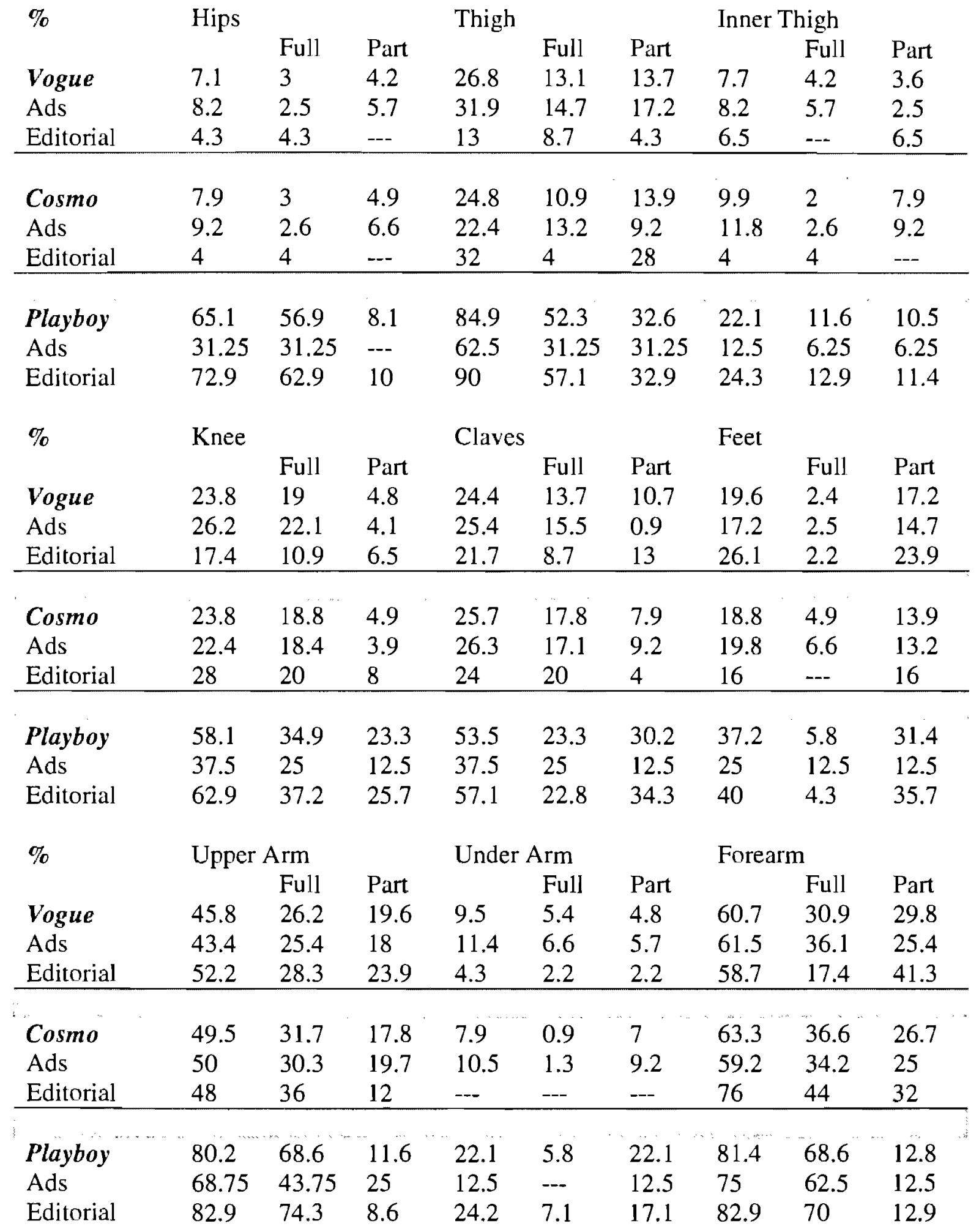




\begin{tabular}{lllllll}
$\%$ & Hands & \multicolumn{5}{c}{ Inner Wrist } \\
& & Full & Part & & Full & Part \\
Vogue & 75.6 & 35.1 & 40.5 & 6.5 & 3.6 & 3 \\
Ads & 79.5 & 39.3 & 40.2 & 8.2 & 4.1 & 4.1 \\
Editorial & 65.2 & 23.9 & 41.3 & 2.2 & 2.2 & --- \\
\hline & & & & & & \\
Cosmo & 79.2 & 57.4 & 21.8 & 4.9 & 4 & 0.9 \\
Ads & 76.3 & 53.9 & 2.3 & 3.9 & 2.6 & 1.3 \\
Editorial & 88 & 68 & 20 & 8 & 8 & $\ldots$ \\
\hline & & & & & & \\
Playboy & 87.2 & 59.3 & 27.9 & 11.6 & 10.5 & 1.2 \\
Ads & 87.5 & 37.5 & 50 & 18.75 & 18.75 & -- \\
Editorial & 87.1 & 64.2 & 22.8 & 10 & 8.6 & 1.4
\end{tabular}

Table 6.5: Figure eye/gaze overview

\begin{tabular}{|c|c|c|c|c|c|c|c|c|c|}
\hline$\%$ & Vogu & & & Cost & & & Playb & & \\
\hline & $\mathrm{Ad}$ & Ed & & $\mathrm{Ad}$ & Ed & & $\mathrm{Ad}$ & Ed & \\
\hline Open & 68.8 & 73.9 & 70.3 & 77.6 & 72 & 76.2 & 68.75 & 88.6 & 84.9 \\
\hline Direct & 46.7 & 32.6 & 42.3 & 59.2 & 60 & 59.4 & 56.25 & 74.3 & 71 \\
\hline Indirect & 22.1 & 54.3 & 28 & 18.4 & 12 & 16.8 & 12.5 & 14.3 & 13.9 \\
\hline Partial & 15.6 & 13.1 & 14.9 & 3.9 & 12 & 6 & 12.5 & 7.1 & 8.1 \\
\hline Direct & 7.4 & 2.2 & 6 & 2.6 & -- & 2 & --- & 4.3 & 3.5 \\
\hline Indirect & 8.2 & 10.9 & 8.9 & 1.3 & 12 & 4 & 12.5 & 2.8 & 4.6 \\
\hline No $V$ is & 9 & 6.5 & 8.3 & 13.2 & 4 & 10.9 & 12.5 & 1.4 & 3.5 \\
\hline Closed & 6.6 & 6.5 & 6.5 & 5.3 & 12 & 6.9 & 6.25 & 2.9 & 3.5 \\
\hline
\end{tabular}

Table 6.6: Figure eye visibility

\begin{tabular}{lllllll}
$\%$ & $\begin{array}{l}\text { Both Eyes } \\
\text { Visible }\end{array}$ & P Vis & No V & Single Eye & L shade & D shade \\
Vogue & 61.9 & 17.9 & 8.3 & 11.9 & 19 & 5.9 \\
Ads & 64 & 18 & 9 & 9 & 15.6 & 7.4 \\
Editorial & 56.2 & 17.5 & 6.6 & 19.7 & 28.2 & 2.2 \\
\hline Cosmo & 63.3 & 15.9 & 10.9 & 9.9 & 18.8 & 4.9 \\
Ads & 63.1 & 15.8 & 13.2 & 7.9 & 9.2 & 9.2 \\
Editorial & 64 & 16 & 4 & 16 & 16 & 16 \\
\hline & & & & & & \\
Playboy & 70.9 & 16.3 & 3.5 & 9.3 & 8.1 & 9.3 \\
Ads & 68.75 & 6.25 & 12.5 & 12.5 & 12.5 & 18.75 \\
Editorial & 71.4 & 18.6 & 1.4 & 8.6 & 7.1 & 7.1
\end{tabular}


Table 6.7: Figure gaze direction and focus

\begin{tabular}{|c|c|c|c|c|c|c|c|c|c|}
\hline \multirow[t]{2}{*}{$\%$} & \multicolumn{3}{|c|}{ Vogue } & \multicolumn{3}{|c|}{ Cosmo } & \multicolumn{3}{|c|}{ Playboy } \\
\hline & $\mathrm{Ad}$ & Ed & & $\mathrm{Ad}$ & Ed & & Ad & Ed & \\
\hline DIRECT & 54.1 & 32.7 & 48.3 & 61.8 & 60 & 61.4 & 56.25 & 78.6 & 74.4 \\
\hline Front & 34.4 & 23.9 & 31.5 & 36.9 & 32 & 35.6 & 31.25 & 32.9 & 32.6 \\
\hline Side & 9 & 4.4 & 7.8 & 3.9 & 4 & 3.9 & 12.5 & 21.4 & 20.9 \\
\hline Side Up & 3.3 & --- & 2.4 & 9.2 & 12 & 10 & 6.25 & 12.9 & 11.6 \\
\hline Up & 4.9 & 4.4 & 4.8 & 7.9 & 12 & 8.9 & 6.25 & 7.1 & 7 \\
\hline Side Down & 0.9 & --- & 0.6 & 1.3 & --- & 1 & --- & --- & --- \\
\hline Down & 1.6 & $\ldots$ & 1.2 & 2.6 & $\ldots$ & 2 & $\ldots$ & 1.4 & 2.3 \\
\hline INDIRECT & 30.3 & 54.3 & 36.9 & 19.7 & 24 & 20.8 & 25 & 17.1 & 18.6 \\
\hline CLOSED & 6.6 & 6.5 & 6.5 & 5.3 & 12 & 6.9 & 6.25 & 2.9 & 3.5 \\
\hline NO VIS & 9 & 6.5 & 8.3 & 13.2 & 4 & 10.9 & 12.5 & 1.4 & 3.5 \\
\hline Focus & 68.9 & 65.2 & 67.9 & 57.9 & 56 & 57.4 & 50 & 87.1 & 80.2 \\
\hline
\end{tabular}

\section{Appendix 7: Source materials}

Item 7.0: Catalogue of source magazines

Allure. (October 2008). New York: Condé Nash Publications

Cosmopolitan. (December 2008), vol. 245 (6). Printed in the U.S.A.: Hearst magazines.

Cosmopolitan. (January 2009), vol. 246 (1). Printed in the U.S.A.: Hearst magazines.

Playboy. (December 2008), vol. 55, (12). Printed in the U.S.A.: Playboy magazines.

Playboy. (January 2009), vol. 56, (1). Printed in the U.S.A.: Playboy magazines.

Vanity Fair. (March 2009), No. 583. New York: Condé Nash Publications

Vogue. (December 2008). New York: Condé Nash Publications

Vogue. (January 2009). New York: Condé Nash Publications 


\section{REFERENCES}

Ahmed, S. (2004). “Affective Economies." Social Text, 22(2), 117-139.

Arthurs, J. (2004). Television and sexuality: Regulation and the politics of taste. Berkshire: Open University Press.

Audit Bureau of Circulations. (n.d.) "Top 100 ABC magazines by average circulation”. Retrieved November 2008, from: http:/www.magazine.org/CONSUMER_MARKETING/CIRC_TRENDS/18425.aspx.

Barthes, R. (1981). Camera lucida: Reflections on photography. (R. Howard, Trans.). New York: Hill and Wang, division of Farrar, Straus, and Grioux. (Original work published 1980).

Batchen, G. et al. (2001). "The body and technology." Art Journal, 60(1), 20-39.

Beetles, A. C., \& Harris, L. C. (2005). Consumer attitudes towards female nudity in advertising: An empirical study. Marketing Theory, 5 (4), 397-432.

Belsey, C. (2005). Culture and the real. New York: Routledge.

Berger, J. (1972). Ways of Seeing. London: Penguin Books.

Bishop, M. (2007). The making of a pre-pubescent porn star: Contemporary fashion for elementary school girls. In A. C. Hall \& M. J. Bishop (Eds). Pop porn: Pornography in American culture. (pp. 45-56). Westport, CT: Praeger Publishers.

Bogaert, A.F., \& Turkovich, D. A. (1993). A content analysis of Playboy centerfolds from 1953 through 1990: Changes in explicitness, objectification, and model's. Journal of Sex Research, 30 (2), 135-139.

Borsodi, B. (n.d.). Artist homepage. Retrieved November 2008, from: http://www.belaborsodi.com/

Brayton, J. (2006). Visual Art. In L. L. Haywood (Ed.). The women's movement today: An encyclopedia of third-wave feminism. (vol. 2, pp. 337-338). Westport, CT: Greenwood Press.

Breazeale, K. (2003). In spite of women: Esquire magazine and the construction of the male consumer. In G. Dines \& J. M. Humez (Eds.). Gender, race, and class in media: A textreader. (pp. 230-243). Boston: Sage.

Boyle, K. (2003). The pornography debates: Beyond cause and effect. In G. Dines \& J. M. Humez (Eds.). Gender, race, and class in media: A text-reader. (pp. 406-416). Boston: Sage.

Buddenbaum, J. M., \& Novak, K. B. (2001). Applied communication research. Ames, IA.: Iowa State University Press.

Caputi, J. (2003). Everyday pornography. In G. Dines \& J. M. Humez (Eds.). Gender, race, and class in media: A text-reader. (pp. 434-450). Boston: Sage.

Courtney, A., \& Whipple, T. (1983). Sex stereotyping in advertising. Lexington, MA: Heath.

Crane, D. (2003). Gender and hegemony in fashion magazines: Women's interpretations of fashion photographs. In G. Dines \& J. M. Humez (Eds.). Gender, race, and class in media: A text-reader. (pp. 314-332). Boston: Sage.

Cronin, A. M. (2000). Advertising and consumer citizenship: Gender, images and rights. New York: Routledge.

Deleuze, G., \& Guattari, F. (1987). A thousand plateaus: Capitalism and schizophrenia. 
(B. Massumi, Trans). Minneapolis \& London: University of Minnesota Press.

Department of Justice Canada. (n.d.) "Canadian law - pornography." Retrieved June 05, 2009, from: http://laws.justice.gc.ca/en/result.

Driver, S. (2004). "Pornographic pedagogies? The risk of teaching "Dirty." Popular

Cultures', M/C Journal, 7 (4), electronic document at http://journal.media-

culture.org.au/0410/03_teaching.php. (Online available).

Fugami, T. (2006). Dichotomies coalesce - Chris Jordan: Intolerable Beauty: Portraits of American mass consumption. Afterimage, 33 (4), 38-39.

Goffman, E. (1976). Gender advertisements. New York: Harper Colophon Books.

Grenville, B. The uncanny: Experiments in cyborg culture. Vancouver, B.C.: Arsenal Pulp Press, 2002.

Guillet de Monthoux, P. (2000). Performing the absolute. Marina Abramovic organizing the unfinished business of Arthur Schopenhauer. Organization Studies, 21 (0), 29-51.

Hall, A. C., \& Bishop, M. J. (Eds). (2007). Pop pom: Pornography in American culture. Westport, CT: Praeger Publishers.

Harvey, H., \& Robinson, K. (2007). Hot bodies on campus: The performance of porn chic. In A. C. Hall \& M. J. Bishop (Eds). Pop porn: Pornography in American culture. (pp. 57-74). Westport, CT: Praeger Publishers.

Hayles, N. Katherine. How We Became Posthuman: In Cybernetics, Literature, and Informatics. Chicago, Ill.: University of Chicago Press, 1999.

Itzin, C. (1992). Pornography: Women, violence, and civil liberties. New York: Oxford University Press.

Jensen, R., \& Dines, G. (1998). The content of mass-market pornography. In G. Dines, R. Jensen, \& A. Russo. Pornography: The production and consumption of inequality. (pp. 65-100). London: Routledge.

Jhally, S. (2003). Image based culture: Advertising and popular culture. In G. Dines \& J. M. Humez (Eds.). Gender, race, and class in media: A text-reader. (pp. 249-267). Boston: Sage.

Johnson, M. L. (2006). Pornography, and feminism. In L. L. Haywood (Ed.). The women's movement today: An encyclopedia of third-wave feminism. (vol. 2, pp. 246-248). Westport, CT: Greenwood Press.

Jordan, C. (n.d.). Chris Jordan: Photographic arts. November 2008, from http://www.chrisjordan.com/

Kilbourne, J., \& Jhally, S. (Producer/director/editor). (2000). Killing us softly: Advertising's image of women. (video). Northampton, MA : Media Education Foundation ; Toronto : Kineticvideo.com.

Kinnick, K. N. (2007). Pushing the envelope: The role of mass media in the mainstreaming of pornography. In A. C. Hall \& M. J. Bishop (Eds). Pop porn: Pornography in American culture. (pp. 7-26). Westport, CT: Praeger Publishers.

Kovel, J. (1990). The antidialectic of pornography. In M. S. Kimmel (Ed.). Men confront pornography. (pp. 153-167). New York: Crown Publishers, Inc.

Kozloff, M. (1979). Photography and fascination: Essays. Danbury, N.H.: Addison House.

Kuhn, A. (1985). The power of the image: Essays on representation and sexuality. London: Routledge \& Kegan Paul.

Kuhn, A. (1995). Lawless seeing. In G. Dines \& J. M. Humez (Eds.). Gender, race, and class in media: A text-reader. (pp. 271-278). Thousand Oaks, CA.: Sage. 
LaChapelle, D. (1996). LaChapelle land. New York: Simon \& Schuster \& Callaway.

Lasch, C. (1979). The culture of narcissism. New York: Warner Books

Leiss, W., Kline, S., \& Jhally, S. (1986). Social communication in advertising: Persons, products, and images of well-being. New York: Methuen.

Lester, P. M. (2000). Visual Communication: Images with messages. Second Ed. Belmont, CA: Wadsworth/Thomas Learning.

Levy, A. (2005). Fenale chauvinist pigs: Women and the rise of raunch culture. New York: Free Press.

McElroy, W. (1995). A woman's right to pornography. New York: St. Martin's Press.

McKee, A. (2006). The aesthetics of pornography: The insights of consumers. Continuum: Journal of Media and Cultural Studies, 20 (4), 523-539.

McLuhan, M. (1951). The mechanical bride: Folklore of industrial man. Boston: Beacon Press.

McNair, B. (1996). Mediated Sex: Pornography and the postmodem culture. New York: Arnold.

McNair, B. (2002). Striptease culture: Sex, media and the democratisation of desire. New York: Routledge.

Merskin, D. (2006). Where are the clothes? The pornographic gaze in mainstream American fashion advertising. In T. Reichert \& J. Lambiase (Eds.). Sex in consumer culture: The erotic content of media and marketing. (pp. 199-217). Mahwah, NJ: Lawrence Erlbaum Associates, Publishers.

Michelson, P. (1971). The aesthetics of pornography. New York: Herder and Herder.

Miller, S. (n,d.) Artist homepage. Retrieved March 2009, from: http://www.consumptuous.com/index.php

Minor, V. H. (1994). Art history's history. Englewood Cliffs, N.J.: Prentice Hall, Inc.

Mitchell, W. J. T. (2005). What do pictures want? The lives and loves of images. Chicago: The University of Chicago Press.

Monk-Turner, E. et al. (2008). Who is gazing at whom? A look at how sex is used in magazine a dvertisements. Journal of Gender Studies, 17 (3), 201-209.

Morgan, R. (1980). Theory and practice: Pornography and rape. In L. Lederer (Ed.). Take back the night: Women on pornography. New York: Morrow.

Myers, K. (1987). Fashion 'n' passion. In R. Betterton (Ed.). Looking on: Images of femininity in the visual arts and media. (pp. 58-65). London: Pandora.

Nelson, R. S., \& Shiff, R (Eds.). (1996). Critical terms for art history. Chicago: The University of Chicago Press.

O'Sullivan, S. (2001). "The aesthetics of affect: Thinking art beyond representation." Angelaki, $6(3), 125-135$.

Ouellette, L. (2003). Inventing the Cosmo girl: Class identity and girl-style American dreams. In G. Dines \& J. M. Humez (Eds.). Gender, race, and class in media: A text-reader. (pp. 116-128). Boston: Sage.

Paasonen, S., Nikunen, K., \& Saarenmaa, L. (Eds.). (2007). Pormification: Sex and sexuality in media culture. New York: Berg.

Paul, P. (2005). Pornified: How pornography is damaging our lives, our relationships, and our familes. New York: Owl Books.

Pornography (1). (n.d.). The American Heritage $($ New Dictionary of Cultural Literacy, Third Edition. Retrieved June 05, 2009, from Dictionary.com website:

http://dictionary.classic.reference.com/browse/pornography

Pornography (2). (n.d.). The American Heritage $®$ Dictionary of the English Language, Fourth 
Edition. Retrieved June 05, 2009, from Dictionary.com website: http://dictionary.classic.reference.com/browse/pornography

Reichert, T., \& Carpenter, C. (2004). An update on sex in magazine advertising: 1983 to 2003. Journal of Mass Communication Quarterly, 81 (4), 823-838.

Reichert, T., \& Lambiase, J. (Eds.). (2003). Sex in advertising: Perspectives on the erotic appeal. Mahwah, NJ: Lawrence Erlbaum Associates, Publishers.

Reichert, T., \& Lambiase, J. (Eds.). (2006). Sex in consumer culture: The erotic content of media and marketing. Mahwah, NJ: Lawrence Erlbaum Associates, Publishers.

Reinharz, S. (1992). Feminist methods in social research. New York: Oxford University Press.

Rich, F. (2003). Naked capitalists. In G. Dines \& J. M. Humez (Eds.). Gender, race, and class in media: A text-reader. (pp. 48-60). Boston: Sage.

Rutherford, P. (2007). A world made sexy: Freud to Madonna. Toronto: University of Toronto Press.

Samuels, S. (2006). Art, third wave feminist. In L. L. Haywood (Ed.). The women's movement today: An encyclopedia of third-wave feminism. (vol. 1, pp. 20-23). Westport, CT: Greenwood Press.

Sarracino, C., \& Scott, K. (2008). The porning of America: The rise of porn culture, what it means, and where we go from here. Boston: Beacon Press.

Schneider-Adams, L. (1996). The methodologies of art: An introduction. New York: Harper Collins Publishers.

Schor, N. (1987). Reading in detail: Aesthetics and the feminine. New York: Methuen.

Schroeder, J. E., \& Borgerson, J. L. (2003). Dark desire: Fetishism, ontology, and representation in contemporary advertising. In T. Reichart \& J. Lambiase (Eds.), Sex in advertising:

Perspectives on the erotic appeal. (pp. 65-87). Mahwah, NJ: Lawrence Erlbaum Associates, Publishers.

Solso, R. (1994). A truly marvelous feast: Visual perspective. In Cognition and the visual arts. (pp. 157-187). Cambridge, MA: MIT Press.

Steele, V. (1996). Fetish: Fashion, sex and power. New York: Oxford University Press.

Sullivan, G. (2005). Art practice as research: Inquiry in the visual arts. Thousand Oaks, CA.: Sage.

Van Leeuwen, T., \& Carey, J. (Eds.). (2001). Handbook of visual analysis. London: Sage.

Wicke, J. (1993). Through a gaze darkly: Pornography's academic market. In P. Church-Gibson \& R. Gibson (Eds.). Dirty looks: Women - Pornography - Power. (pp. 62-80). London: British Film Institute.

Williams, L. (1993). A Provoking Agent: The pornography and performance art of Annie Sprinkle. In P. Church-Gibson, \& R. Gibson (Eds.). Dirty looks: Women - Pornography - Power. (pp. 176-191). London: British Film Institute.

Williams, L. (1998). Hard Core: Power, pleasure, and the "frenzy of the visible." Berkeley, CA: University of California Press.

Willis, E. (1982). Toward a feminist sexual revolution. Social Text, 6, 3-21.

Wissinger, E. (2007). "Always on display: Affective production in the modeling industry." The affective turn: Theorizing the social. (pp. 231-260). London: Duke University Press. 